\title{
Olefin Recovery from Chemical Industry Waste Streams
}

\author{
Final Report
}

Contract Number DE-FC02-98CH10930

Contract Period: September 30, 1998 to August 31, 2003

Total Value: $\$ 1,259,381$

by

Membrane Technology and Research, Inc.

1360 Willow Road

Menlo Park, CA 94025

Telephone: (650) 328-2228 Ext. 159

Fax: (650) 328-6580

e-mail: andre@mtrinc.com

November 21, 2003

prepared for

The U.S. Department of Energy Office of Industrial Technology

Washington, D.C.

Contributors to this Report:
A. R. Da Costa (P.I./P.M.)
R. Daniels
A. Jariwala
Z. He
A. Morisato
I. Pinnau
J.G. Wijmans

\begin{abstract}
For a period of four years after acceptance of all items to be delivered under this contract, the Government agrees to use these data for Government purposes only, and they shall not be disclosed outside the Government (including disclosure for procurement purposes) during such period without permission of the Contractor, except that, subject to the foregoing use and disclosure prohibitions, such data may be disclosed for use by support contractors. After the aforesaid 4-year period, the Government has a royalty-free license to use, and to authorize others to use on its behalf, these data for Government purposes, but is relieved of all disclosure prohibitions and assumes no liability for unauthorized use of these data by third parties. This Notice shall be affixed to any reproductions of these data, in whole or in part.
\end{abstract}




\section{EXECUTIVE SUMMARY}

The objective of this project was to develop a membrane process to separate olefins from paraffins in waste gas streams as an alternative to flaring or distillation. Flaring these streams wastes their chemical feedstock value; distillation is energy and capital cost intensive, particularly for small waste streams.

We have discovered novel, robust, plasticization-resistant perfluoropolymer membranes that selectively permeate the olefin component of olefin/paraffin gas mixtures. These membranes are made from perfluoropolymers such as Hyflon ${ }^{\circledR} \mathrm{AD}$ (Solvay Solexis, Thorofare, NJ), the copolymer of tetrafluoroethylene and 2,2,4-trifluoro-5-trifluoromethoxy-1,3-dioxole, and Cytop ${ }^{\mathrm{TM}}$ (Asahi Glass, Japan), poly(perfluorobutenyl vinyl ether). The configuration of these membranes was optimized and the membranes were successfully scaled up in our commercial casting machine. Defect-free threeand four-inch spiral-wound modules were prepared. Membrane performance was evaluated in bench-scale membrane stamp and membrane module tests. These parametric tests showed that the optimized membranes had consistently good laboratory performance at commercially relevant operating conditions. In contrast, membranes made from other materials did not perform well under these conditions.

Perfluoropolymer membrane modules were evaluated at three plants. The first field test was performed at a Chevron Phillips slurry reactor polypropylene plant in Pasadena, TX. The membrane system recovered propylene from a reactor purge stream that contained propane and other inerts. The second and third field tests, performed at Equistar ethylene crackers in Channelview, TX and Chocolate Bayou, TX, separated propylene from propane upstream of a $\mathrm{C}_{3}$-splitter. The results obtained in the first two field tests were used to optimize the configuration of the membrane. An optimized Cytop-based membrane was used in the third field test. This membrane maintained a propylene/propane selectivity of 3 during 12 weeks of operation, but selectivity dropped to 2 in the last two weeks of the field test.

Our economic analysis showed that membranes with a propylene/propane selectivity of at least 3 and propylene pressure-normalized flux (permeance) greater than 20 gas permeation units (GPU; 1 GPU $\left.=1 \times 10^{-6} \mathrm{~cm}^{3}(\mathrm{STP}) / \mathrm{cm}^{2} \cdot \mathrm{s} \cdot \mathrm{cmHg}\right)$ are adequate for the economic recovery of propylene from reactor purge (vent) streams. This performance yields a favorable payback of one to two years, depending on the value of the recovered propylene. Therefore, the initial target of the technology developed in this project is the recovery of propylene from reactor purge streams. Approximately 120 U.S. plants could benefit from this technology. This represents a $\$ 100$ million business opportunity. 


\section{TABLE OF CONTENTS}

EXECUTIVE SUMMARY $\ldots \ldots \ldots \ldots \ldots \ldots \ldots \ldots \ldots \ldots \ldots \ldots \ldots \ldots \ldots \ldots \ldots$

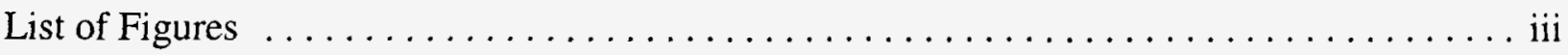

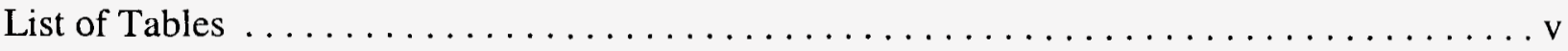

1. INTRODUCTION $\ldots \ldots \ldots \ldots \ldots \ldots \ldots \ldots \ldots \ldots \ldots \ldots \ldots \ldots \ldots \ldots$

1.1 Identification and Significance of the Problem $\ldots \ldots \ldots \ldots \ldots \ldots \ldots$

1.2 Technical Approach and Background Information $\ldots \ldots \ldots \ldots \ldots \ldots$

2. PHASE II RESEARCH OBJECTIVES $\ldots \ldots \ldots \ldots \ldots \ldots \ldots \ldots \ldots \ldots \ldots \ldots$

3. EXPERIMENTAL METHODS $\ldots \ldots \ldots \ldots \ldots \ldots \ldots \ldots \ldots \ldots \ldots \ldots$

3.1 Preparation of Composite Membranes . . . . . . . . . . . . . . . 7

3.2 Measurement of the Gas Permeation Properties of Composite Membranes . . . . 8

3.3 Preparation and Testing of Bench-Scale Spiral-Wound Modules . . . . . . . . . 9

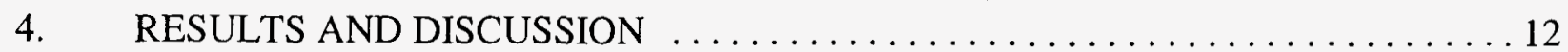

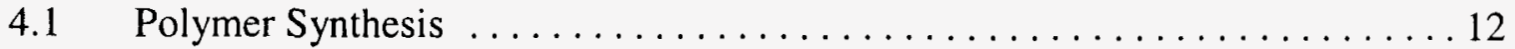

4.2 Optimization and Development of Membranes and Modules . . . . . . . . . 16

4.3 Bench-Scale Parametric Tests: Database for Computer Simulations . . . . . . 28

4.4 Design and Operation of Pilot System at Field Sites . . . . . . . . . . . . . 37

5. TECHNICAL AND ECONOMIC ANALYSIS $\ldots \ldots \ldots \ldots \ldots \ldots \ldots \ldots \ldots \ldots \ldots$

5.1 Polypropylene Reactor Vents $\ldots \ldots \ldots \ldots \ldots \ldots \ldots \ldots \ldots \ldots \ldots \ldots \ldots$

5.2 The Effect of Membrane Permeation Properties on Process Economics . . . . . 50

5.3 The Effect of Market Price on Process Economics . . . . . . . . . . . . . . . . 50

5.4 The Effect of Propylene Recovery on Process Economics . . . . . . . . . . 52

6. PROCESS BENEFITS AND COMMERCIALIZATION PLAN $\ldots \ldots \ldots \ldots \ldots \ldots$

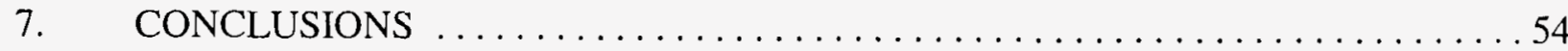

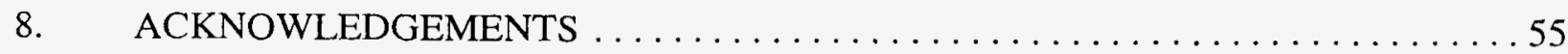

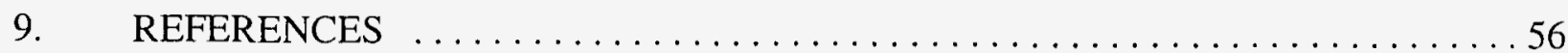




\section{List of Figures}

Figure 1. Simplified schematic of an olefin polymerization plant. . . . . . . . . . 2

Figure 2. A membrane separation system for the recovery and recycle of propylene currently used as fuel or flared. . . . . . . . . . . . . . . . . . . . .

Figure 3. Three additional examples of petrochemical processes that produce purge gas streams

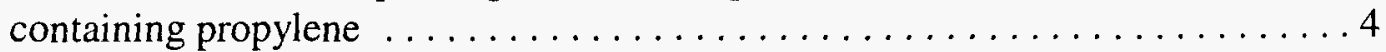

Figure 4. Schematic diagram of the support film casting machine. $\ldots \ldots \ldots \ldots \ldots \ldots$

Figure 5. Schematic diagram of the thin-film coating machine. $\ldots \ldots \ldots \ldots \ldots$

Figure 6. Flow diagram of the pure-gas permeation test system. $\ldots \ldots \ldots \ldots \ldots \ldots$

Figure 7. Schematic diagram of the module-winding operation. $\ldots \ldots \ldots \ldots \ldots$

Figure 8. Schematic diagram of a spiral-wound membrane module. . . . . . . . 10

Figure 9. Flow diagram of the bench-scale test apparatus used to determine the performance

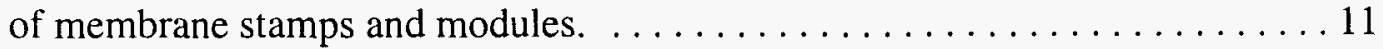

Figure 10. Two-stage polyimide synthesis process. $\ldots \ldots \ldots \ldots \ldots \ldots \ldots \ldots \ldots$

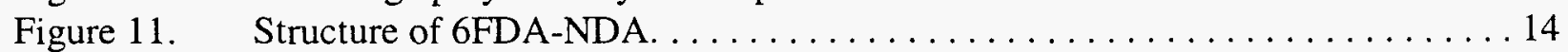

Figure 12. Chemical structure of BPDA-TMPD. $\ldots \ldots \ldots \ldots \ldots \ldots \ldots \ldots \ldots \ldots$

Figure 13. Polythiocarbonate synthesis scheme $\ldots \ldots \ldots \ldots \ldots \ldots \ldots \ldots \ldots \ldots$

Figure 14. The effect of activity on propylene permeance (top) and propylene/propane selectivity (bottom) for PDMS/BPDA-TMPD/PTMSP/PVDF membrane module

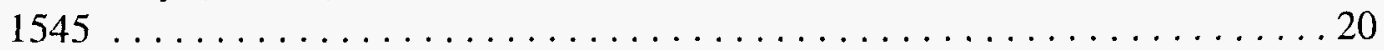

Figure 15. Change in propylene and propane permeance (top) and propylene/propane selectivity (bottom) with time for PDMS/BPDA-TMPD/PTMSP/PVDF membrane module 1545

Figure 16. Chemical structures of perfluorinated polymers. . . . . . . . . . . . 24

Figure 17 . Phase envelope for a $60 \%$ propylene $/ 40 \%$ propane gas mixture (top) and the effect of temperature on the permeation properties of a $1 \times 2 \%$ PDMS $/ 1 \times 0.5 \%$ Hyflon AD 60/PET membrane stamp at a constant pressure of 165 psia (bottom) . . . . . 26

Figure 18. The effect of pressure (activity) on permeance (top) and propylene/propane selectivity for $2 \times 1 \%$ Hyflon AD 60/Teflon ${ }^{\circledR}$ AF 2400/PEI module 1449 . . . . . 29

Figure 19. The effect of temperature on permeance (top) and propylene/propane selectivity (bottom) over time for a $2 \times 1 \%$ Hyflon AD 60/Teflon AF 2400/PEI membrane stamp.

Figure 20. Phase envelope for a gas mixture containing $20 \%$ ethylene, $20 \%$ ethane, $30 \%$ propylene and $30 \%$ propane (top) and the effect of temperature on the permeation properties of a Hyflon AD 60/Teflon AF 2400/PEI membrane stamp at a constant

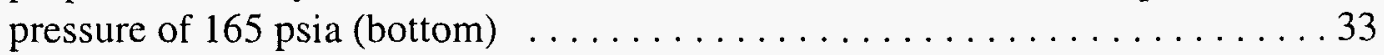

Figure 21. The effect of propylene content on separation performance of a $2 \times 2.5 \%$ PDMS $/ 1 \times 0.25 \%$ Cytop/PEI membrane stamp . . . . . . . . . . 34

Figure 22. Long-term performance of a $2 \times 2.5 \%$ PDMS $/ 1 \times 0.25 \%$ Cytop/PEI membrane stamp.

Figure 23. Long-term performance of $2 \times 2.5 \%$ PDMS/ $1 \times 0.25 \%$ Cytop/PEI 3 -inch module 2414. .36 
Figure 24. Membrane pilot system for olefin/paraffin separation at the Chevron Phillips polypropylene plant in Pasadena, TX. . . . . . . . . . . . . . 38

Figure 25. Results of field tests at Chevron Phillips. Propylene and propane permeances (top) and propylene/propane selectivity (bottom) for $1 \times 2 \% \mathrm{PDMS} / 1 \times 0.5 \%$ Hyflon $\mathrm{AD}$

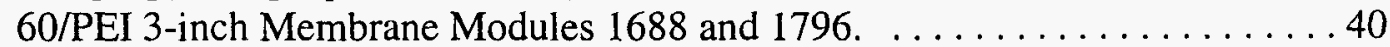

Figure 26. Results of field tests at Chevron Phillips. Temperature profiles for the feed (top) and residue (bottom) of the 3 -inch membrane module. . . . . . . . . . . 41

Figure 27. Membrane system installed at the Equistar petrochemical complex in Channelview,

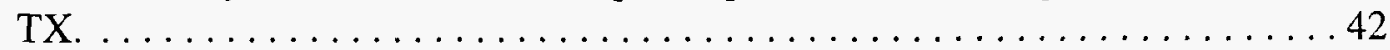

Figure 28. Propylene/propane selectivity of 3-inch membrane module 2110 and 4-inch membrane module 1945 tested at Equistar's Channelview petrochemical complex.

Figure 29. Membrane system installed at Equistar's Chocolate Bayou Petrochemical Complex.

Figure 30. Results from field tests at Equistar's Chocolate Bayou plant. Propylene and propane permeances (top) and propylene/propane selectivity (bottom) for $1 \times 2 \%$ PDMS $/ 1 \times 0.25 \%$ Cytop/PEI 3-inch Membrane Module 2413. . . . . . . . . 45

Figure 31. Block flow diagram of a typical polyolefin production process. . . . . . . . 48

Figure 32. Stream composition in a membrane purge-gas treatment system designed to recover $80 \%$ monomer (propylene) and purge $39 \mathrm{scfm}$ of propane. . . . . . . . . . 49

Figure 33. The effect of propylene flux on membrane system payback time at propylene/propane

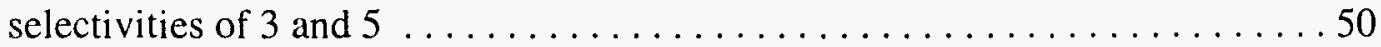

Figure 34. U.S. spot price of polymer-grade propylene, $1996-2003 . \ldots \ldots \ldots \ldots \ldots \ldots$

Figure 35. The effect of propylene spot price on membrane system payback time at propylene/propane selectivities of 3 and $5 \ldots \ldots \ldots \ldots \ldots \ldots \ldots \ldots \ldots \ldots \ldots \ldots \ldots \ldots$

Figure 36. The effect of propylene recovery on membrane system payback time at propylene/propane selectivities of 3 and $5 \ldots \ldots \ldots \ldots \ldots \ldots \ldots \ldots \ldots \ldots \ldots \ldots$ 


\section{List of Tables}

Table 1. Potential Recovery of Propylene and Ethylene from Olefin-Containing Vent Gas

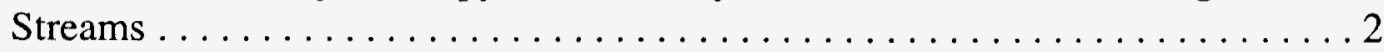

Table 2. Results of Fluorinated Polyimide Syntheses $\ldots \ldots \ldots \ldots \ldots \ldots \ldots \ldots$

Table 3. Results of Polythiocarbonate Syntheses . . . . . . . . . . . . . . 16 Table 4. Summary of Membrane Screening Data for Permeation of Propylene/Propane Gas

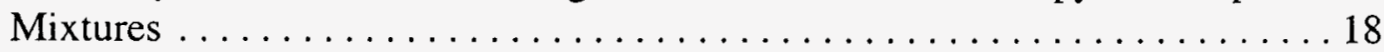

Table 5. Pressure-Normalized Fluxes of 6FDA-NDA Composite Membrane Stamps at $25{ }^{\circ} \mathrm{C}$

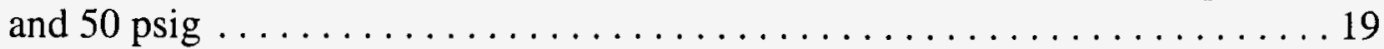

Table 6. Pure-Gas Permeation Properties of PDMS/BPDA-TMPD/PTMSP/PVDF Membrane Module 1545 Before and After Tests with a Propylene/Propane Gas Mixture . . 22

Table 7. Pure-Gas Properties of Polythiocarbonate Composite Membrane Stamps at $25^{\circ} \mathrm{C}$ and

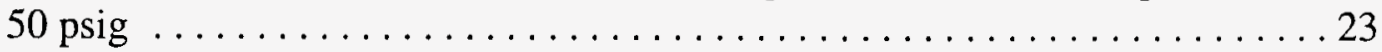

Table 8. Properties of PPO Composite Membranes . . . . . . . . . . . . . . 24

Table 9. Pure-Gas Permeation Properties of a $1 \times 2 \%$ PDMS $/ 1 \times 0.5 \%$ Hyflon AD $60 /$ PEI Composite Membrane Stamp at 30 psig and $25{ }^{\circ} \mathrm{C} \ldots \ldots \ldots \ldots \ldots 27$

Table 10. Permeation Properties of a $2 \times 2 \%$ PDMS $/ 1 \times 0.25 \%$ Cytop/PEI Composite Membrane Stamp with a $60 \%$ Propylene $40 \%$ Propane Gas Mixture . . . . . . . . . 27

Table 11. Pure-Gas Permeation Properties of a $1 \times 2 \%$ PDMS $/ 1 \times 0.25 \%$ Cytop/PEI Composite Membrane Stamp Before and After Tests with a $60 \%$ Propylene $/ 40 \%$ Propane Gas

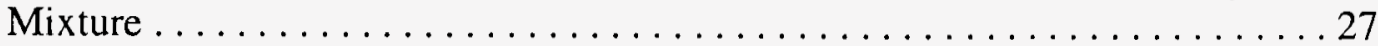

Table 12. Summary of Propylene/Propane Membrane Module Pilot Test Results . . . . . 37

Table 13. Composition of Streams Tested with 3-inch Membrane Module 1688 at the Chevron Phillips Polypropylene Plant in Pasadena, TX . . . . . . . . . . 38

Table 14. Initial Permeation Properties of 3-inch Membrane Module 1688 Tested at the Chevron Phillips Polypropylene Plant in Pasadena, TX ............. 39

Table 15. Pure-Gas Permeation Properties Before and After Pilot Tests for a $1 \times 2 \%$ PDMS $/ 1 \times 0.5 \%$ Hyflon AD 60/PEI Composite Membrane . . . . . . . . . . . 42

Table 17. Composition of Streams Tested with 3-inch Membrane Module 2413 at Equistar's Propylene Plant at Chocolate Bayou, TX ................ 46

Table 18. Initial Permeation Properties of $1 \times 2 \%$ PDMS $/ 1 \times 0.25 \%$ Cytop/PEI 3 -inch Membrane Module 2413 tested at Equistar's Propylene Plant at Chocolate Bayou, TX . . . 46

Table 19. Pure-Gas Permeation Properties Before and After Pilot Tests of $1 \times 2 \%$ PDMS/1×0.25\% Cytop/PEI Membrane Module 2413 at Equistar's Channelview Petrochemical Complex ...................... 46

Table 20. Capital and Operating Cost of the Full-Scale Propylene/Hydrogen Recovery System

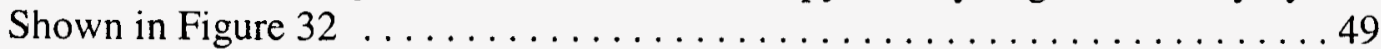

Table 21. Membrane Process Impact and Benefits $\ldots \ldots \ldots \ldots \ldots \ldots \ldots \ldots$ 


\section{INTRODUCTION}

\subsection{Identification and Significance of the Problem}

Ethylene and propylene are the principal building blocks of the petrochemical industry and the largest- and second-largest-volume organic chemicals produced, respectively. More than 40 billion pounds of ethylene and 29 billion pounds of propylene are produced annually in the United States. ${ }^{1}$ Global production of ethylene and propylene exceeds 200 billion pounds and 90 billion pounds, respectively.

Most propylene is co-produced with ethylene by steam cracking of hydrocarbons. ${ }^{1}$ A major portion of the production cost of these chemicals is associated with the olefin/paraffin separation step, currently performed by distillation. Various estimates place the energy consumption of this step between 60 and 120 trillion Btu/year in the United States alone. ${ }^{2}$ The separation is costly and energy intensive because the boiling points of ethylene and propylene are very similar to those of ethane and propane, respectively. As a result, separation requires very large distillation columns with 180 to 200 trays and high reflux ratios. Even small improvements in these separations would result in significant energy and cost savings. ${ }^{3-6}$

The size of the distillation columns required to separate propylene/propane and ethylene/ethane mixtures also influences the handling of small- to medium-sized by-product and vent streams that contain these gases. In the U.S. petrochemical industry, such streams are flared or used as fuel instead of being separated and used or recycled to the process.

Figure 1 shows a simplified schematic of a polyolefin plant that produces an olefin/paraffin by-product stream. In the polymerization step, monomer, catalyst and other agents are contacted in a high-pressure reactor. The polymer product is transferred continuously to a low-pressure flash tank, where the residual monomer and other gases are released. These gases are compressed and recirculated to the reactor, and the polymer is removed for further downstream processing.

As the polymerization reaction proceeds, inert gases-principally the paraffin counterpart of the monomer-build up in the process loop. These inert gases enter the process in the feed gas, which typically contains $99 \%$ olefin monomer and about $1 \%$ paraffin. Unreacted paraffin builds up in the reactor to concentrations of 20-30 vol\%. Paraffin build-up is controlled by continuously removing a fraction of the monomer flash-tank recycle stream as a purge, which is subsequently flared. The $2-3$ moles of olefin monomer lost with every mole of paraffin purged represent $1-2 \%$ of the total feed to the plant and an annual value on the order of $\$ 1$ million per plant. A typical polyolefin plant loses approximately $500 \mathrm{lb} / \mathrm{hr}$ of monomer from the reactor vent stream. Together, the streams from the 120 U.S. polyolefin plants represent a total resource recovery opportunity of more than 500 million lb/year of monomer. 


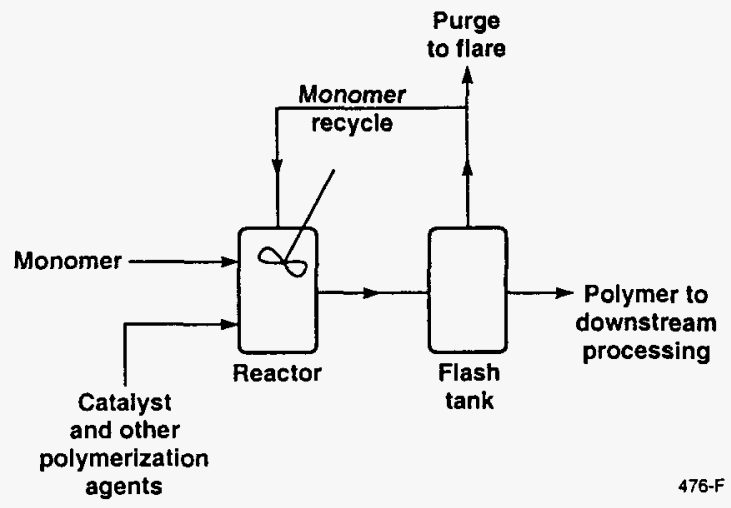

Figure 1. Simplified schematic of an olefin polymerization plant.

Polyolefin production is one of many sources of olefin/paraffin reactor vent streams. Table 1 lists seven large-scale chemical processes that generate olefin-containing vent streams. ${ }^{1,7}$ The amount of olefin used in each process and the amount that is vented, flared or used as fuel, and therefore potentially recoverable, is shown. Unless an ethylene/ethane or propylene/propane splitter is in use at the same site for another purpose, all of these by-product streams must be used as fuel. As fuel, the value of ethylene or propylene is typically about $\$ 0.04 / \mathrm{lb}(\$ 2.00 / \mathrm{MMBtu})$; as refinery-grade chemical feedstock (90-95\% olefin), the value is about $\$ 0.16 / \mathrm{lb}$. We estimate that 850 million pounds of olefin currently lost as a waste gas from these seven processes are potentially recoverable.

Table 1. Potential Recovery of Propylene and Ethylene from Olefin-Containing Vent Gas Streams $^{7}$

\begin{tabular}{|c|c|c|c|c|}
\hline $\begin{array}{l}\text { Source of } \\
\text { Gas Stream }\end{array}$ & $\begin{array}{c}\text { Total U.S. } \\
\text { Production } \\
\left(10^{9} \mathrm{lb} / \text { year }\right)\end{array}$ & $\begin{array}{c}\text { Olefin } \\
\text { Consumption } \\
\left(10^{9} \mathrm{lb} / \text { year }\right)\end{array}$ & $\begin{array}{l}\text { Fraction of Olefin } \\
\text { Recoverable (\%) }\end{array}$ & $\begin{array}{c}\text { Recoverable } \\
\text { Olefin } \\
\left(10^{9} \mathrm{lb} / \text { year }\right)\end{array}$ \\
\hline \multicolumn{5}{|l|}{ Propylene Processes } \\
\hline $\begin{array}{l}\text { Acrylonitrile } \\
\text { Cumene } \\
\text { Propylene Oxide } \\
\text { Isopropanol } \\
\text { Polypropylene } \\
\text { Total Propylene Recovered }\end{array}$ & $\begin{array}{c}2.6 \\
5.0 \\
3.4 \\
1.2 \\
10.0\end{array}$ & $\begin{array}{c}2.1 \\
1.8 \\
2.6 \\
0.9 \\
10.0\end{array}$ & $\begin{array}{l}5.0 \\
4.0 \\
2.0 \\
4.0 \\
1.5\end{array}$ & $\begin{array}{l}0.11 \\
0.07 \\
0.05 \\
0.04 \\
0.15 \\
0.42\end{array}$ \\
\hline \multicolumn{5}{|l|}{ Ethylene Processes } \\
\hline $\begin{array}{l}\text { Ethylene Dichloride } \\
\text { Polyethylene } \\
\quad \text { Total Ethylene Recovered }\end{array}$ & $\begin{array}{l}13.3 \\
25.0\end{array}$ & $\begin{array}{c}3.2 \\
25.0\end{array}$ & $\begin{array}{l}2.0 \\
1.5\end{array}$ & $\begin{array}{l}0.06 \\
0.37 \\
0.43\end{array}$ \\
\hline
\end{tabular}




\subsection{Technical Approach and Background Information}

Olefin/paraffin separations have been the focus of academic and industrial interest for a number of years but almost all of the published work has focused on facilitated transport membranes. ${ }^{9-11}$ Unfortunately, facilitated transport membranes are plagued by unsolved stability problems and their commercial application in the near future is unlikely. Absorption ${ }^{12}$ and pressure swing adsorption (PSA $)^{13,14}$ have been suggested, and a membrane contactor using absorption into silver nitrate has been tested at the pilot scale. ${ }^{10}$ However, none of these processes will be adopted by industry unless a breakthrough in performance is achieved. In the meantime, most of the plants producing these streams continue to flare or use the gas as fuel.

Our approach to the problem of olefin/paraffin separation was to develop a membrane process to recover the olefin monomer from the olefin/paraffin by-product streams currently used as fuel. The process is based on robust, plasticization-resistant polymer membranes that selectively permeate the olefin component. These membranes are potentially useful in hybrid distillation-membrane processes for propylene feedstock production. Given the similarity between ethylene/ethane and propylene/propane mixtures, we expect to obtain similar permeation properties for both vapor pairs.

A schematic diagram of the target application-propylene recovery from a polypropylene plant vent stream-is shown in Figure 2. The membrane separation step produces a propylene stream that is recycled to the reactor, leaving only the residual propane to be flared or used as fuel.

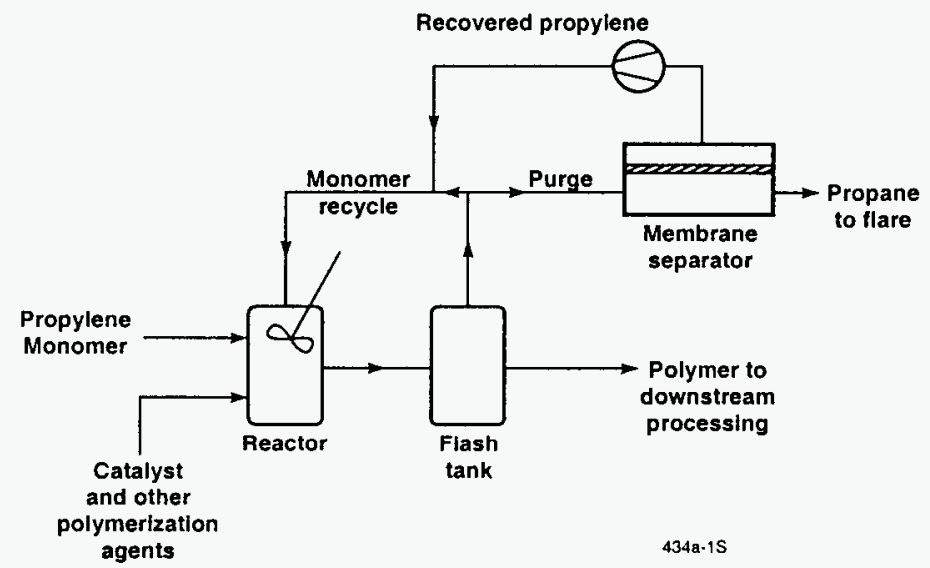

Figure 2. A membrane separation system for the recovery and recycle of propylene currently used as fuel or flared.

Three other processes that generate similar vent streams are shown in Figure 3. In these processes, the chemical yield based on the propylene feedstock is between 92 and $95 \%$. Most of the shortfall in yield is associated with propylene lost with the propane purge stream. 

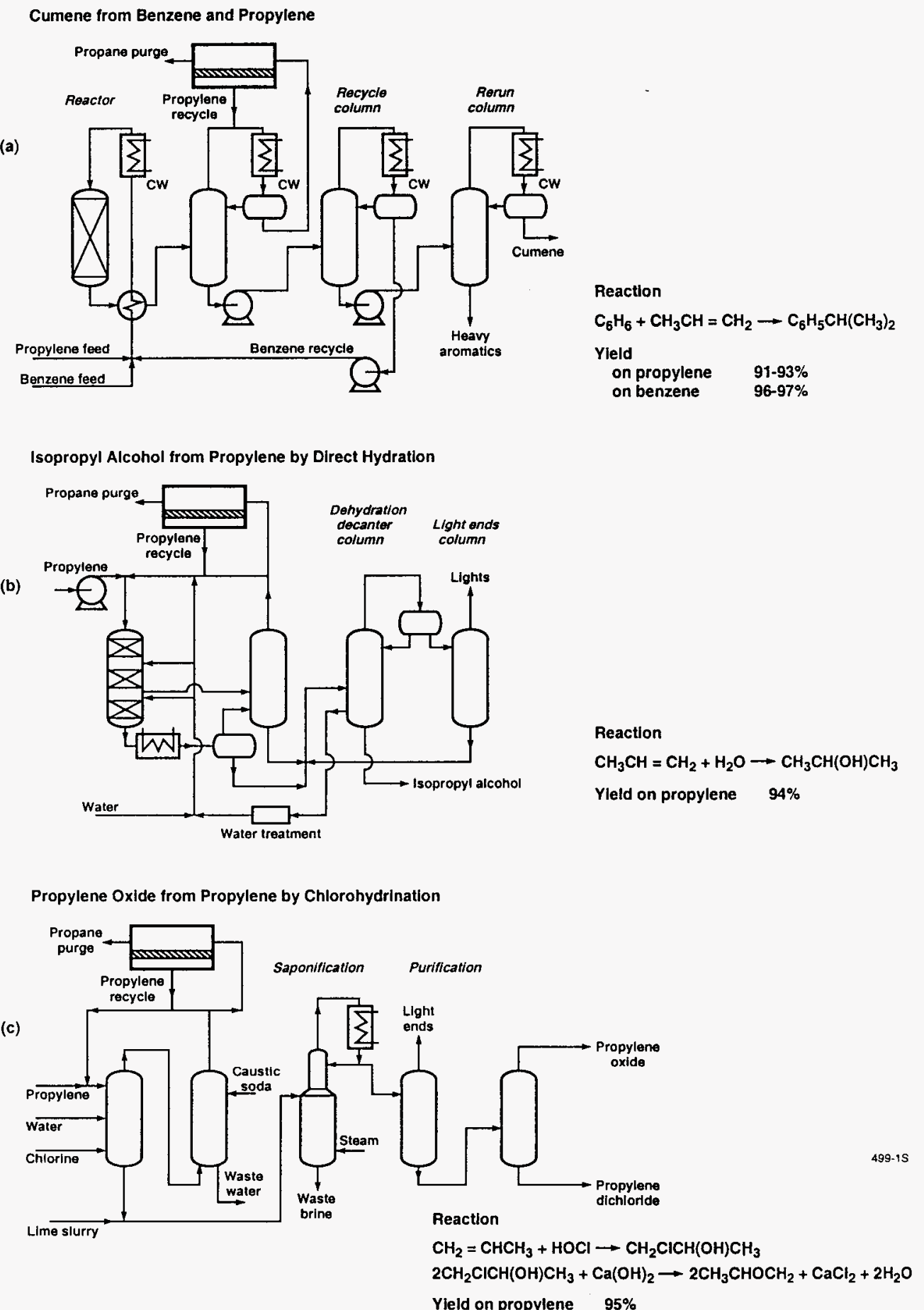

Figure 3. Three additional examples of petrochemical processes that produce purge gas streams containing propylene. In each example, propylene could be separated and recovered for recycle to the process by a membrane system. ${ }^{8}$ 
A selective membrane separates the components of a gas or vapor mixture because the components permeate the membrane at different rates. The permeability, $P\left[\mathrm{~cm}^{3}(\mathrm{STP}) \mathrm{cm} / \mathrm{cm}^{2} \cdot \mathrm{s} \cdot \mathrm{cmHg}\right]$ of a polymer membrane for a gas is defined as the rate at which the gas moves through a standard thickness $(1 \mathrm{~cm})$ of the material under a standard driving force (a pressure difference of $1 \mathrm{cmHg}$ ). A measure of the ability of a membrane to separate two gases is the selectivity, $\alpha$, defined as the ratio of the gas permeabilities. Thus, for olefin/paraffin separations, the selectivity can be expressed as:

$$
\alpha=\frac{P_{\text {olefin }}}{P_{\text {paraffin }}}
$$

Equation 1 can be written as:

$$
\alpha=\frac{D_{\text {olefin }}}{D_{\text {paraffin }}} \cdot \frac{k_{\text {olefin }}}{k_{\text {paraffin }}}
$$

In equation $2, D$ is the diffusion coefficient of the gas in the membrane $\left(\mathrm{cm}^{2} / \mathrm{s}\right)$, a measure of the gas mobility; $k$ is the Henry's law sorption coefficient $\left[\mathrm{cm}^{3}(\mathrm{STP}) / \mathrm{cm}^{3} \cdot \mathrm{cmHg}\right.$, which links the concentration of the gas in the membrane material to the pressure in the adjacent gas.

The ratio of the Henry's law solubility coefficients, $k_{\text {olefin }} / k_{\text {paraffin }}$, can be viewed as the solubility selectivity of the membrane. The solubility selectivity reflects the relative condensabilities of the two gases. Because the boiling points of the olefins and their paraffin counterparts are so similar, we expect this term to be close to one. The ratio of the diffusion coefficients, $D_{\text {olefin }} / D_{\text {paraffin }}$, can be viewed as the mobility selectivity of the membrane. The diffusion selectivity reflects the different sizes of the permeating molecules. Olefins are only slightly smaller than the corresponding paraffins, but the combination of this size difference and differences in molecule shape can result in different rates of diffusion through the membrane, thus enabling the separation of olefin/paraffin pairs.

We selected rigid glassy polymers for membrane development because they separate on the basis of mobility selectivity. ${ }^{15-17}$ (In contrast, solubility selectivity dominates in rubbery polymers.) Our initial efforts focused on fluorinated polyimides. These polymers are soluble in common organic solvents and can therefore be made into thin-film composite membranes. However, we subsequently became aware of a patent issued to Petroleum Energy Center (Tokyo, Japan) that claimed essentially all fluorinated polyimides for the separation of propylene from propane and ethylene from ethane. ${ }^{18}$

We then focused membrane material development on alternative polymers, including non-fluorinated polyimides, fluorinated polythiocarbonates, and poly(dimethylphenylene oxide) (PPO). Identifying a solvent for non-fluorinated polyimides that would allow preparation of composite membranes was an additional challenge. None of these membranes performed satisfactorily at conditions typical of industrial processes. 
Ultimately, we found that exceptional membranes could be made from Hyflon ${ }^{\circledR}$ AD 60 and Cytop ${ }^{\mathrm{TM}}$, two commercially available perfluorinated polymers. Our membrane development efforts, parametric permeation data, and technical and economical analyses are described in detail in Sections 4 and 5 .

\section{PHASE II RESEARCH OBJECTIVES}

The overall objective of this project was to develop robust, high-performance polymeric membranes that preferentially permeated the olefin component of olefin/paraffin mixtures. We planned to use these membranes to demonstrate the technical and economic feasibility of a membrane separation process to recover olefins from waste gas streams. The ultimate goal was commercialization of the process.

Our approach was to execute a two-phase project prior to commercialization. In the first phase of the project, covered by this report, we conducted the basic research and development leading to membrane module performance tests under industrial conditions. The second phase of the project is the subject of a pending new award by U.S. DOE to design, develop, and build a demonstration unit to be installed and operated at a petrochemical plant. ${ }^{19}$ This phase will begin in 2004 . The objective of this unit will be to demonstrate process performance (i.e., the achievement of specific olefin recoveries and purities) in addition to membrane permeation performance.

The specific objectives of the first phase of the project were:

1. Complete development of polymeric olefin/paraffin selective membranes.

2. Fabricate these membranes into membrane modules.

3. Test these membrane modules first in laboratory experiments with model gas mixtures and then with industrial process streams at sites provided by cooperating potential industrial users of the technology.

4. Based on the data obtained, perform a realistic economic and technical analysis of the viability and energy saving and waste reduction potential of the proposed technology.

All of these objectives were fully met, and the technical and economic feasibility of the proposed process was demonstrated. The new membranes developed in this project are robust and outperform all existing polymeric membranes at high-activity conditions (e.g., pressures greater than 100 psig and ambient or higher temperatures). Such high-activity conditions are typical in industry. The permeation properties of the membranes-a propylene/propane selectivity of 3-5 and a propylene permeance (pressure-normalized flux) of 50-100 GPU-are well within the target range for successful commercial application. The membranes were made into spiral-wound modules and tested extensively in-house before evaluation at three petrochemical plants.

In the subsequent system demonstration project, MTR will be involved in supporting and monitoring the performance of a system through the first 6 to 12 months of operation. Any design flaws will be rectified until the system is operating satisfactorily. Successful operation of this prototype plant is an essential prerequisite to adoption of the new technology by the chemical industry. 


\section{EXPERIMENTAL METHODS}

\subsection{Preparation of Composite Membranes}

Composite membranes consist of a very thin nonporous selective polymer film on a microporous support layer. The support layer provides the mechanical strength that allows the selective film to be as thin as $0.2 \mu \mathrm{m}$, resulting in high permeation fluxes. An optional intermediate or "gutter" layer may be used between the selective layer and the support layer. The nonporous gutter layer is much more permeable than the selective layer. It provides a smooth, defect-free surface for deposition of the extremely thin selective layer. In addition, the gutter layer provides a conduit to transport the permeating gas to the pores of the microporous support.

The casting machine used to prepare the microporous support membranes is shown in Figure 4. The casting solution, consisting of a polymer solution dissolved in a water-miscible solvent, is doctored onto a moving belt of nonwoven polyester. The belt passes into a water bath, which precipitates the polymer to form the film. The coated web is collected on a take-up roll, washed overnight to remove any remaining solvent and dried to form the support film.

Figure 4. Schematic diagram of the support film casting machine.

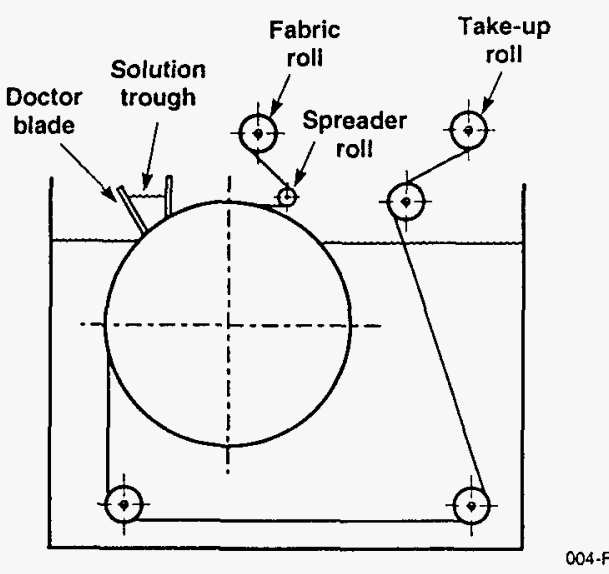

In the absence of a gutter layer, the microporous support membrane provides a finely porous surface for deposition of the very thin selective layer. MTR produces several microporous support membranes from commercially available polymers, such as polyvinylidene fluoride (PVDF), polyetherimide (PEI), polysulfone, and polyacrylonitrile (PAN). We developed several membrane configurations with either PVDF or PEI. 
The optional gutter layer and the selective layer were applied by the continuous coating process shown in Figure 5. The support membrane from the feed roll passes into the coating tank, which contains a dilute solution of the polymer. The moving support membrane is coated with a polymer layer $50-100 \mu \mathrm{m}$ thick. After evaporation of the solvent in a drying oven, a 0.2 -to-2.0- $\mu \mathrm{m}$-thick polymer film is left on the support membrane. The thickness of the film depends on the polymer and the solution concentration.

Figure 5. Schematic diagram of the thin-film coating machine.

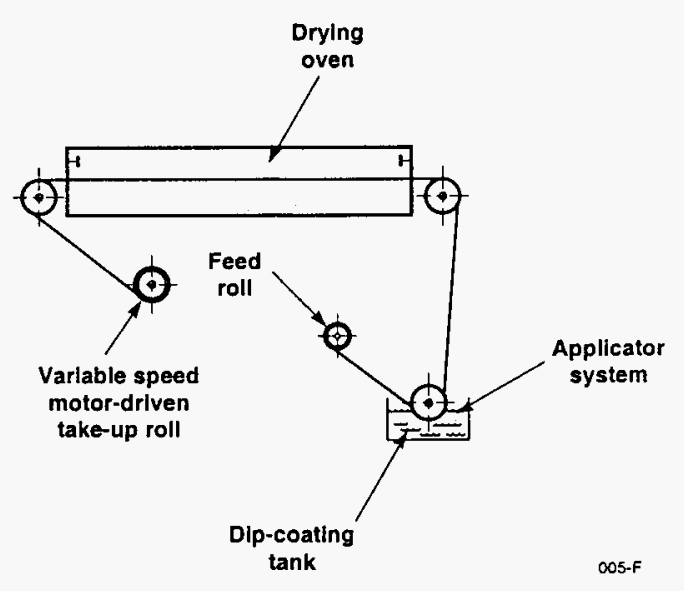

The gutter layer seals defects and improves fluid distribution and flow within the membrane. Some membrane configurations also included a polydimethylsiloxane (PDMS) protective layer to seal defects and prevent damage during module preparation.

\subsection{Measurement of the Gas Permeation Properties of Composite Membranes}

Pure-gas membrane permeation properties were measured using the test system shown schematically in Figure 6. Each of the four test cells holds a circular membrane stamp. The feed gas for each cell can be selected independently from seven different gas cylinders and each cell has an independent feed pressure control. The flow rate of the permeate gas is determined with a bubble flow meter.

The purpose of the permeation experiments with pure gases was to ensure that the composite membranes were defect-free. Composite membranes are considered to be defect-free if the pure-gas selectivity is within $95 \%$ of the known pure-gas selectivity for a thick, isotropic film of the material. The mixed-gas permeation properties of the membranes were evaluated in the system described in Section 3.3. 


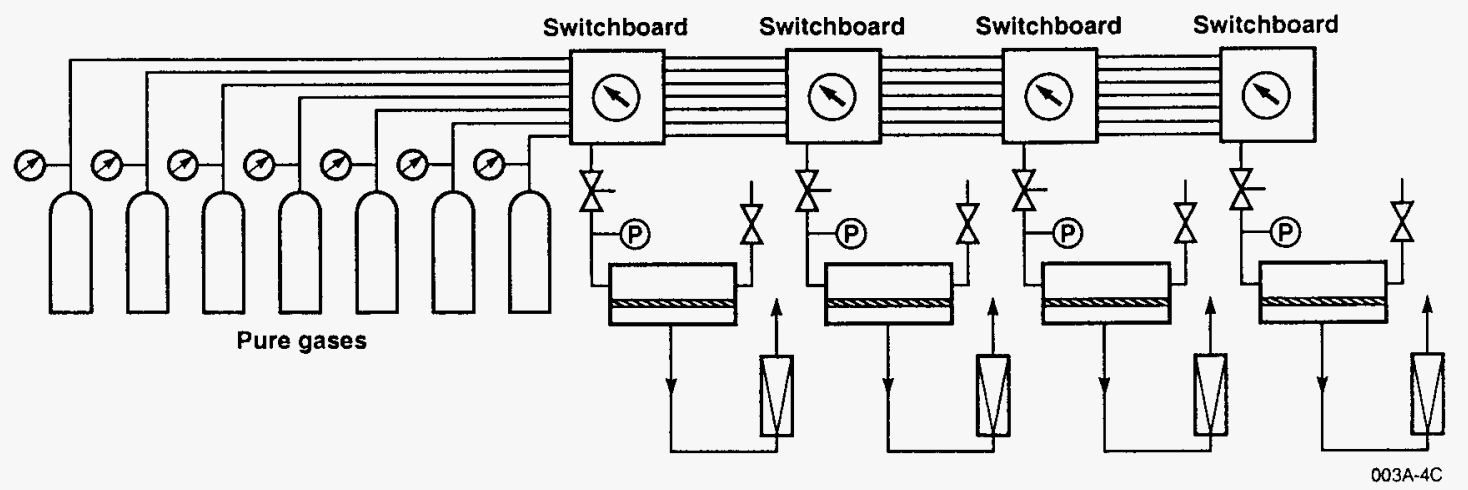

Figure 6. Flow diagram of the pure-gas permeation test system.

\subsection{Preparation and Testing of Bench-Scale Spiral-Wound Modules}

Defect-free membranes were packaged into spiral-wound modules using the winding operation shown schematically in Figure 7. Bench-scale modules are 40 inches long and 3 inches in diameter and contain $0.8 \mathrm{~m}^{2}$ of membrane. Modules for pilot tests are 4 inches in diameter and contain $3.3 \mathrm{~m}^{2}$ of membrane; commercial modules are 8 inches in diameter and contain $20 \mathrm{~m}^{2}$ of membrane.

To prepare modules, the membrane is cut to size and folded around the feed-spacer material and the product distribution pipe. The membrane envelope is then moved to the wind-up machine. The product collection pipe is placed in the jaws of a motor clutch, and the membrane envelope is glued along the edges and ends and wound around the product pipe. During the winding operation, the material is kept under slight tension. When the operation is complete, a layer of reinforced tape is used to keep the membrane envelope in place and fiberglass is applied to seal the module. The module is then fitted with end caps and placed in a pressure housing.

A schematic of a spiral-wound module and mode of operation are shown in Figure 8. In the simplest module, a single membrane envelope is wound around a perforated central collection tube and the module is placed inside a tubular pressure vessel. Feed gas passes axially down the module across the membrane envelope. A portion of the feed permeates the envelope, flows to the center, and exits through the collection tube. 

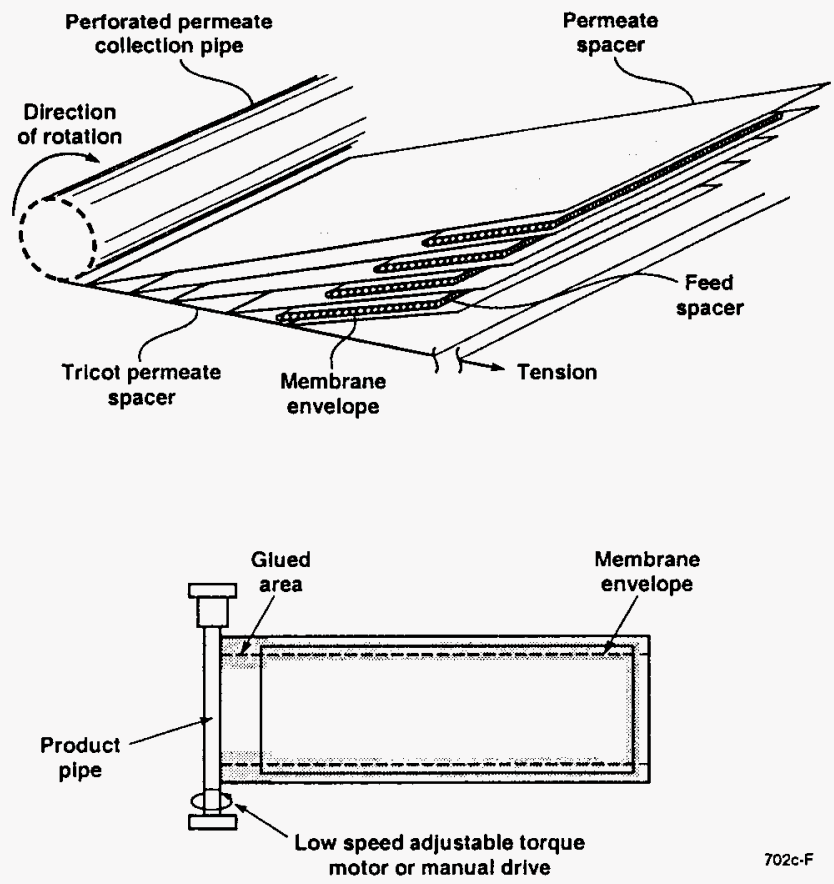

702e-F

Figure 7. Schematic diagram of the module-winding operation.

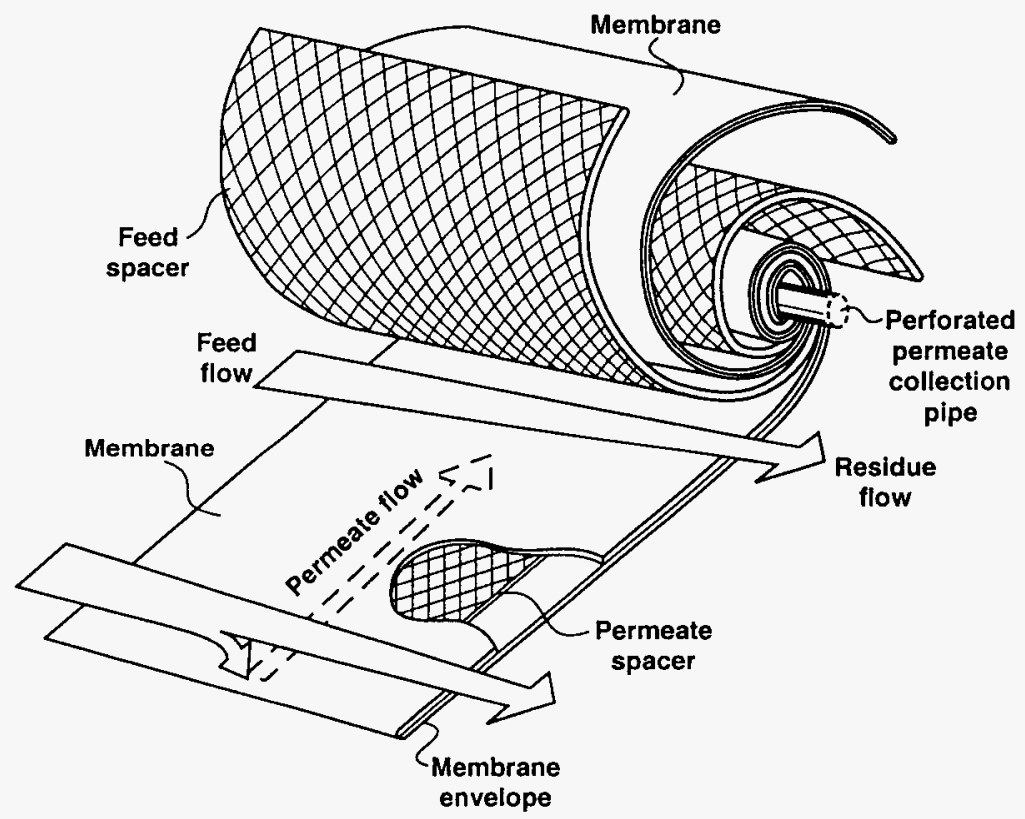

Figure 8. Schematic diagram of a spiral-wound membrane module. 
The high-pressure bench-scale system shown in Figure 9 was used to test membrane stamps and modules with gas mixtures to generate design basis data for commercial-scale processes. This test system is a closed-loop, total-recycle system for performing continuous separation tests with both stamp cells and modules. The system is equipped with a two-stage, 7.5-hp diaphragm compressór that can deliver up to $22 \mathrm{scfm}$ flow at pressures up to $1,500 \mathrm{psig}$.

The gas is fed into a stamp test cell or a high-pressure vessel containing the module. The pressure of the residue gas is reduced; then the gas is mixed with the permeate gas and recompressed to about 30 psig by a small diaphragm compressor. This combined stream forms the feed gas to the larger compressor. (In this system, both residue and permeate streams are recycled, and no gas is lost.) The test system has an on-line gas chromatography sampling loop so that feed, residue, and permeate streams can be sampled continuously. The sampling loop uses a $\mathrm{P} 200 \mathrm{H}$ portable thermal conductivity detector (TCD) gas chromatograph (GC) with appropriate columns for olefin/paraffin analysis. Make-up gas is added to the low-pressure side of the recycle loop.

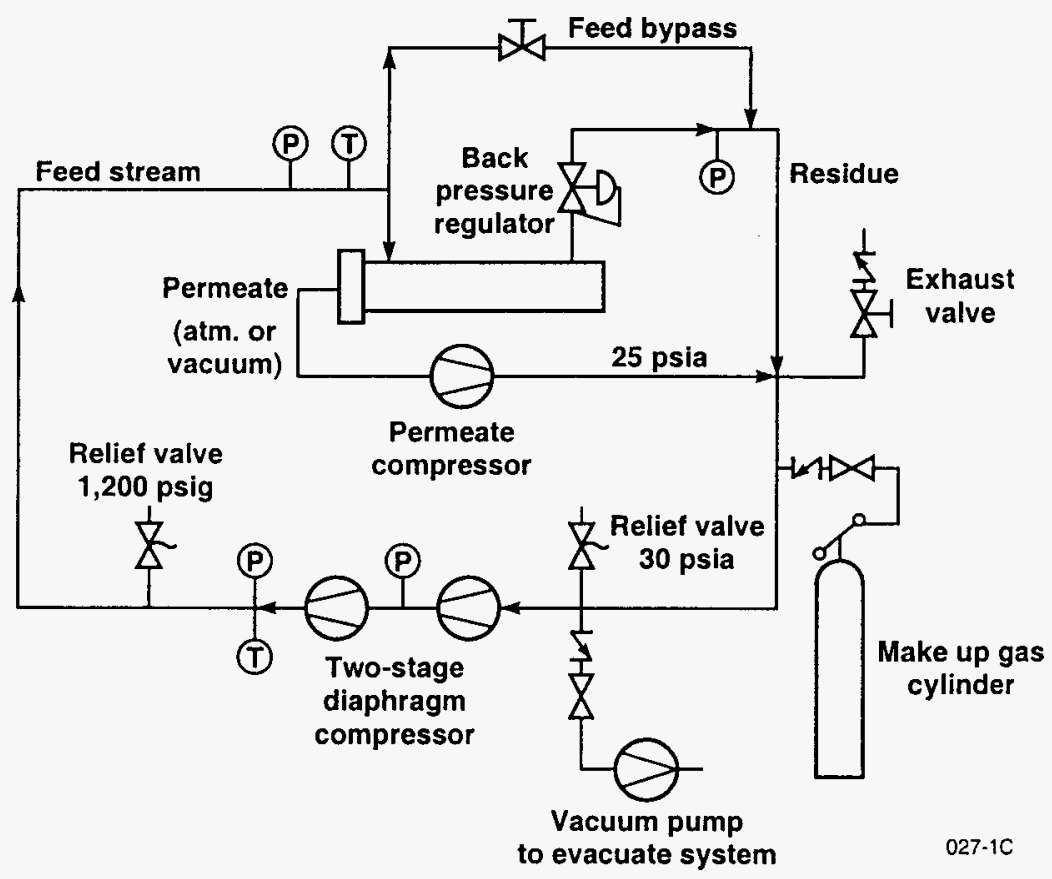

Figure 9. Flow diagram of the bench-scale test apparatus used to determine the performance of membrane stamps and modules. The maximum feed pressure is 1,500 psig; the maximum feed flow rate is $22 \mathrm{scfm}$. 


\section{RESULTS AND DISCUSSION}

\subsection{Polymer Synthesis}

Our membrane material development work focused on finding polymeric materials that satisfy the following criteria:

(1) Soluble in at least one organic solvent commonly used to prepare membranes.

(2) Rigid and glassy (to achieve selectivity); relatively permeable to olefins.

(3) Robust and stable in olefin/paraffin mixtures at the high vapor activities characteristic of industrial conditions.

We synthesized small quantities of fluorinated polyimides, non-fluorinated polyimides, and fluorinated polythiocarbonates with commercial monomers according well documented literature methods. Other membrane materials, including PPO and perfluorinated polymers, were purchased.

\section{Fluorinated Polyimides}

Polyimides as a class are resistant to solvents and high temperatures. These polymers are currently used as membrane materials for gas separation applications such as hydrogen recovery in refinery applications, removal of carbon dioxide from natural gas, and air separation.

Polyimides are formed from an aromatic dianhydride and an aromatic diamine in a two-stage process (Figure 10). The first stage is the polycondensation of the two species to form an intermediate poly(amic acid). The second stage, dehydration of the poly(amic acid), produces an imide linkage. Dehydration and imidization are induced by either heating to a high temperature or by a chemical reaction. Thermal imidization often results in insoluble and infusible polyimides; chemical imidization usually produces soluble polyimides. The imidization ratio is easily controlled in the chemical imidization technique by, for example, varying the concentration of catalysts or the imidization time. 

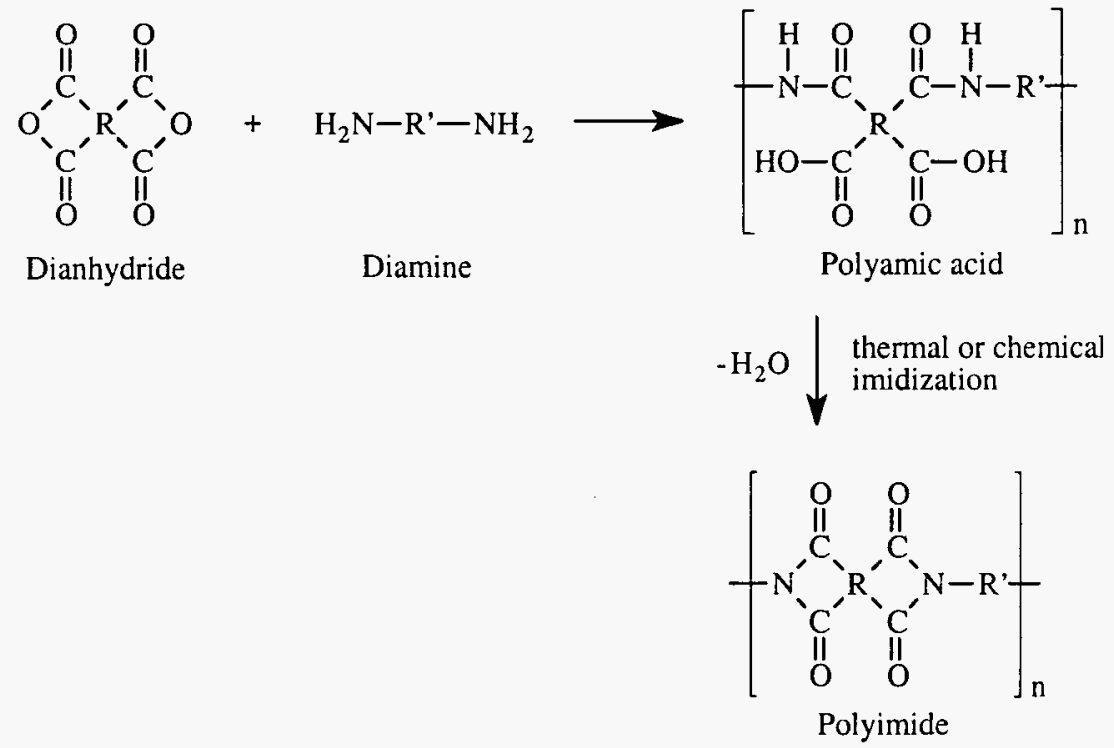

Figure 10. Two-stage polyimide synthesis process.

Table 2 lists the high-molecular-weight fluorinated polyimides that were synthesized in this project. All polymerization and imidization reactions were carried out in dimethylacetamide (DMAc) under a dry nitrogen atmosphere at temperatures below $5{ }^{\circ} \mathrm{C}$ unless otherwise noted.

Table 2. Results of Fluorinated Polyimide Syntheses

\begin{tabular}{||c|c|c|c||}
\hline $\begin{array}{c}\text { Monomers: } \\
\text { Anhydride-Amine* }\end{array}$ & $\begin{array}{c}\text { Polymer } \\
(\mathrm{g})\end{array}$ & $\begin{array}{c}\text { Yield } \\
(\%)\end{array}$ & Notes \\
\hline 6FDA-DPPAT & 7.2 & 94.7 & \\
\hline 6FDA/BTDA-NDA & 34.8 & 93.8 & \\
\hline 6FDA-DPPAT/NDA & 8.6 & 90 & Room temperature reaction \\
\hline
\end{tabular}

*Anhydrides: 4,4'-(hexafluoroisopropylidene)diphthalic anhydride (6FDA); 3,3',4,4'-benzophenone tetracarboxylic dianhydride (BTDA); amines: 3,8-diamino-6-phenylphenanthridine (DPPAT); 1,5-naphthalenediamine (NDA).

The fluorinated polyimide based on 4,4'-(hexafluoroisopropylidene)diphthalic anhydride (6FDA) and 1,5-naphthalenediamine (NDA) was obtained in high yields. The structure of this polyimide (referred to as 6FDA-NDA) is shown in Figure 11. 


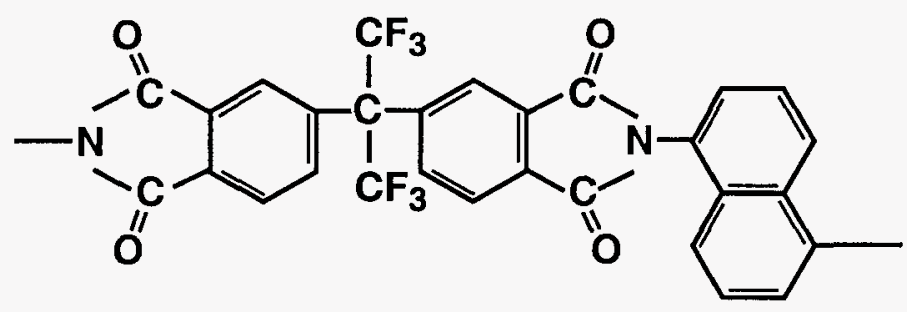

Figure 11. Structure of 6FDA-NDA.

\section{Non-Fluorinated Polyimides}

Non-fluorinated polyimides have separation properties similar to those of fluorinated polyimides. We synthesized the polyimide BPDA-TMPD from 3,3',4,4'-biphenyltetracarboxylic dianhydride (BPDA) and 2,4,6-trimethyl-m-phenylene diamine (TMPD). The structure of BPDA-TMPD is shown in Figure 12.

To obtain high-molecular-weight polyimides, optimization of the polymerization conditions was crucial. The reaction was carried out in a dry nitrogen atmosphere with dimethylacetamide (DMAc) as the polymerization solvent. At room temperature, BPDA is less soluble in DMAc than other dianhydrides. In our protocol, TMPD was dissolved in DMAc at room temperature; the temperature was then increased to $65^{\circ} \mathrm{C}$ while BPDA was added. After the BPDA was completely dissolved, the reaction mixture was cooled to room temperature. As the temperature decreased, the reaction mixture became increasingly viscous and finally gelled.

Excess DMAc was added to dilute the gelled reaction mixture before the imidization catalysts were added. After adding the catalysts, the clear orange reaction mixture became opaque. The mixture was poured into a large amount of methanol to precipitate and purify the resulting polymer, which was washed with water and dried in a oven at $65^{\circ} \mathrm{C}$ for 24 hours.<smiles>CCC(C)(C)N1C(=O)c2ccc(-c3ccc4c(c3)C(=O)N(c3c(C)cc(C)c(C(C)(C)C)c3C)C4=O)cc2C1=O</smiles>

Figure 12. Chemical structure of BPDA-TMPD. 


\section{Fluorinated Polythiocarbonates}

A review of the literature showed that fluorinated polycarbonates are potential candidates for olefin/paraffin separation. Published permeability data for permanent gases indicate that fluorinated polycarbonates are similar to fluorinated polyimides. Fluorinated polycarbonates are not commercially available, but the monomers are readily available.

We prepared fluorinated polythiocarbonates, which are relatively easy to synthesize. Polythiocarbonates are synthesized in an interfacial polymerization process in which a fluorinated bisphenol monomer dissolved in an aqueous phase is contacted with thiophosgene in an organic phase. A phase-transfer catalyst, which is miscible in both phases, is then added to promote polymerization. The basic reaction scheme is shown in Figure 13; a detailed polymerization procedure is given below.

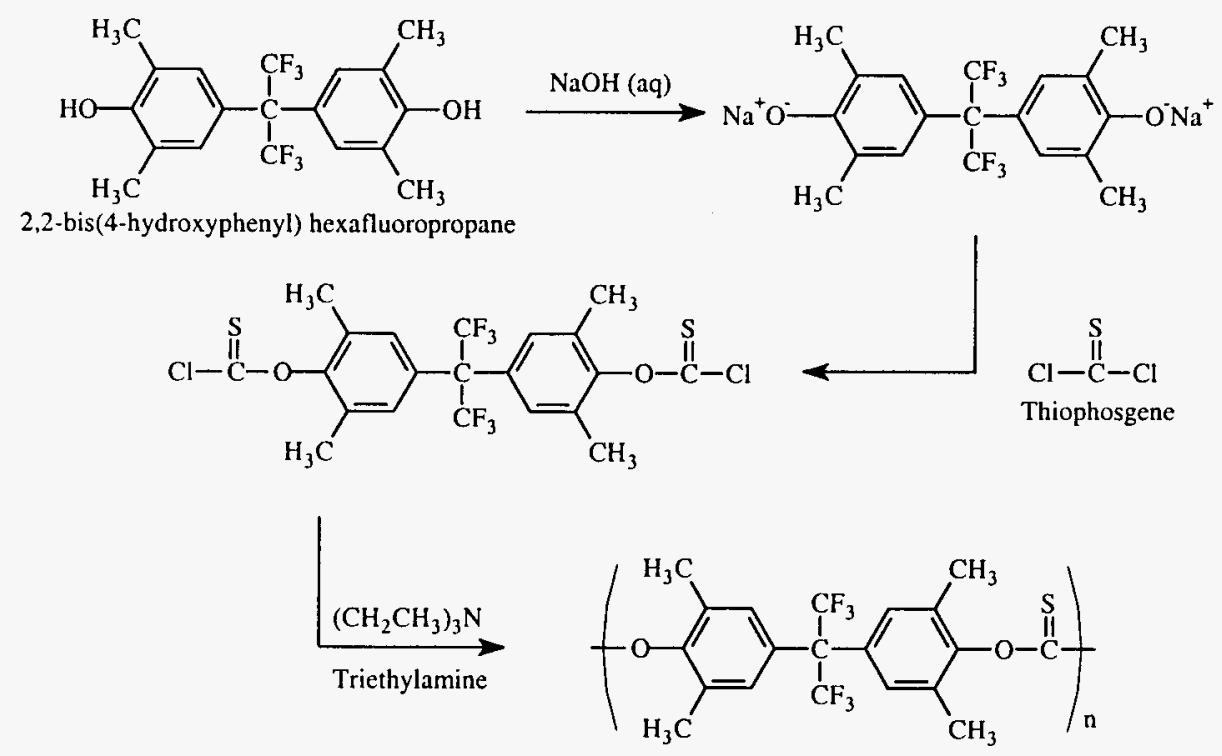

Figure 13. Polythiocarbonate synthesis scheme. The starting monomer is a fluorinated bisphenol; the triethylamine is the transfer catalyst.

A three-necked Pyrex ${ }^{\circledR}$ flask, generally $300 \mathrm{~mL}$ or $500 \mathrm{~mL}$, is used for the reaction. The flask is equipped with a magnetic stirrer, a nitrogen inlet tube, and a $200-\mathrm{mL}$ funnel. First, the flask is charged with the bisphenol monomer, then purged with nitrogen. A solution of $1 \mathrm{~N}$ aqueous sodium hydroxide is added to dissolve the bisphenol. The volume of this aqueous phase is $3,000 \mathrm{~mL}$ per mole of bisphenol monomer; an equal volume of methylene chloride is added as the organic phase to absorb the thiophosgene. Thiophosgene is carefully transferred by a syringe to the reaction flask. A three-to-one molar ratio of thiophosgene to bisphenol is used to compensate for thiophosgene hydrolysis, which occurs continuously in the presence of aqueous sodium hydroxide. 
Thiophosgene is added dropwise to the reaction flask. After all of the thiophosgene has been introduced into the reaction flask, triethylamine (the phase-transfer catalyst) is added. A 0.08-to-1 molar ratio of triethylamine to bisphenol is used. The viscosity of the reaction mixture begins to increase noticeably within half an hour and the reaction is stopped three to four hours after addition of the thiophosgene.

The reaction mixture is washed and extracted five times with de-ionized water to remove the sodium salt. The organic and aqueous phases are separated, and the polymer is precipitated by adding a large amount of methanol to the organic phase. The precipitated polymer is kept in the methanol overnight to decompose unreacted thiophosgene. The polymer is dried in a vacuum oven at about $50{ }^{\circ} \mathrm{C}$.

Table 3 summarizes the results of the polythiocarbonate syntheses. Two polythiocarbonates, poly(thiobisphenol A) and poly(thiobisphenol AF), were prepared in reasonable yield. These polymerizations were carried out at room temperature, under a dry nitrogen atmosphere, in methylene chloride. We used 3,000 mL of $1 \mathrm{~N}$ aqueous $\mathrm{NaOH}, 3$ moles of thiophosgene, and 0.2 moles of triethylamine per mole of bisphenol monomer.

Table 3. Results of Polythiocarbonate Syntheses

\begin{tabular}{|c|c|c|}
\hline Bisphenol Monomer* $^{*}$ & Polymer (g) & Yield (\%) \\
\hline Bisphenol AF & 5.6 & 83.5 \\
\hline Bisphenol A & 6.5 & 86.5 \\
\hline
\end{tabular}

* Bisphenol AF: 4,4'-(hexafluoroisopropylidene)diphenol; bisphenol A: 4,4'-(isopropylidene)diphenol.

\subsection{Optimization and Development of Membranes and Modules}

All membranes developed in this project were composite membranes, as described in Section 3.1. These membranes were initially made with a laboratory-scale casting machine and then scaled up using our 40-inch-wide commercial casting machine.

Several issues must be resolved in bringing membranes from laboratory to commercial scale. For example, formation of an appropriate microporous support membrane for the composite is extremely important. To ensure that the separation is controlled by the selective layer, the support, gutter, and protective layers must not significantly affect the flux of the permeating vapor. Other important attributes of the support membrane are resistance to the solvent used for the coating solution containing the gutter-layer polymer and a smooth surface to ensure uniform coating of this layer. 
Many variables affect the selective layer coating process. To form ultrathin layers that are consistently defect-free and of reproducible thickness, the coating solvent, the polymer concentration in the solvent, the temperature of the solution, and the coating rate must all be optimized. Production of membranes to specification in commercial quantities requires close control of these variables. Scale-up is not always straightforward. For example, larger volumes of coating solution tend to change in consistency during the time required to manufacture a 100- to 200-yard roll of membrane. These and other scale-up issues were resolved to produce membranes in the quantities required for pilot- and commercial-scale modules.

As a preliminary screening step, we compared the performance of composite membranes made in this study with the reported performance of various polymer films. A summary of membrane permeation data is given in Table 4 . To facilitate comparison, we calculated the gas activity, defined as the ratio of feed gas pressure $(P)$ to gas mixture saturation pressure $\left(P_{s a t}\right)$, for each example; in addition, we converted the reported gas permeabilities to the equivalent pressure-normalized flux of a $0.2 \mu \mathrm{m}$ thick membrane. This is a reasonable target for the thickness of the selective layer of a composite membrane.

As shown in Table 4, the propylene/propane selectivities reported in the literature are much higher than those found in this study. However, the test conditions in this study are more challenging and more realistic; they approximate industrial process conditions. Propylene fluxes reported in the literature (Table 4) are too low for commercial applications. In our technical and economic analysis (Section 5), we show the range of commercially attractive propylene fluxes. 
Table 4. Summary of Membrane Screening Data for Permeation of Propylene/Propane Gas Mixtures

\begin{tabular}{|c|c|c|c|c|c|c|}
\hline Polymer* & $\begin{array}{l}\text { Membrane } \\
\text { Type }\end{array}$ & $\begin{array}{c}\text { Feed Gas } \\
\text { Mixture } \\
\text { Pressure } \\
\text { (psia) }\end{array}$ & $\begin{array}{c}\text { Activity } \\
\left(\mathrm{P} / \mathrm{P}_{\text {sat }}\right. \\
\mathrm{x} 100) \\
(\%)\end{array}$ & $\begin{array}{c}\text { Propylene Flux } \\
\text { for a } \\
0.2-\mu m-T h i c k \\
\text { Membrane } \\
\text { (GPU) }\end{array}$ & $\begin{array}{l}\text { Propylene/ } \\
\text { Propane } \\
\text { Selectivity }\end{array}$ & Reference \\
\hline 6FDA-TMPD & Film & 29 & 20 & 7.5 & 10 & $\begin{array}{l}\text { Shimazu et } \\
\text { al. }^{20}\end{array}$ \\
\hline 6FDA-BAAF & Composite & 59 & 30 & 3.4 & 7.3 & $\begin{array}{l}\text { Staudt-Bickel } \\
\text { and Koros }\end{array}$ \\
\hline 6FDA-NDA & Film & 29 & 20 & 0.3 & 55 & $\begin{array}{l}\text { Shimazu et } \\
\text { al. }^{20}\end{array}$ \\
\hline 6FDA-NDA & Composite & 65 & 50 & 18 & 6.6 & This Study \\
\hline BPDA-TMPD & Film & 59 & 20 & 17 & 8 & $\begin{array}{l}\text { Tanaka et } \\
\text { al. }{ }^{17}\end{array}$ \\
\hline BPDA-TMPD & Composite & 39 & 40 & 90 & 2 & This Study \\
\hline PPO & Film & 26 & 10 & 3.2 & 18 & Ilinitch et al. ${ }^{16}$ \\
\hline PPO & Composite & 135 & 75 & 890 & 1.5 & This Study \\
\hline $\begin{array}{l}\text { Hyflon and } \\
\text { Cytop }\end{array}$ & Composite & 165 & 100 & 50 & $3-5$ & This Study \\
\hline
\end{tabular}

* The polyimide 6FDA-BAAF is formed by the reaction of 4,4'-(hexafluoroisopropylidene)diphthalic anhydride (6FDA) and 2,2-bis(4-aminophenyl)hexafluoropropane (BAAF). Other acronyms are defined in Section 4.1.

\section{Fluorinated Polyimide Composite Membranes}

Our initial efforts to develop polymers having high olefin permeability and high olefin/paraffin selectivity focused on fluorinated polyimides. These polymers are soluble in common organic solvents and can, therefore, be made into thin-film composite membranes. We prepared composite membranes consisting of a polyvinylidene fluoride (PVDF) support membrane, a poly(4-methyl-2-pentyne) (PMP) gutter layer, and the selective polymer layer. Some membranes were then overcoated with a polydimethylsiloxane (PDMS; grade 940) protective layer to seal any defects.

The pure-gas permeation properties of a representative fluorinated polyimide, 6FDA-NDA, are given in Table 5. Development of these membranes was abandoned after we became aware of a Petroleum Energy Center patent that claimed essentially all fluorinated polyimides as membrane materials for the separation of propylene from propane and ethylene from ethane. ${ }^{9}$ 
Table 5. Pressure-Normalized Fluxes of 6FDA-NDA Composite Membrane Stamps at $25^{\circ} \mathrm{C}$ and 50 psig

\begin{tabular}{|l|c|c|c|c|c||}
\hline \multirow{2}{*}{ Membrane $^{*}$} & \multicolumn{5}{|c|}{ Pressure-Normalized Flux (GPU) } \\
\cline { 2 - 6 } & $\mathrm{N}_{2}$ & $\mathrm{O}_{2}$ & $\mathrm{CH}_{4}$ & $\mathrm{H}_{2}$ & $\mathrm{CO}_{2}$ \\
\hline 6FDA-NDA on 1 $1 \%$ PMP/PVDF & 20 & 60 & 20 & 330 & 285 \\
\hline $1 \times 2 \%$ PDMS/6FDA-NDA on 1 $1 \%$ PMP/PVDF & 7 & 30 & 6 & 190 & 180 \\
\hline
\end{tabular}

* The shorthand for one coat of a $1 \%$ polymer solution is $1 \times 1 \%$; for one coat of a $2 \%$ solution, $1 \times 2 \%$.

\section{Non-Fluorinated Polyimide Composite Membranes}

Our next step was to develop non-fluorinated polyimide composite membranes. We selected BPDA-TMPD, the product of 3,3',4,4'-biphenyltetracarboxylic dianhydride (BPDA) and 2,4,6-trimethyl-m-phenylenediamine; the synthesis of this polyimide is described in Section 4.1. As discussed in Section 3.1, composite membranes are formed by coating a thin layer of a solution of the polymer in a volatile solvent onto a support membrane. Polymers such as BPDA-TMPD are soluble only in relatively nonvolatile solvents. We discovered a novel solvent, hexafluoroisopropanol (HFIP), that dissolves non-fluorinated polyimides and allows preparation of composite membranes. To reduce consumption of this costly solvent, we developed a novel solvent system consisting of $1 \%$ HFIP in chloroform. We made composite membranes on PVDF support with a PTMSP gutter layer and a PDMS overcoat to seal any pinholes on the BPDA-TMPD selective layer.

Membrane modules and stamps were tested with a 50\% propylene/50\% propane gas mixture at different pressures and temperatures. Figure 14 shows the effect of activity on the propylene permeance and propylene/propane selectivity of a BPDA-TMPD membrane module. Activity-the ratio of the operating pressure to the saturation pressure of the mixture-is expressed in percent. The temperature in this test was about $15^{\circ} \mathrm{C}$; the pressure was varied from 50 to $80 \mathrm{psig}$. 

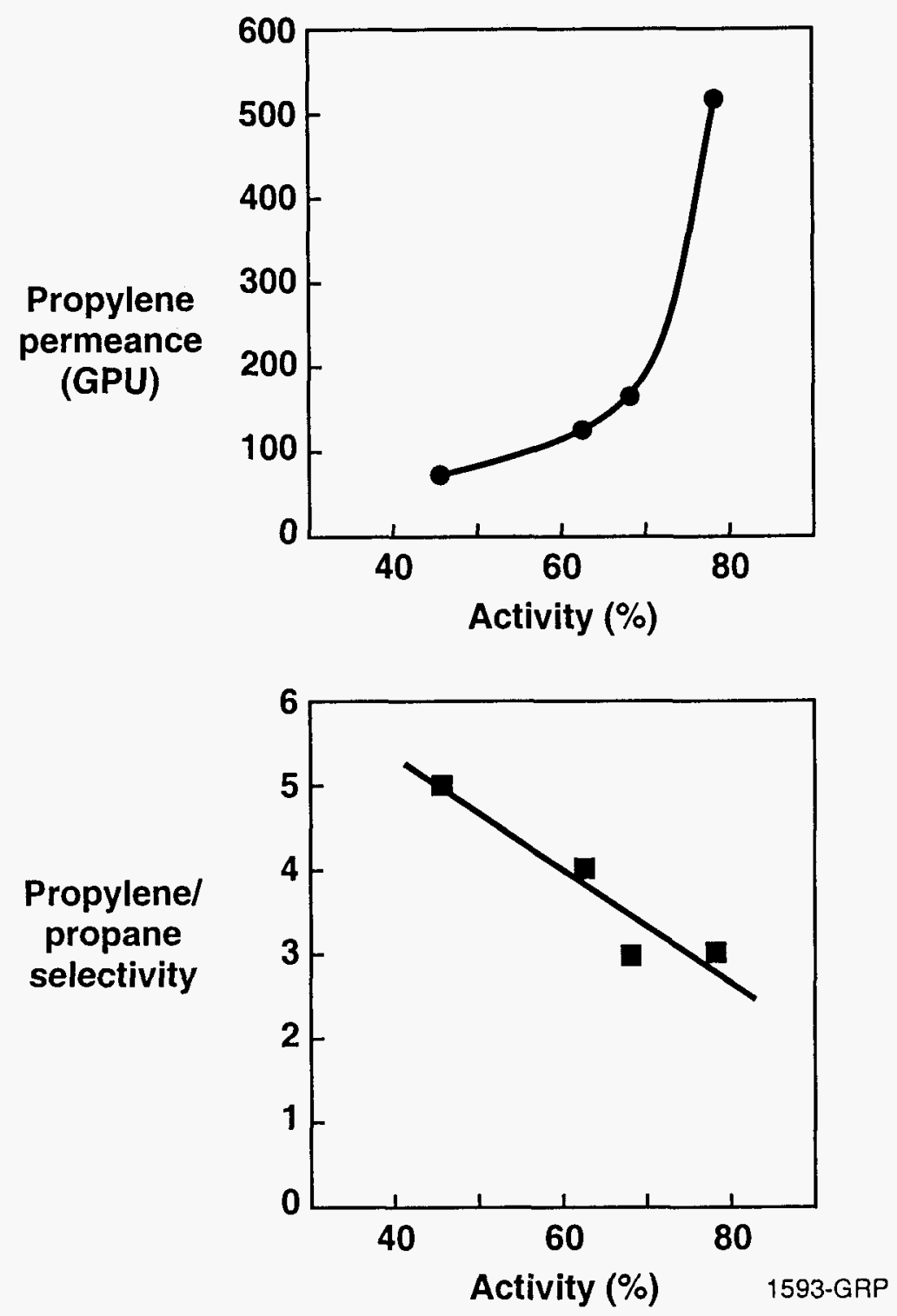

Figure 14. The effect of activity on propylene permeance (top) and propylene/propane selectivity (bottom) for PDMS/BPDA-TMPD/PTMSP/PVDF membrane module 1545 . Gas mixture: $50 \%$ propylene $/ 50 \%$ propane; temperature: $15^{\circ} \mathrm{C}$.

Initially, the propylene flux increases slowly with activity; then, at an activity of about $70 \%$, the flux increases sharply. At high activity, plasticization of the polymer occurs and polymer chain mobility increases, leading to increased diffusion in the polymer and reduced selectivity. The non-fluorinated polyimide membranes perform well initially, but they are clearly susceptible to plasticization at high activities. 
We then evaluated the stability of these membranes over an eight-day period at $45 \%$ gas activity conditions. The fluxes and selectivities for membrane module 1545 are shown as a function of time in Figure 15. Steady-state conditions were observed after about eight hours of operation. During that time, propylene/propane selectivity increased from 2.5 to 4 , then gradually dropped to about 2 . Fluxes increased significantly over time.
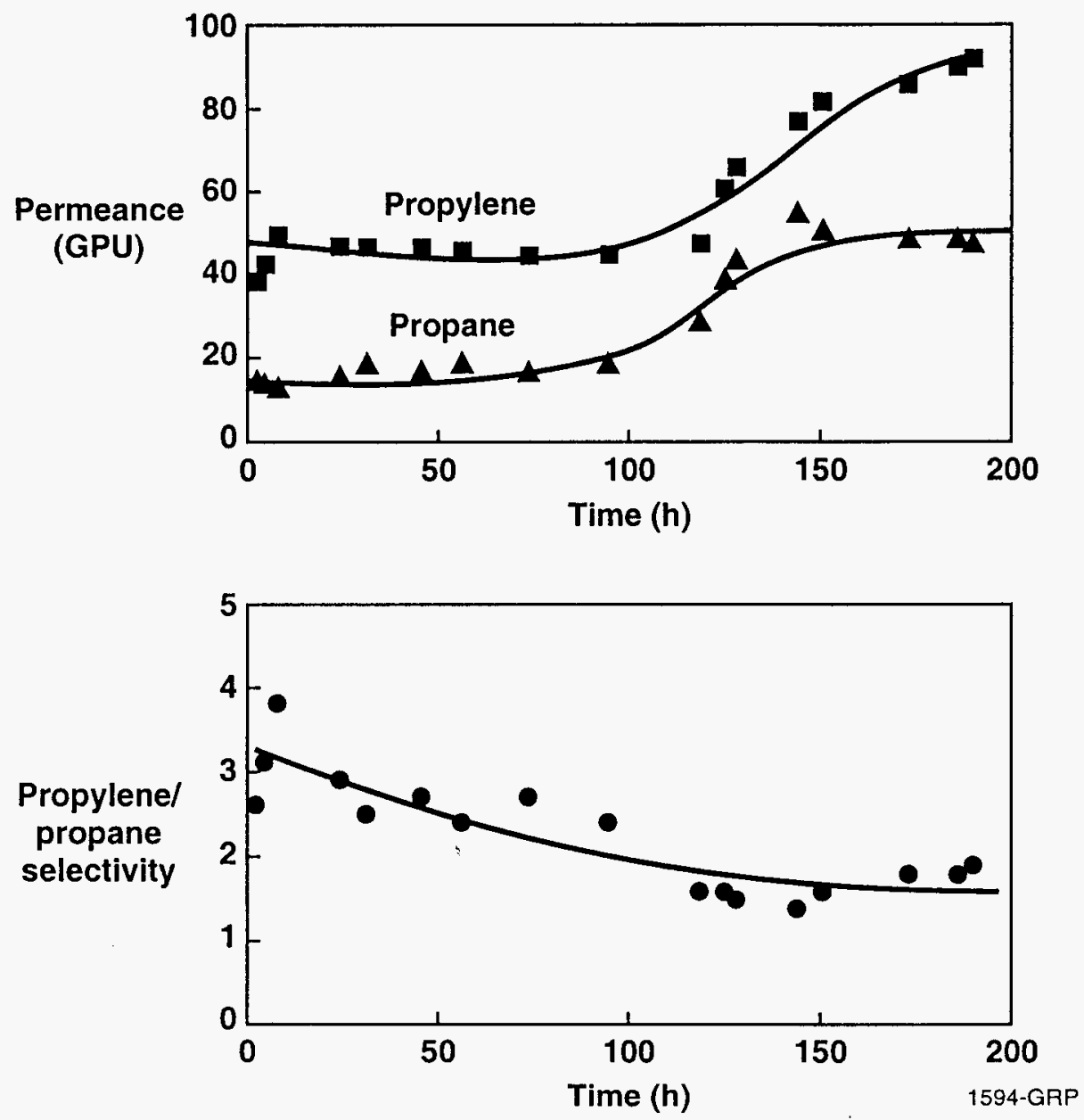

Figure 15. Change in propylene and propane permeance (top) and propylene/propane selectivity (bottom) with time for PDMS/BPDA-TMPD/PTMSP/PVDF membrane module 1545. Gas mixture: $60 \%$ propylene $/ 40 \%$ propane; pressure: 50 psig; temperature: $30{ }^{\circ} \mathrm{C}$. 
After the gas mixture tests, the module was retested with pure gases to determine the integrity of the membrane. The data in Table 6 show that the oxygen/nitrogen selectivity had decreased significantly after operation with the gas mixture. The results indicate that, even at relatively low activity, the performance of the non-fluorinated polyimide membrane deteriorates during long-term operation due to plasticization. Most literature data (Table 4) were obtained with films during short-term experiments, sometimes with vacuum on the permeate side. A commercially useful membrane for olefin separation must maintain mechanical integrity and separation performance during continuous operation in a high-activity environment. Our results indicate that BPDA-TMPD membranes are not suitable for commercial olefin/paraffin separation.

Table 6. Pure-Gas Permeation Properties of PDMS/BPDA-TMPD/PTMSP/PVDF Membrane Module 1545 Before and After Tests with a Propylene/Propane Gas Mixture*

\begin{tabular}{|c|c|c|c|}
\hline \multirow{2}{*}{ Time of Tests } & \multicolumn{2}{|c|}{ Pressure-Normalized Flux (GPU) } & \multirow{2}{*}{$\begin{array}{c}\mathrm{O}_{2} / \mathrm{N}_{2} \\
\text { Selectivity }\end{array}$} \\
\hline & $\mathrm{O}_{2}$ & $\mathrm{~N}_{2}$ & \\
\hline Before Gas Mixture Test & 6 & 1 & 6 \\
\hline After Gas Mixture Test & 5 & 2 & 2.5 \\
\hline
\end{tabular}

- Pressure: $50 \mathrm{psig}$, temperature: $20^{\circ} \mathrm{C}$.

\section{Polythiocarbonate Composite Membranes}

We also evaluated polythiocarbonates as membrane materials. These polymers were synthesized in our laboratory as discussed in Section 4.1. The pure-gas permeation properties of composite membranes prepared with these materials are given in Table 7. The propylene/propane and ethylene/ethane selectivities of the membrane with the poly(thiobisphenol A) selective layer were too low to be useful for the intended separation; this polymer was eliminated as a candidate for further development. The corresponding selectivities of the poly(bisphenol AF) membrane were encouraging, but the olefin fluxes were substantially less than the target values of $30 \mathrm{GPU}$. We therefore concluded that the permeation properties of polythiocarbonate membranes are not adequate for commercial olefin/paraffin separations. 
Table 7. Pure-Gas Properties of Polythiocarbonate Composite Membrane Stamps at $25^{\circ} \mathrm{C}$ and 50 psig

\begin{tabular}{||l|c|c||}
\hline \multirow{2}{*}{ Gas } & \multicolumn{2}{|c|}{ Permeation Flux (GPU) } \\
\cline { 2 - 3 } & Poly(thiobisphenol A) & Poly(thiobisphenol AF) \\
\hline Nitrogen & 2.0 & 1.6 \\
Oxygen & 13 & 6.8 \\
Hydrogen & 110 & 85 \\
Ethylene & 4.6 & 1.3 \\
Ethane & 3.0 & 0.28 \\
Propylene & 29 & 1.4 \\
Propane & 15 & 0.23 \\
\hline \multicolumn{1}{|c|}{ Gas Pair } & \multicolumn{2}{|c|}{ Selectivity } \\
\hline Oxygen/Nitrogen & Poly(thiobisphenol A) & Poly(thiobisphenol AF) \\
Hydrogen/Nitrogen & 6.2 & 6.6 \\
Ethylene/Ethane & 55 & 83 \\
Propylene/Propane & 1.3 & 6.8 \\
\hline
\end{tabular}

\section{Poly(dimethylphenylene oxide) Composite Membranes}

Parallel to the polymer synthesis effort, we developed poly(dimethylphenylene oxide) (PPO) composite membranes. PPO is commercially available. According to literature reports, the polymer has reasonable olefin/paraffin permeation properties. (Literature data were obtained for low pressure only.)

We carried out pure-gas and mixed-gas permeation tests with PPO composite membranes. The membrane structure consisted of a polydimethylsiloxane (PDMS) protective layer, the PPO selective layer, a poly(trimethylsilylpropyne) (PTMSP) gutter layer, and a PVDF support. Table 8 shows the results of our permeation tests with pure gases and a 50/50 propylene/propane gas mixture. The propylene/propane selectivities of 3-3.5 and propylene fluxes of 70-80 GPU at 50 psig were encouraging. At $120 \mathrm{psig}$, which is close to typical pressures of industrial applications (150 psig), propylene flux increased an order of magnitude and selectivity dropped to an unacceptable level for an economically feasible process. 
Table 8. Properties of PPO Composite Membranes ${ }^{a}$

\begin{tabular}{||c|c|c|c|c|c|c|c||}
\hline \multirow{2}{*}{ Membrane } & \multirow{2}{*}{$\begin{array}{c}\mathrm{P} \\
\mathrm{psig})\end{array}$} & \multicolumn{2}{|c|}{$\begin{array}{c}\text { Pure-Gás Flux } \\
(\mathrm{GPU})\end{array}$} & $\begin{array}{c}\text { Pure-Gas } \\
\text { Selectivity }\end{array}$ & \multicolumn{2}{|c|}{$\begin{array}{c}\text { Mixed-Gas Flux } \\
(\mathrm{GPU})^{b}\end{array}$} & $\begin{array}{c}\text { Mixed-Gas } \\
\text { Selectivity }\end{array}$ \\
\cline { 3 - 8 } & $\mathrm{O}_{2}$ & $\mathrm{~N}_{2}$ & $\mathrm{O}_{2} / \mathrm{N}_{2}$ & $\mathrm{C}_{3} \mathrm{H}_{6}$ & $\mathrm{C}_{3} \mathrm{H}_{8}$ & $\mathrm{C}_{3} \mathrm{H}_{6} / \mathrm{C}_{3} \mathrm{H}_{8}$ \\
\hline Stamp & 50 & 25 & 6 & 4 & 70 & 20 & 3.5 \\
\hline Module & 50 & 18 & 6 & 3 & 83 & 29 & 2.9 \\
\hline Module & 120 & - & - & - & 840 & 600 & 1.4 \\
\hline
\end{tabular}

${ }^{2}$ Membrane: $1 \times 4 \%$ PDMS $/ 1 \times 1 \% \mathrm{PPO} / 1 \times 1.5 \%$ PTMSP/PVDF. All experiments were carried out at $25^{\circ} \mathrm{C}$.

${ }^{b}$ Gas mixture: $50 / 50 \mathrm{C}_{3} \mathrm{H}_{6} / \mathrm{C}_{3} \mathrm{H}_{8}$.

\section{Perfluoropolymer Composite Membranes}

We found that exceptional membranes can be made from copolymers of tetrafluoroethylene and 2,2,4-trifluoro-5-trifluoromethoxy-1,3-dioxole, commercially available as Hyflon ${ }^{\circledR}$ AD (Solvay Solexis, Thorofare, NJ) and from poly(perfluorobutenyl vinyl ether), commercially available as Cytop $^{\mathrm{TM}}$ (Asahi Glass, Japan). The chemical structures of these polymers are shown in Figure 16.

Both Hyflon and Cytop are amorphous, glassy perfluoropolymers with glass transition temperatures in the range of 100 to $140^{\circ} \mathrm{C}$. These polymers exhibit a rare combination of good mechanical properties, high thermal stability (thermal decomposition at $400{ }^{\circ} \mathrm{C}$ ), and exceptional chemical resistance. These properties can be explained by the strength of the C-F bonds (bond energy: 485 $\mathrm{kJ} / \mathrm{mol}$ ) and the $\mathrm{C}-\mathrm{C}$ bonds (bond energy: $360 \mathrm{~kJ} / \mathrm{mol}$ ) in fluorocarbons. Perfluoropolymers are among the most chemically resistant polymers available. They are insoluble in all solvents except a few perfluoro compounds and are unaffected by acids and alkalis; fuels and oils; low-molecular-weight esters, ethers and ketones; aliphatic and aromatic amines; strong oxidizing substances; and other chemicals. These characteristics make them ideal membrane materials for use in hostile environments.

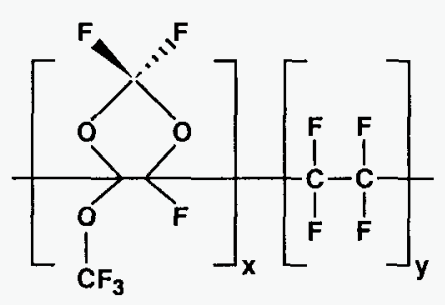

Hyilon AD (Solvay Solexis)

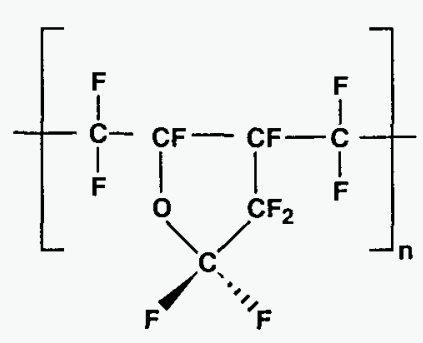

Cytop (Asahi Glass)

Figure 16. Chemical structures of perfluorinated polymers. 
We developed composite perfluoropolymer membranes of various structures. The optimal membrane configurations consisted of a PDMS protective layer, a perfluorinated selective layer (Cytop or Hyflon $\mathrm{AD} \mathrm{60)}$, and a polyetherimide (PEI) support layer. Permeation tests were performed with a $60 \%$ propylene and $40 \%$ propane gas mixture at $150 \mathrm{psig}$. The temperature was varied from $50{ }^{\circ} \mathrm{C}$ to $20^{\circ} \mathrm{C}$ to determine the effect of saturation and condensation on membrane permeation properties and integrity. At 150 psig, the mixture condenses at $27^{\circ} \mathrm{C}$. The same stamp was used for all tests, which were conducted using a compressor and circulation loop.

A phase envelope for the gas mixture used in the tests is plotted along with propylene flux and propylene/propane selectivity in Figure 17. The results indicate that propylene flux almost doubled at saturation conditions. Despite supersaturated conditions, however, the propylene/propane selectivity remained unchanged at around 3 . The pure-gas permeation properties of the stamp were not adversely affected by exposure to partially liquid propylene/propane mixture, as shown by the results of pure-gas tests before and after given in Table 9 . We are not aware of similar performance for any other polymeric membrane. 

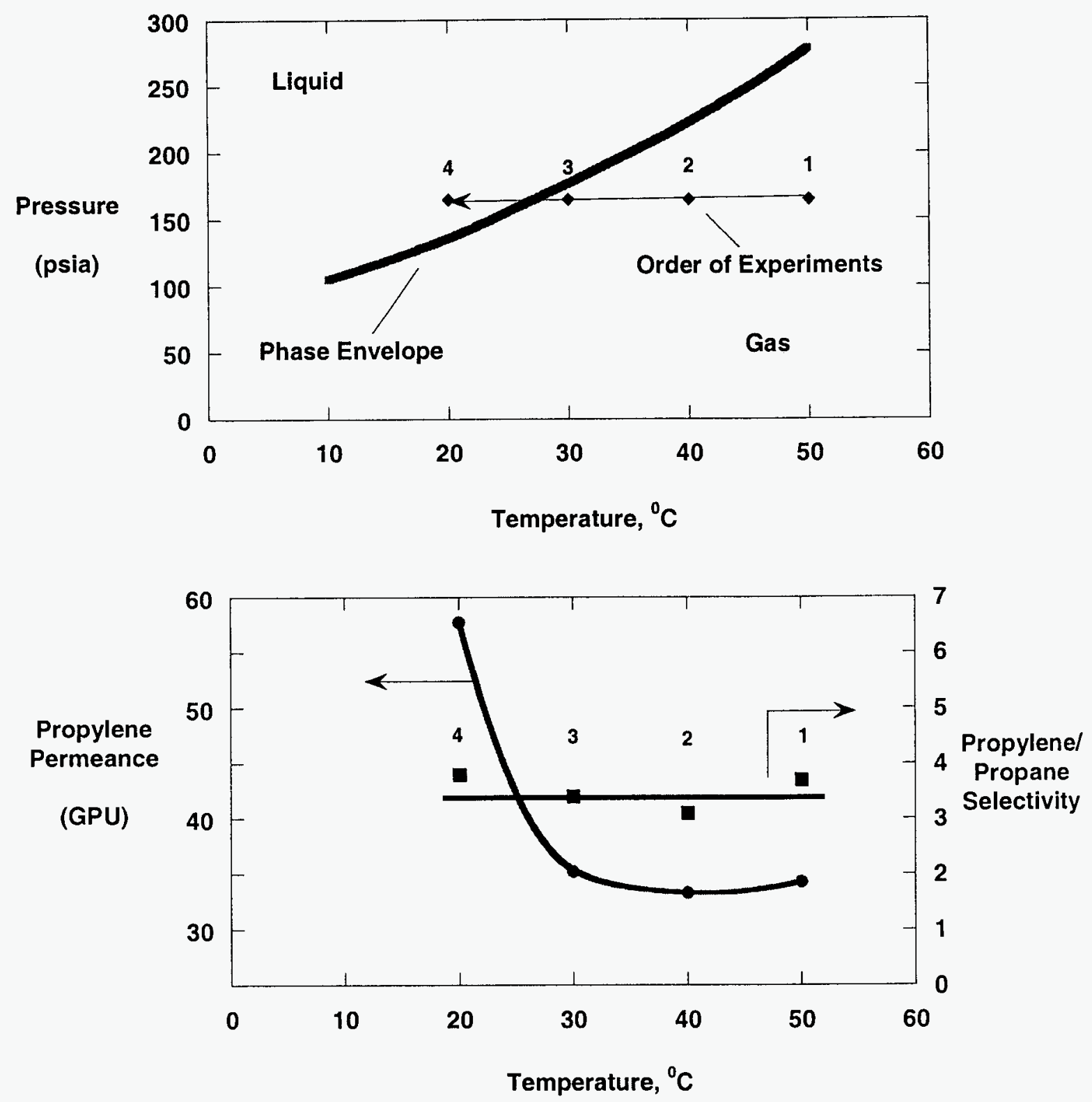

Figure 17. Phase envelope for a $60 \%$ propylene $40 \%$ propane gas mixture (top) and the effect of temperature on the permeation properties of a $1 \times 2 \%$ PDMS $/ 1 \times 0.5 \%$ Hyflon $\mathrm{AD}$ 60/PET membrane stamp at a constant pressure of 165 psia (bottom). In the top figure, the arrow shows the order of experiments and the temperature and pressure at which each permeation measurement was made. 
Table 9. Pure-Gas Permeation Properties of a $1 \times 2 \%$ PDMS $/ 1 \times 0.5 \%$ Hyflon AD $60 /$ PEI Composite Membrane Stamp at 30 psig and $25^{\circ} \mathrm{C}$

\begin{tabular}{||l|c|c|c|}
\hline \multirow{2}{*}{$\begin{array}{c}\text { Before or After } \\
\text { Exposure to Propylene/Propane Mixture }\end{array}$} & Pressure-Normalized Flux (GPU) & \multirow{2}{*}{$\begin{array}{c}\mathrm{O}_{2} / \mathrm{N}_{2} \\
\text { Selectivity }\end{array}$} \\
\cline { 2 - 4 } Before & $\mathrm{O}_{2}$ & $\mathrm{~N}_{2}$ & 3 \\
\hline After & 150 & 50 & 3 \\
\hline
\end{tabular}

The permeation properties of a Cytop-based membrane are shown in Table 10 for the propylene/propane mixture and in Table 11 for pure gases. Separation performance was maintained even after a cumulative operating time of nine hours. Cytop-based membranes are less permeable than Hyflon-based membranes but more selective. Both membrane types perform significantly better than conventional polymeric membranes at conditions relevant to industry. These membranes were subsequently used in parametric and pilot tests.

Table 10. Permeation Properties of a $2 \times 2 \%$ PDMS $/ 1 \times 0.25 \%$ Cytop/PEI Composite Membrane Stamp with a $60 \%$ Propylene $/ 40 \%$ Propane Gas Mixture

\begin{tabular}{||c|c|c|c|c|c||}
\hline \multirow{2}{*}{$\begin{array}{c}\text { Operating } \\
\text { Time (hour) }\end{array}$} & \multirow{2}{*}{$\begin{array}{c}\text { Pressure } \\
(\mathrm{psig})\end{array}$} & $\begin{array}{c}\text { Temperature } \\
\left({ }^{\circ} \mathrm{C}\right)\end{array}$ & \multicolumn{2}{|c|}{ Pressure-Normalized Flux (GPU) } & \multirow{2}{*}{$\begin{array}{c}\mathrm{C}_{3} \mathrm{H}_{6} / \mathrm{C}_{3} \mathrm{H}_{8} \\
\text { Selectivity }\end{array}$} \\
\cline { 4 - 6 } & 100 & 22 & $\mathrm{C}_{3} \mathrm{H}_{6}$ & $\mathrm{C}_{3} \mathrm{H}_{8}$ & \\
\hline 5 & 150 & 48 & 3.8 & 0.7 & 5.5 \\
\hline 9 & 142 & 20 & 7 & 1.5 & 4.7 \\
\hline
\end{tabular}

Table 11. Pure-Gas Permeation Properties of a $1 \times 2 \%$ PDMS $/ 1 \times 0.25 \%$ Cytop/PEI Composite Membrane Stamp Before and After Tests with a 60\% Propylene/40\% Propane Gas Mixture*

\begin{tabular}{|l|c|c|c|c|c|c|c|c|c||}
\hline \multirow{2}{*}{$\begin{array}{c}\text { Time of } \\
\text { Test }\end{array}$} & \multicolumn{4}{|c|}{ Pressure-Normalized Flux (GPU) } & \multicolumn{4}{c||}{ Selectivity } \\
\cline { 2 - 11 } & $\mathrm{O}_{2}$ & $\mathrm{~N}_{2}$ & $\mathrm{CH}_{4}$ & $\mathrm{CO}_{2}$ & $\mathrm{H}_{2}$ & $\mathrm{O}_{2} / \mathrm{N}_{2}$ & $\mathrm{~N}_{2} / \mathrm{CH}_{4}$ & $\mathrm{CO}_{2} / \mathrm{CH}_{4}$ & $\mathrm{H}_{2} / \mathrm{CH}_{4}$ \\
\hline Before & 41 & 9.4 & 4.6 & 117 & 281 & 4.4 & 2 & 25.4 & 61 \\
\hline After & 30 & 7.3 & 4.4 & 106 & 146 & 4.1 & 1.7 & 24.1 & 33 \\
\hline
\end{tabular}

* Pressure: 50 psig; temperature: $25^{\circ} \mathrm{C}$. 


\subsection{Bench-Scale Parametric Tests: Database for Computer Simulations}

We performed several parametric tests with perfluorinated composite membranes to develop design basis data for computer simulations.

\section{Effect of Pressure}

A membrane module was tested at 50 psig for 90 hours, at 100 psig for 20 hours, and at 150 psig (a typical pressure for industrial applications) for 6 hours at a constant temperature of $30^{\circ} \mathrm{C}$. Increasing pressure at constant temperature led to an increase in the activity of the gas mixture, which causes membrane swelling and plasticization.

The results shown in Figure 18 indicate stable long-term performance. The pressure-normalized fluxes were modest but increased with pressure and activity due to membrane swelling. Propylene/propane selectivity did not change significantly. As shown in Section 4.2, no conventional membranes had similar performance. 

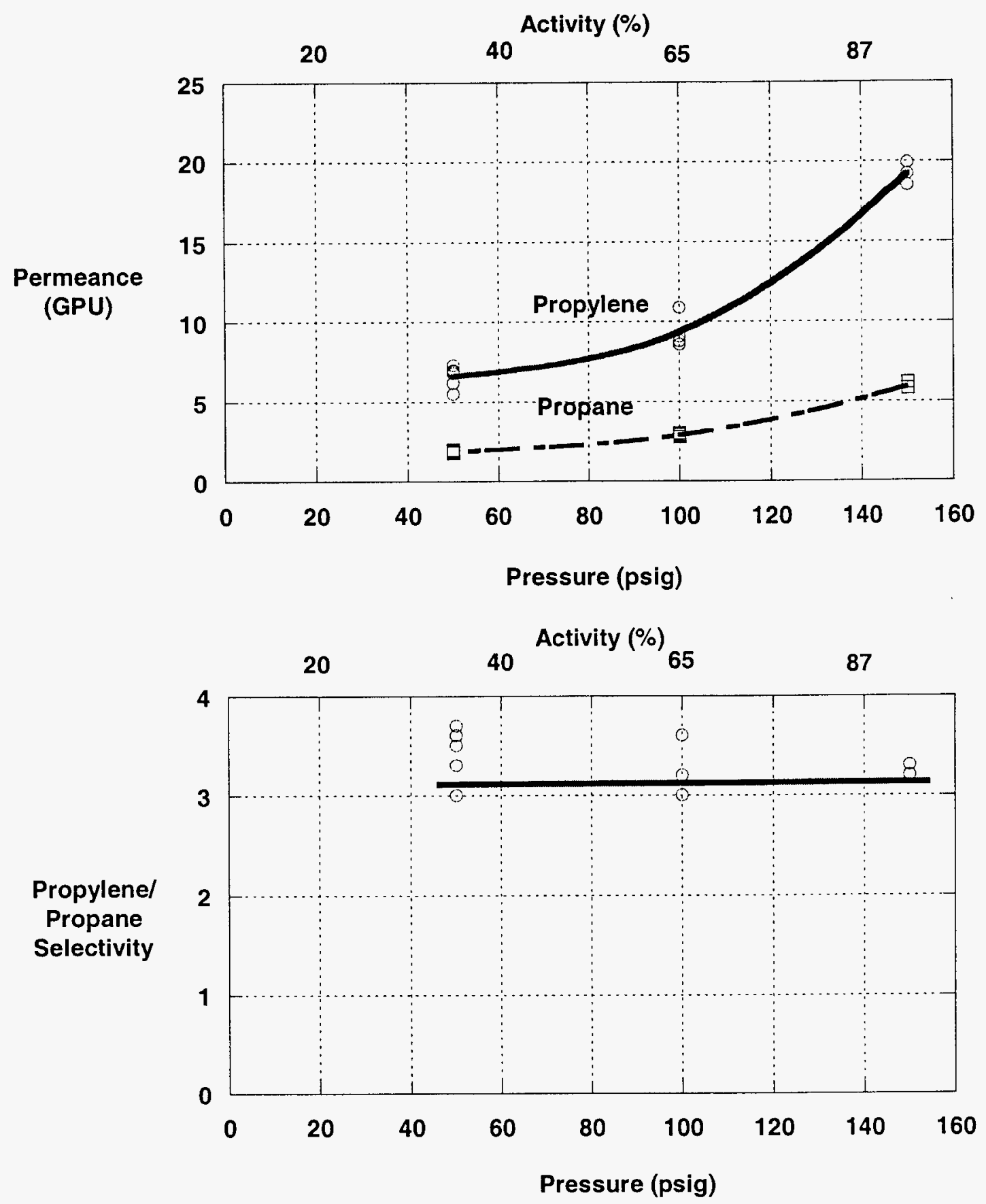

Figure 18. The effect of pressure (activity) on permeance (top) and propylene/propane selectivity (bottom) for $2 \times 1 \%$ Hyflon AD 60/Teflon ${ }^{\circledR}$ AF 2400/PEI module 1449. Mixture: $60 \%$ propylene $/ 40 \%$ propane. Temperature: $30{ }^{\circ} \mathrm{C}$. 


\section{Effect of Temperature}

The effect of temperature was studied with a membrane of configuration similar to the one described above and a similar propylene/propane mixture. In this case, the pressure was maintained constant at $150 \mathrm{psig}$ and the temperature was varied from $50{ }^{\circ} \mathrm{C}$ to $20^{\circ} \mathrm{C}$. The dew point of the mixture was $27^{\circ} \mathrm{C}$. The temperature variation led to an increase in gas activity from 60 to $100 \%$, resulting in plasticization of the membrane and an increase in the diffusion of permeating components across the membrane (Figure 19). A drop in permeance according to the Arrhenius equation was not observed. These tests clarified the effect of saturation and condensation on membrane permeation properties. Pressure-normalized fluxes and selectivity remained almost constant over a five-hour period at each temperature. At $30{ }^{\circ} \mathrm{C}$, increases in flux led to a small drop in selectivity. Plasticization did not cause damage to the membrane. At $20^{\circ} \mathrm{C}$, the test was limited to one hour due to the difficulty of operating with significant amounts of liquids in a compressor-driven system. 

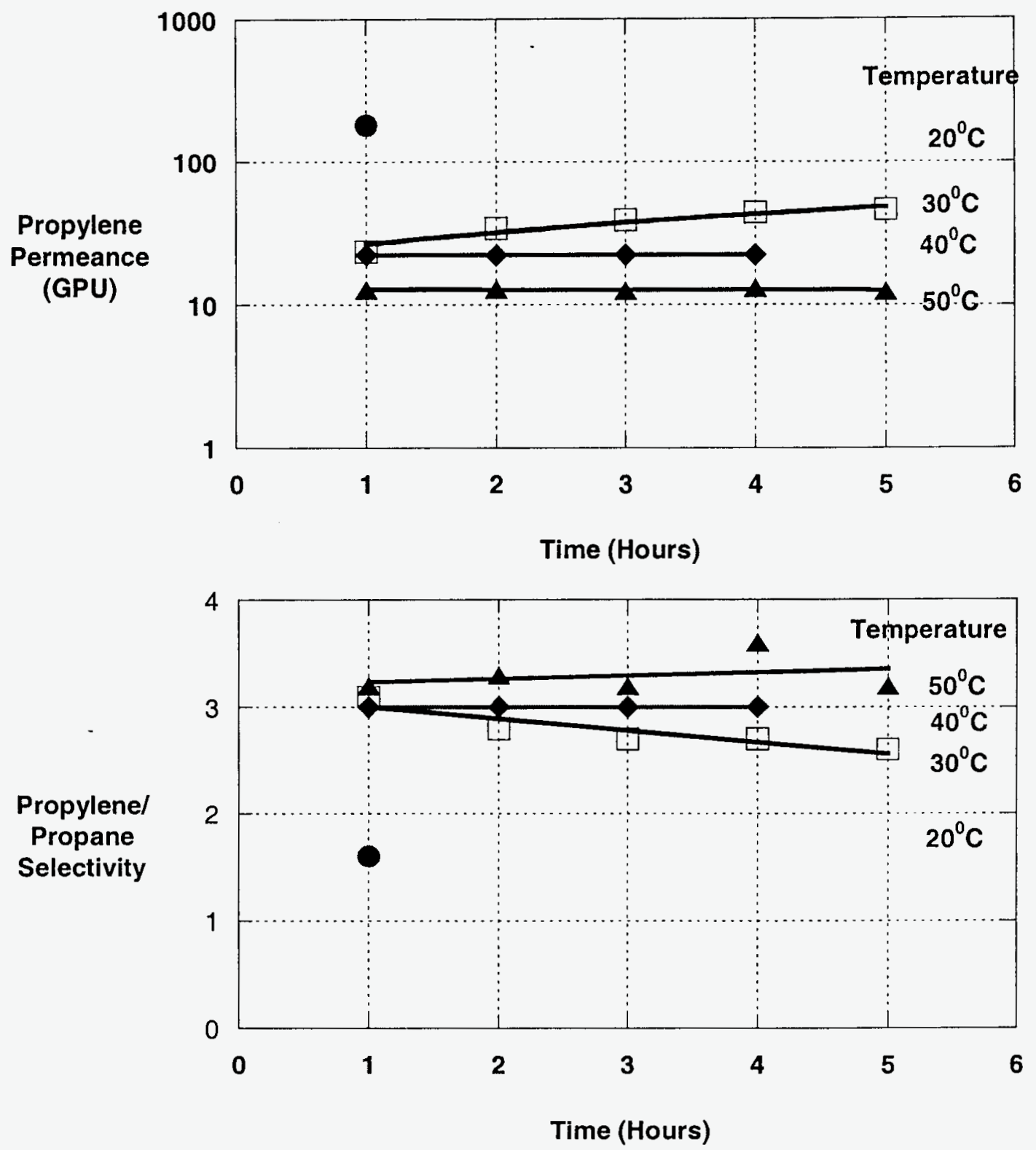

Figure 19. The effect of temperature on permeance (top) and propylene/propane selectivity (bottom) over time for a $2 \times 1 \%$ Hyflon AD 60/Teflon AF 2400/PEI membrane stamp. Mixture: $60 \%$ propylene $/ 40 \%$ propane; pressure $150 \mathrm{psig}$. 


\section{Effect of Olefin/Paraffin Composition}

The technology developed in this project has equal significance for ethylene/ethane and propylene/propane mixtures. The results of tests with ethylene/ethane mixtures are shown in Figure 20 . With a $50 \%$ ethylene $/ 50 \%$ ethane gas mixture at $9 \%$ activity $\left(50\right.$ psig and $\left.20{ }^{\circ} \mathrm{C}\right)$, the ethylene/ethane selectivity of a Hyflon AD 60/Teflon AF 2400/PEI composite membrane stamp is only 2 and the ethylene pressure-normalized flux is $8 \mathrm{GPU}$.

In the case of a four-component gas mixture containing $20 \%$ ethylene, $20 \%$ ethane, $30 \%$ propylene, and $30 \%$ propane, temperature variation tests at $150 \mathrm{psig}$ showed constant ethylene/ethane selectivity of 1.5 even near saturation conditions; however, ethylene flux increased from 30 to $60 \mathrm{GPU}$. This performance is not adequate for economic recovery of ethylene. Therefore we focused our efforts on the separation of propylene from propane. 

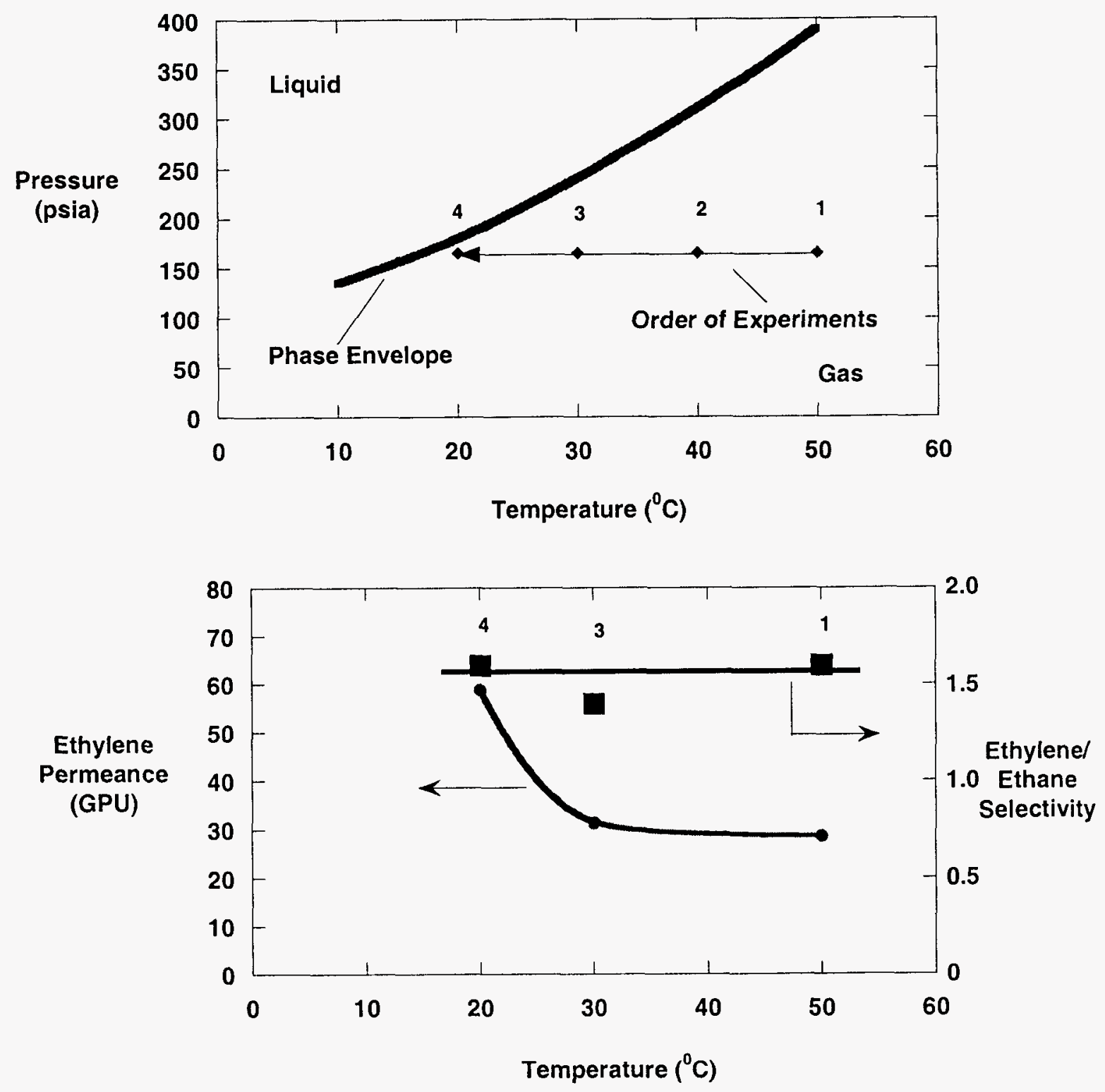

Figure 20. Phase envelope for a gas mixture containing 20\% ethylene, $20 \%$ ethane, $30 \%$ propylene and $30 \%$ propane (top) and the effect of temperature on the permeation properties of a Hyflon AD 60/Teflon AF 2400/PEI membrane stamp at a constant pressure of 165 psia (bottom). In the top figure, the arrow shows the order of experiments and the temperature and pressure at which each permeation measurement was made. 
We studied the effect of the propylene content of the gas mixture on membrane separation performance. The propylene content of a binary mixture was varied from $10 \%$ to $90 \%$. As shown in Figure 21, propylene/propane selectivity remained essentially unchanged although gas activity dropped from 90 to $77 \%$ over this range. These data confirm results presented in Section 4.2 and earlier in this section: the performance of perfluorinated membranes is independent of gas activity.

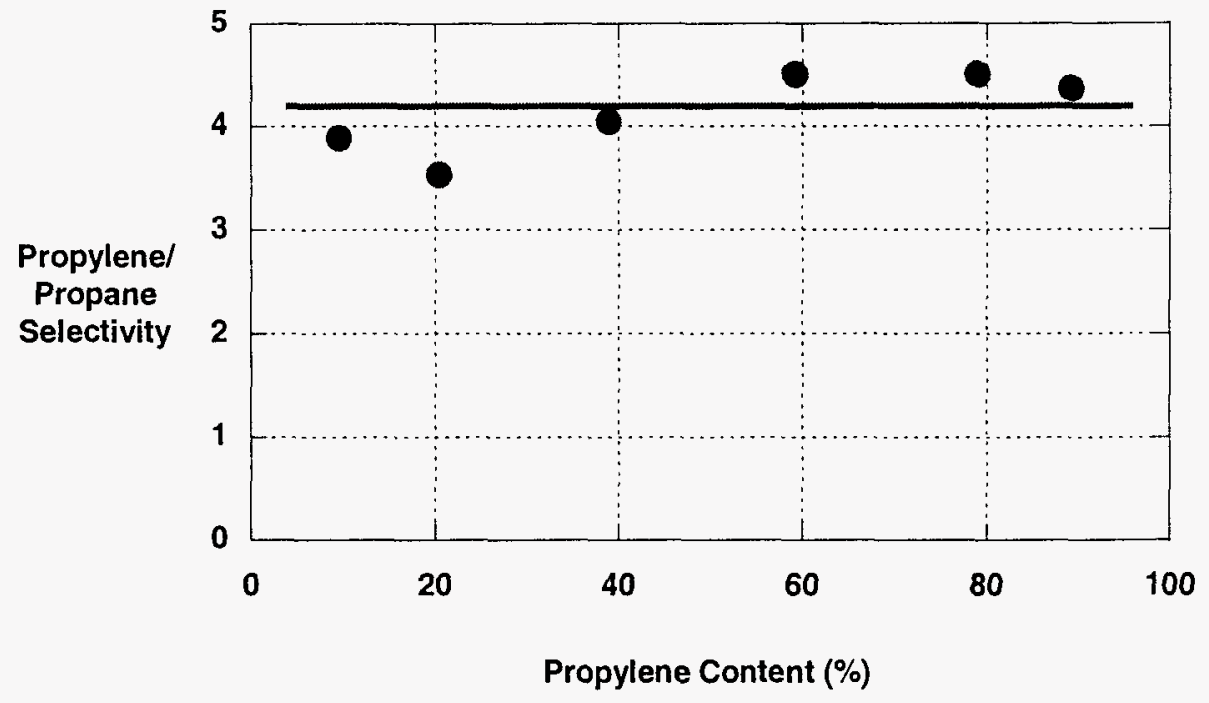

Figure 21. The effect of propylene content on separation performance of a $2 \times 2.5 \%$ PDMS/l $\times 0.25 \%$ Cytop/PEI membrane stamp. Pressure: $150 \mathrm{psig}$; temperature: $35^{\circ} \mathrm{C}$; gas mixture: propylene and propane.

\section{Long-Term Tests and Stability}

Long-term performance stability is essential for commercial membrane applications. We tested a membrane stamp for a month and a bench-scale module for a week at $150 \mathrm{psig}$ and $35^{\circ} \mathrm{C}$ in our laboratory-scale closed-loop high-pressure system. Membrane performance was checked daily during these continuous tests. The results shown in Figures 22 and 23 are similar and indicate that the module was robust and defect-free. Except for the initial variation in the propylene pressure-normalized flux of the stamp prior to reaching steady-state conditions, performance was stable. The steady-state propylene/propane selectivity was just over 3. The propylene pressure-normalized flux was rather low, but at saturation conditions we achieved fluxes of 50-100 GPU. 

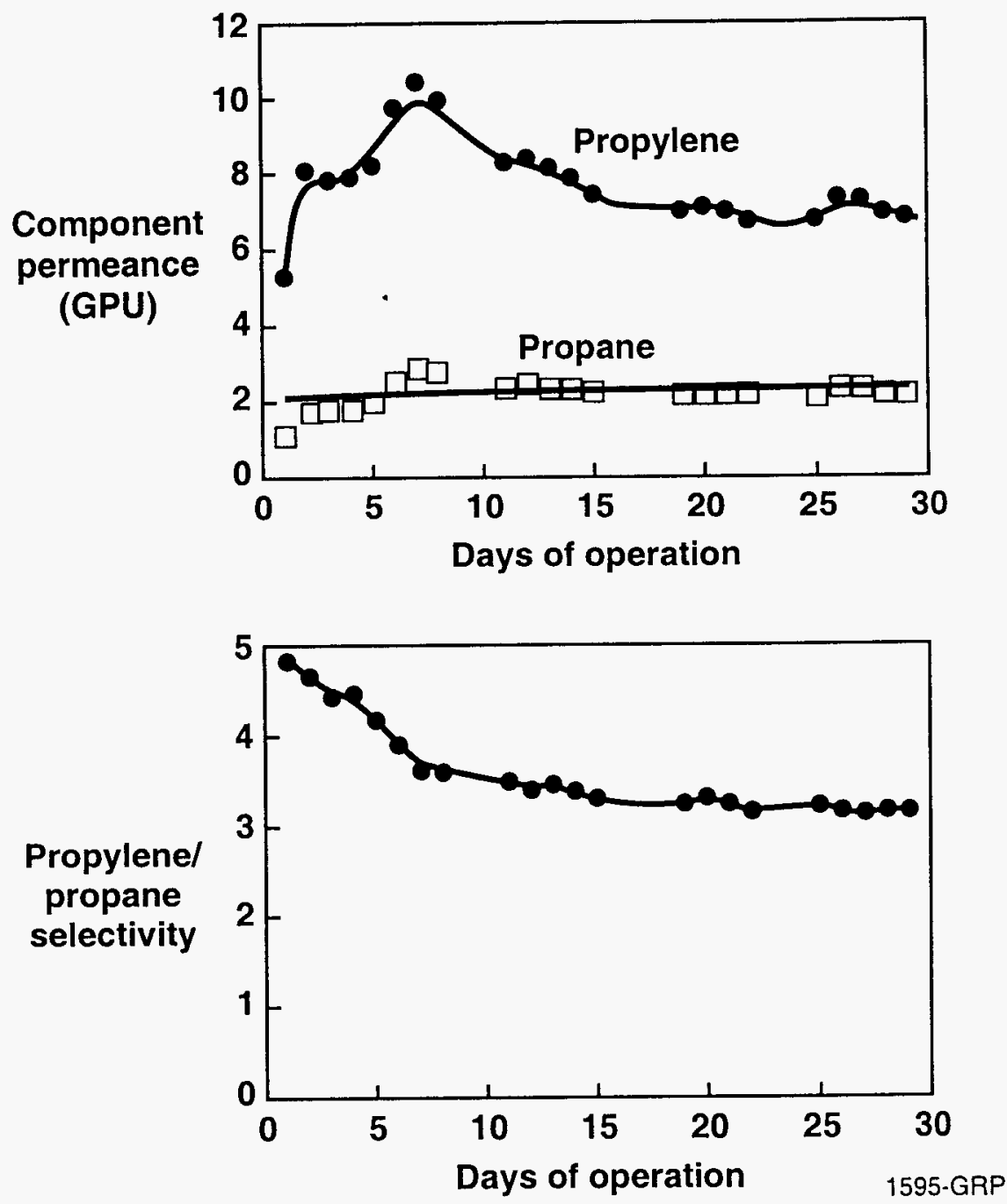

Figure 22. Long-term performance of a $2 \times 2.5 \%$ PDMS $/ 1 \times 0.25 \%$ Cytop/PEI membrane stamp. Pressure: $150 \mathrm{psig}$; temperature: $35{ }^{\circ} \mathrm{C}$; gas mixture: $60 \%$ propylene $/ 40 \%$ propane. 

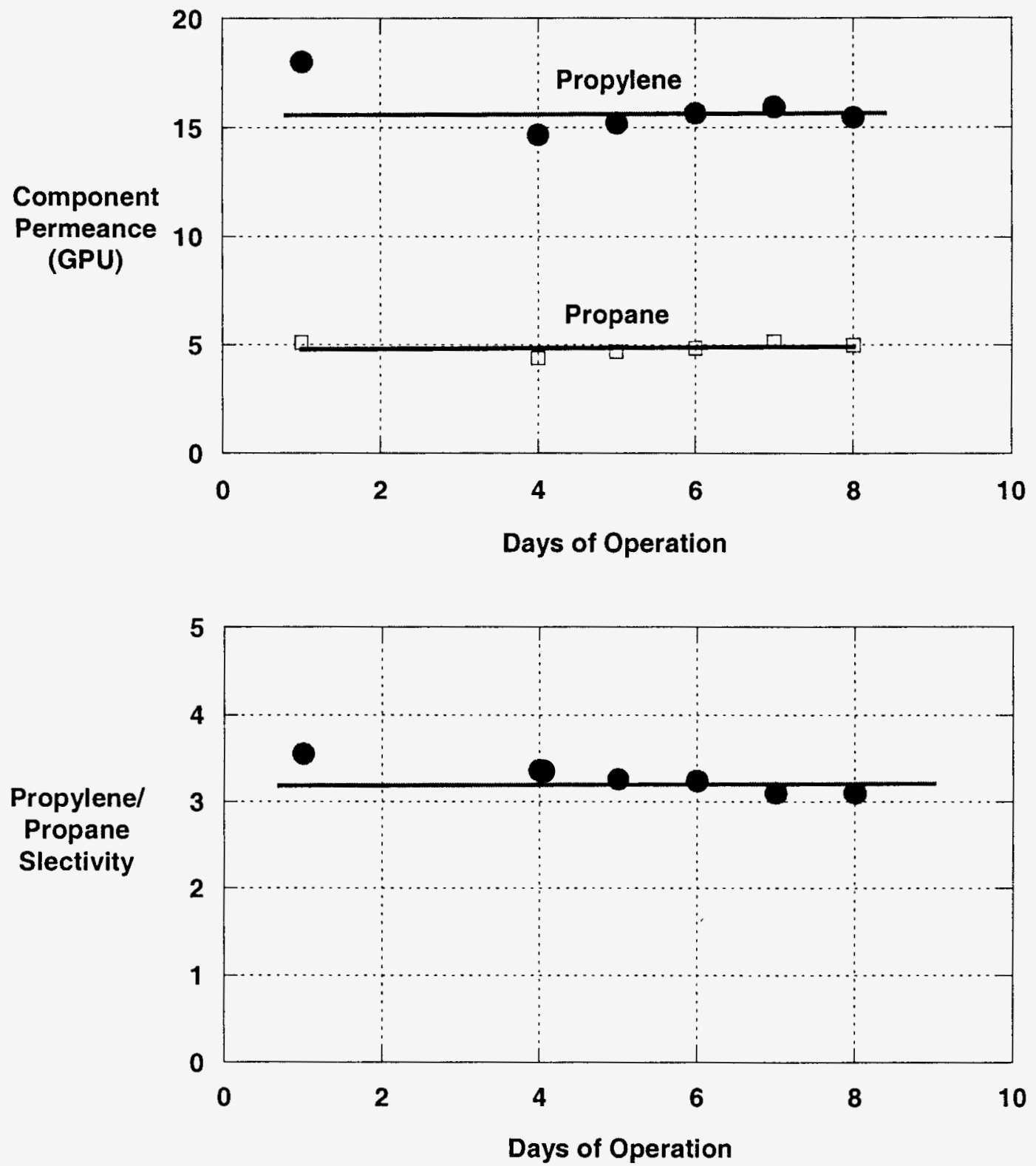

Figure 23. Long-term performance of $2 \times 2.5 \% \mathrm{PDMS} / \mathrm{l} \times 0.25 \% \mathrm{Cytop} / \mathrm{PEI} 3$-inch module 2414 . Pressure 150 psig; temperature: $35^{\circ} \mathrm{C}$; gas mixture: $50 \%$ propylene $/ 50 \%$ propane. 


\subsection{Design and Operation of Pilot System at Field Sites}

The objective of the pilot tests was to verify the performance of membrane modules in an industrial environment. Industrial gas streams typically contain a complex mixture of components. Consistent performance and membrane stability under these conditions is necessary for a successful commercial process.

We designed and built a simple membrane permeation system consisting of 3-inch and 4-inch membrane modules installed in parallel. Other components included a particulate filter installed at the system inlet and mechanical instruments to monitor pressures, temperatures and stream flow rates. Electric or electronic instruments were not used to prevent introduction of potential fire hazards to process plants.

Our discussions with BP, Chevron Phillips, and Equistar included visits to the companies' petrochemical plants in Texas. As a result of these efforts, we performed pilot tests at the Chevron Phillips petrochemical complex in Pasadena, TX and the Equistar petrochemical complexes in Channelview, TX and Chocolate Bayou, TX. Only one of the three pilot tests-the test at the Chevron Phillips petrochemical complex in Pasadena, TX - was performed on a polypropylene reactor purge stream, the target application for our membrane process. BP decided not to go ahead with tests originally planned at its Chocolate Bayou, TX polypropylene plant, and we were unable to find other polypropylene plants that were available for tests. However, Equistar hosted two tests at its ethylene cracker plants on streams with similar propylene and propane content. The results of the tests are summarized in Table 12; details of each test are discussed below.

Table 12. Summary of Propylene/Propane Membrane Module Pilot Test Results

\begin{tabular}{||l|c|c|c|c|c|c|c|}
\hline \multicolumn{1}{|c|}{$\begin{array}{c}\text { Company } \\
\text { (Plant Location) }\end{array}$} & Type of Plant & $\begin{array}{c}\mathrm{P} \\
(\mathrm{psig})\end{array}$ & $\begin{array}{c}\mathrm{T}^{\top} \\
\left({ }^{\circ} \mathrm{C}\right)\end{array}$ & $\begin{array}{c}\text { Activity } \\
(\%)\end{array}$ & $\begin{array}{c}\text { Propylene } \\
\text { Content }\end{array}$ & $\begin{array}{c}\text { Duration } \\
\text { (days) }\end{array}$ & $\begin{array}{c}\text { Initial } \\
\text { Propylene/ } \\
\text { Propane } \\
\text { Selectivity }\end{array}$ \\
\hline $\begin{array}{l}\text { Chevron Phillips } \\
\text { (Pasadena, TX) }\end{array}$ & Polypropylene & 120 & 21 & 90 & 92 & 189 & 3 \\
\hline $\begin{array}{l}\text { Equistar } \\
\text { (Channelview, TX) }\end{array}$ & $\begin{array}{c}\text { Ethylene } \\
\text { Cracker }\end{array}$ & 150 & 37 & 70 & 92 & 93 & 3.4 \\
\hline $\begin{array}{l}\text { Equistar } \\
\text { (Chocolate Bayou, TX) }\end{array}$ & $\begin{array}{c}\text { Ethylene } \\
\text { Cracker }\end{array}$ & 108 & 32 & 60 & 94 & 100 & 4 \\
\hline
\end{tabular}




\section{Tests at the Chevron Phillips Petrochemical Complex in Pasadena, TX}

The membrane system shown in Figure 24 was connected to a liquid-phase polypropylene plant and tested for six months. The tests did not disrupt plant operations. Existing tie-in points were used to divert a small slip stream from the discharge of a second-stage compressor for separation in our membrane system at $120 \mathrm{psig}$ and $20-27^{\circ} \mathrm{C}$. The residue and permeate streams were combined and returned to the first-stage compressor suction scrubber. Typical feed, residue, and permeate streams compositions are shown in Table 13. Representative permeation performance data for all components are given in Table 14.

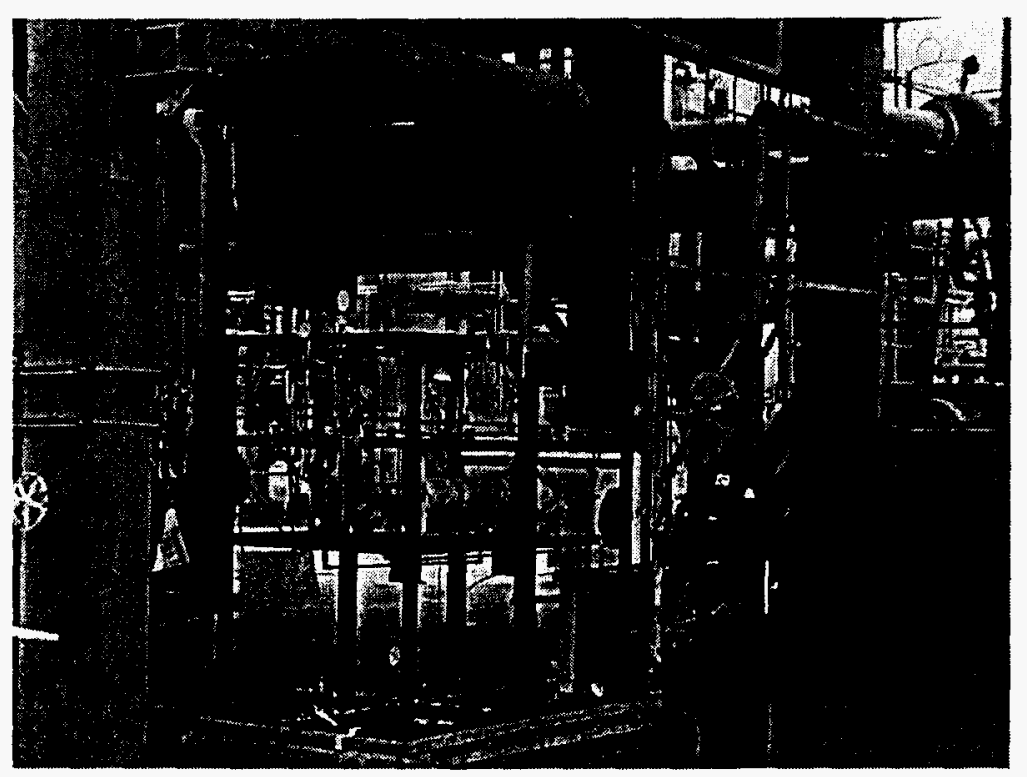

Figure 24. Membrane pilot system for olefin/paraffin separation at the Chevron Phillips polypropylene plant in Pasadena, TX.

Table 13. Composition of Streams Tested with 3-inch Membrane Module 1688 at the Chevron Phillips Polypropylene Plant in Pasadena, TX

\begin{tabular}{||l|c|c|c|}
\hline \multirow{2}{*}{ Component } & \multicolumn{3}{|c|}{ Stream Composition (mole\%) } \\
\cline { 2 - 4 } & Feed & Residue & Permeate \\
\hline Nitrogen & 1.2 & 0 & 0.2 \\
Ethane & 0.1 & 0.1 & 0.1 \\
Propylene & 92.2 & 93.5 & 96.7 \\
Propane & 5.8 & 5.8 & 2.8 \\
Isobutane & 0.6 & 0.6 & 0.1 \\
\hline
\end{tabular}


Table 14. Initial Permeation Properties of 3-inch Membrane Module 1688 Tested at the Chevron Phillips Polypropylene Plant in Pasadena, TX*

\begin{tabular}{|l|c|c|}
\hline \multicolumn{1}{|c|}{ Component } & Component Permeance (GPU) & Propylene/Component Selectivity \\
\hline Nitrogen & 3 & 12.7 \\
Ethane & 35 & 1.1 \\
Propylene & 38 & 1 \\
Propane & 12 & 3.2 \\
Isobutane & 6 & 6.3 \\
\hline
\end{tabular}

* Membrane: 1×2\% PDMS/1×0.5\% Hyflon AD 60/PEI. Pressure: 110 psig; temperature: $20^{\circ} \mathrm{C}$.

Figure 25 shows the propane and propylene permeances and propylene/propane selectivity for the $1 \times 2 \%$ PDMS $/ 1 \times 0.5 \%$ Hyflon AD $60 / \mathrm{PEI} 3$-inch membrane module. The initial propylene/propane selectivity was 3 , similar to the laboratory result, but dropped rapidly to a steady-state value of 1.5 . Replacing the modules after four months of operation improved selectivity only marginally; it settled at around 2. This poor performance was due to condensation of oligomers, high-molecular-weight $\left(\mathrm{C}_{10}-\mathrm{C}_{24}\right)$ paraffins, formed in the polymerization reactor. Trace amounts of these components caused a reduction in the dew point of the gas despite heat-tracing of the main system lines.

The temperature profiles shown in Figure 26 indicate that, except during the start-up period, the temperature of the feed and the residue approached the dew point on only a few occasions. The highmolecular-weight paraffins are present at ppm levels and were not detected in the chemical analysis performed by Chevron Phillips. However, if these paraffins are present in the gas, even in ppm quantities, the dew point of the gas may be higher than the values shown in Figure 26. These low-volatility compounds progressively condensed on the surface of the membrane due to high membrane surface area and cool night temperatures.

At the end of the tests, the modules were removed from the system and stripped. A significant amount of hydrocarbon liquid leaked out. Samples were collected and confirmed by an external laboratory to be the oligomers described above. Examination of the membrane stripped from the modules showed the protective PDMS layer was partially lifted off, exposing the Hyflon layer directly to the gas. The exposure to liquid hydrocarbons confirms the robustness of the perfluorinated membranes. The propylene/propane selectivity dropped from 3 to 2, but the mechanical integrity of the membrane was not affected. Most commercially available membranes would suffer mechanical failure under these conditions. 

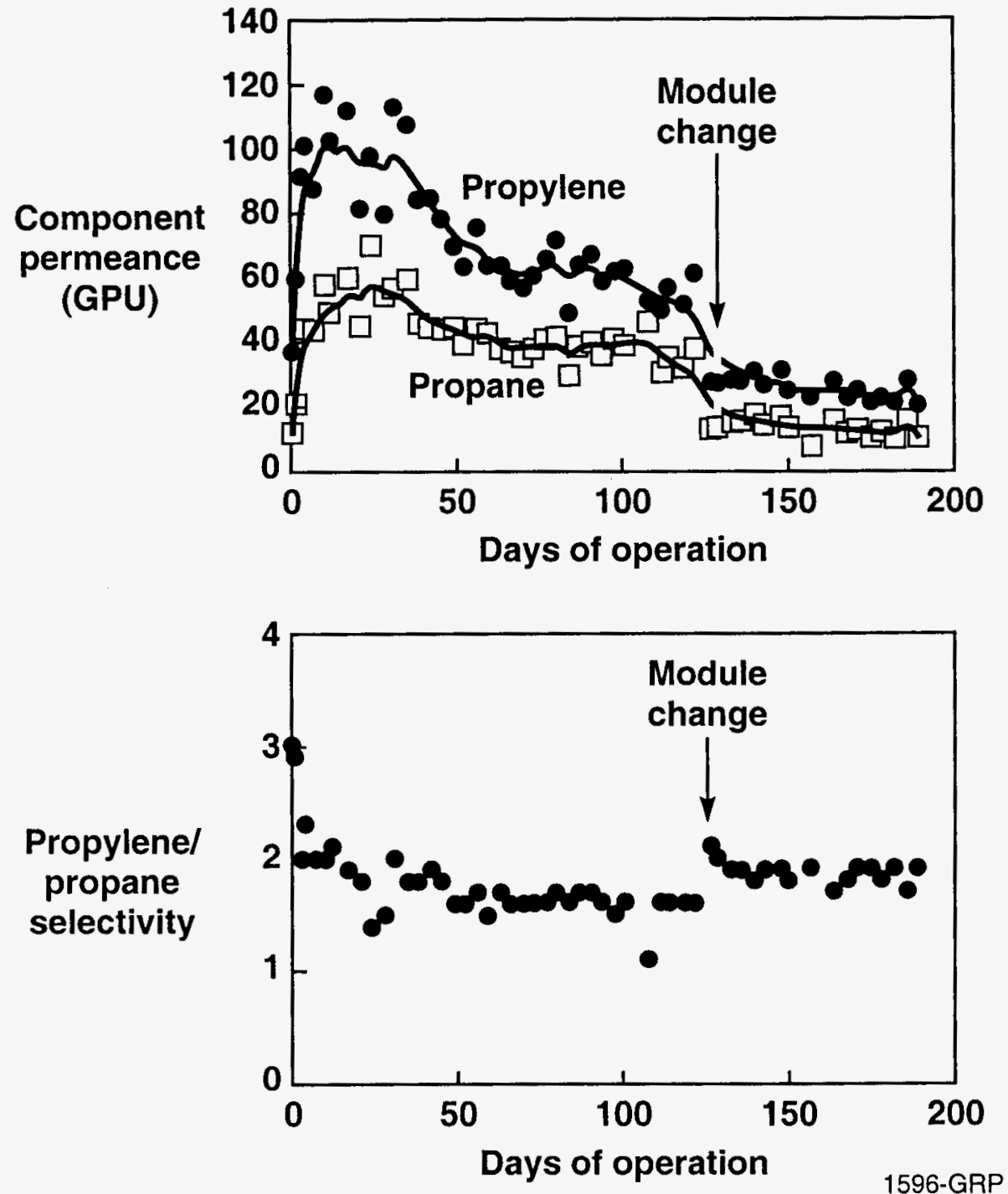

Figure 25. Results of field tests at Chevron Phillips. Propylene and propane permeances (top) and propylene/propane selectivity (bottom) for $1 \times 2 \%$ PDMS/ $1 \times 0.5 \%$ Hyflon AD 60/PEI 3-inch Membrane Modules 1688 and 1796. 

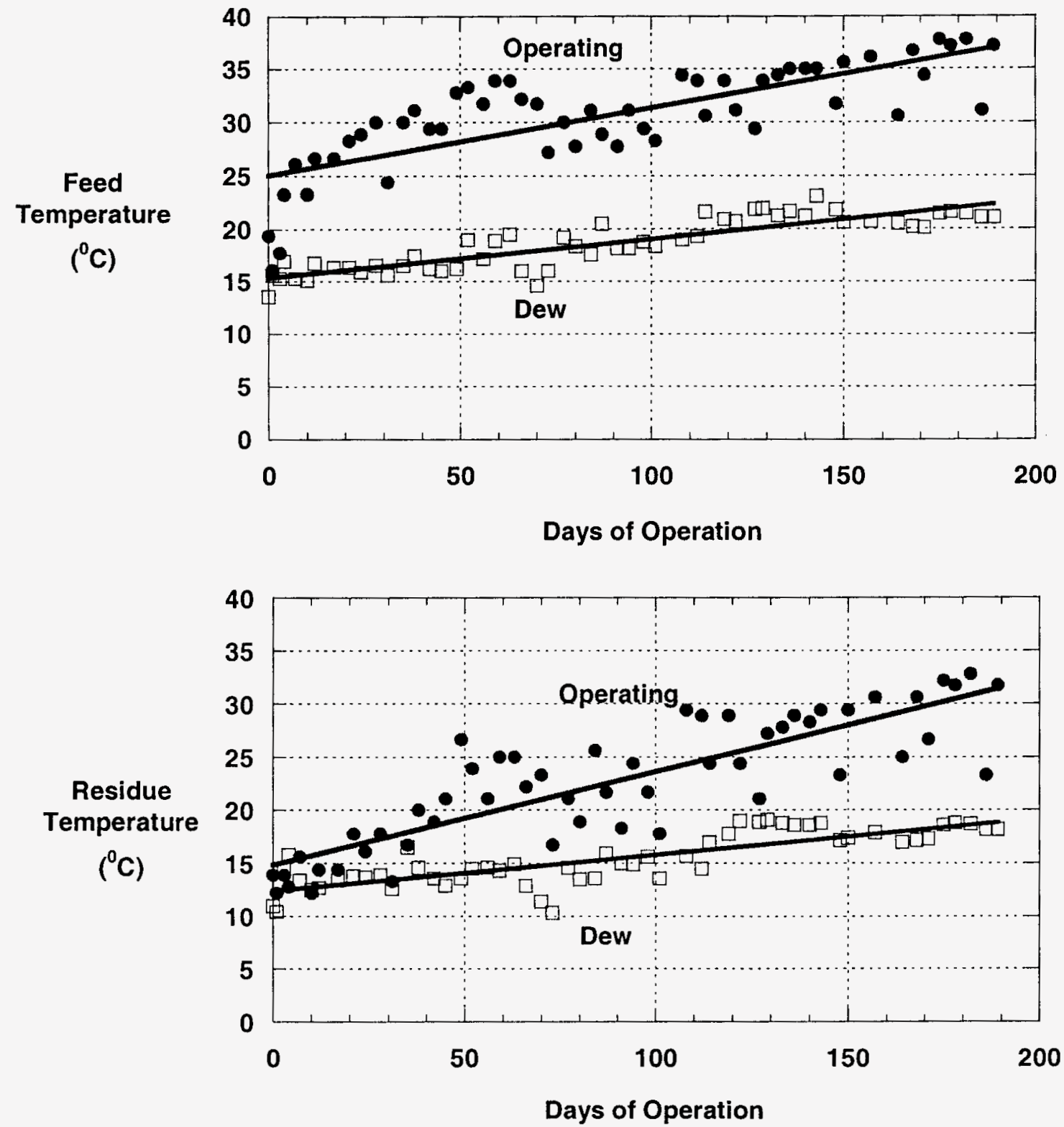

Figure 26. Results of field tests at Chevron Phillips. Temperature profiles for the feed (top) and residue (bottom) of the 3 -inch membrane module. 
Stamps prepared from the membranes that had been stripped from the test modules were tested with pure gases. A comparison of module pure-gas data obtained before the pilot tests and stamp pure-gas data obtained after the tests is given in Table 15 for one of the test modules. Pure-gas fluxes dropped significantly and the membrane became more selective to methane than to nitrogen. These results are indicative of fouling by the high-molecular-weight oligomers.

Table 15. Pure-Gas Permeation Properties Before and After Pilot Tests for a $1 \times 2 \%$ PDMS/1×0.5\% Hyflon AD 60/PEI Composite Membrane

\begin{tabular}{||l|c|c|c|c|c|}
\hline \multirow{2}{*}{ Test Time } & \multicolumn{2}{|c|}{ Pressure-Normalized Flux (GPU) } & \multicolumn{2}{c|}{ Selectivity } \\
\cline { 2 - 6 } & $\mathrm{O}_{2}$ & $\mathrm{~N}_{2}$ & $\mathrm{CH}_{4}$ & $\mathrm{O}_{2} / \mathrm{N}_{2}$ & $\mathrm{~N}_{2} / \mathrm{CH}_{4}$ \\
\hline Before (module 1688) & 125 & 42 & 18 & 3 & 2.3 \\
\hline After (stamp) & 9 & 4 & 9 & 2.3 & 0.4 \\
\hline
\end{tabular}

\section{Tests at the Equistar Petrochemical Complex in Channelview, TX}

The second pilot test was conducted at Equistar's Channelview, TX petrochemical complex. The membrane system used in the first pilot test series was connected to an ethylene cracker propylene plant. Photographs of the system at the Channelview plant are shown in Figure 27. In this test, the selective layer of the membrane was Cytop, which has better permeation properties than Hyflon for this separation.
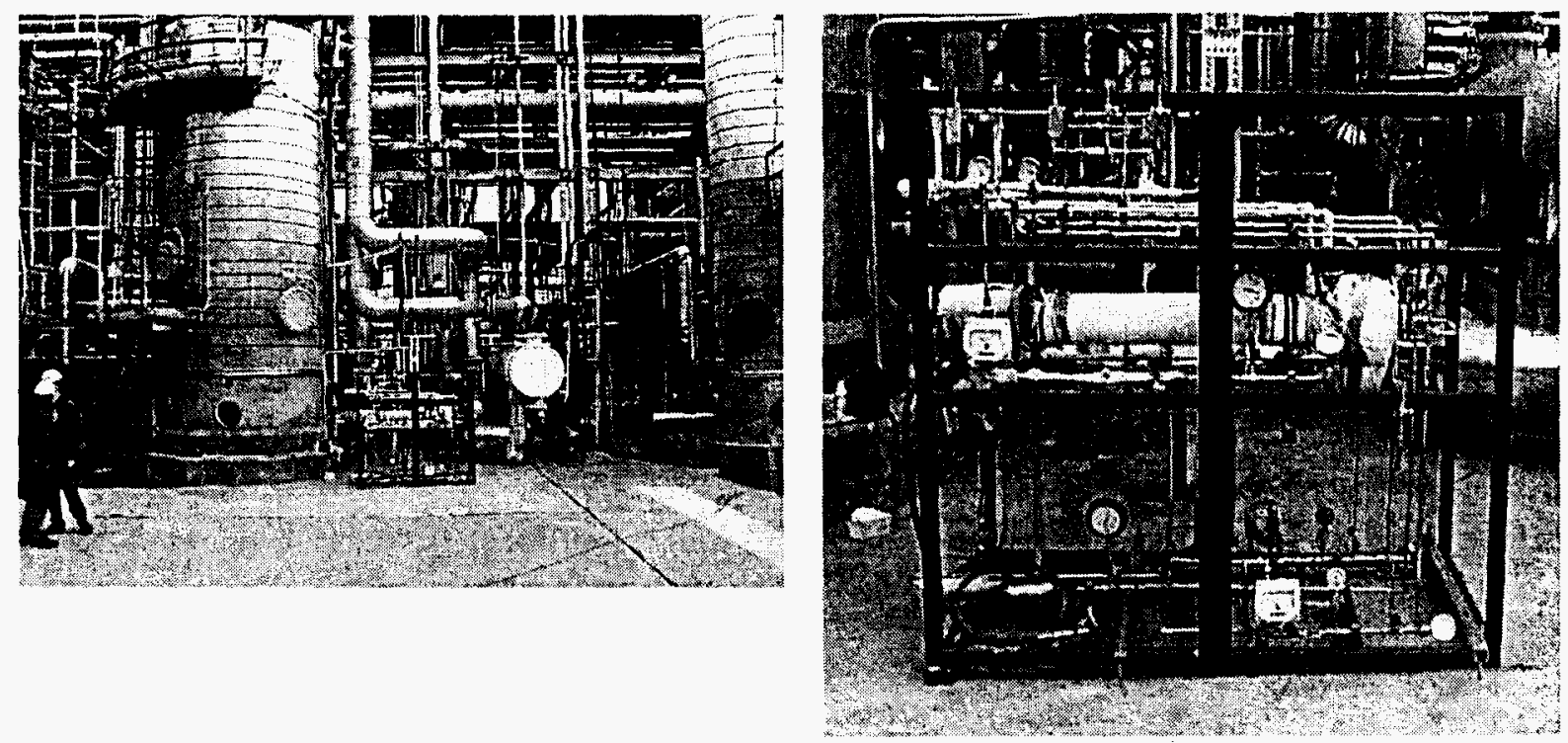

Figure 27. Membrane system installed at the Equistar petrochemical complex in Channelview, TX. 
A slip stream of the depropanizer overhead was fed to the membrane system. This stream contained about $92 \%$ propylene, $3 \%$ propane, $1.7 \%$ methylacetylene and propadiene, and small amounts of other hydrocarbons. The slip stream was fed to a reactor to convert acetylenes to olefins, fractionated to remove "green oil" (heavy hydrocarbons formed in the converter), dehydrated, and fractionated again to remove residual propane. The product was polymer-grade propylene (99.9\%). Chemical-grade propylene (94-96\%) was taken off before the final fractionation step.

The feed to the membrane system was let down from 300 psig to 150 psig and about $100{ }^{\circ} \mathrm{F}$. The residue and permeate streams from the 3 -inch and 4 -inch modules were combined at 40 psig and sent to the first-stage compressor suction. The system operated for six months. The average propylene pressure-normalized flux was in the range of 80-130 GPU but propylene/propane selectivity dropped from almost 3.5 to less than 1.5 (Figure 28). This result was surprising: the propylene content of the gas was similar to that of the gas tested at the Chevron Phillips plant, but gas activity was lower ( $70 \%$ at the Equistar plant versus $90 \%$ at the Chevron Phillips plant, excluding the oligomers). The pure-gas permeation properties of one of the modules are shown in Table 16 before and after the field tests. All pressure-normalized fluxes increased several-fold, indicating the presence of severe leaks in the modules.

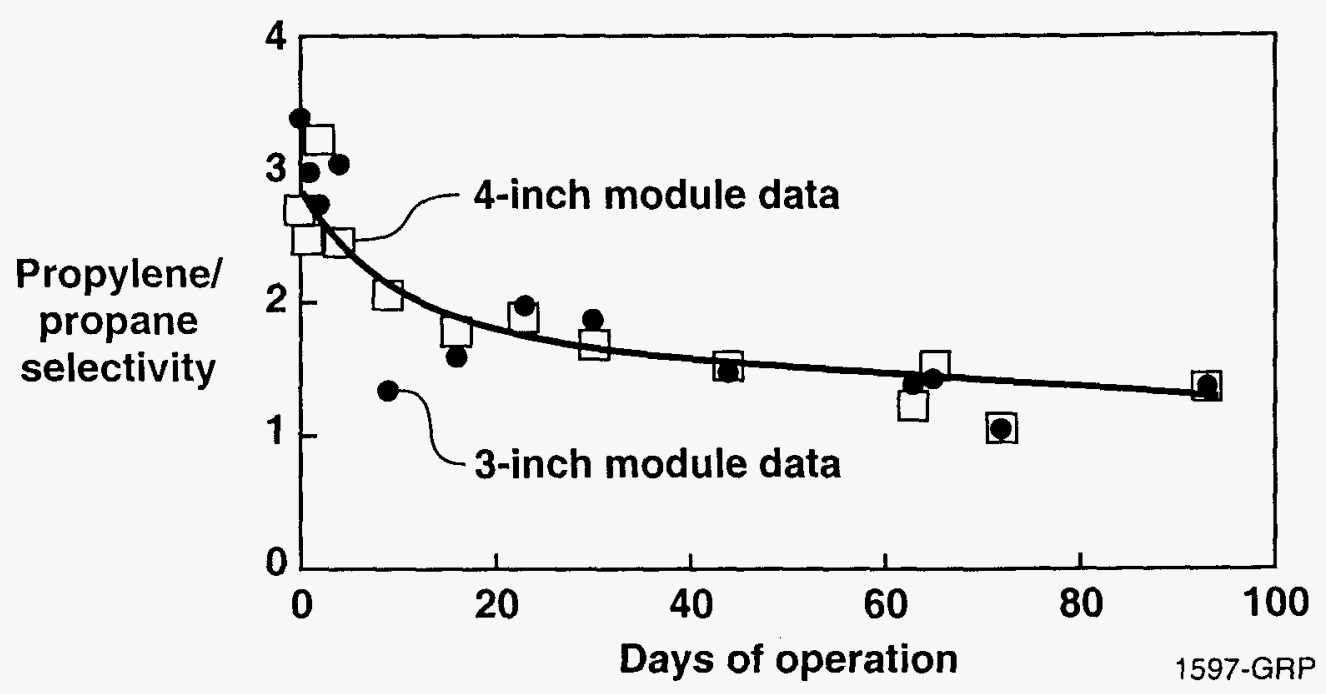

Figure 28. Propylene/propane selectivity of 3-inch membrane module 2110 and 4-inch membrane module 1945 tested at Equistar's Channelview petrochemical complex. 
Table 16. Pure-Gas Permeation Properties of $1 \times 2 \%$ PDMS $/ 1 \times 0.25 \%$ Cytop/PEI Membrane Module 2110 Before and After Tests at Equistar's Channelview Petrochemical Complex

\begin{tabular}{||c|c|c|c|c|c|c|c|c|c|}
\hline \multirow{2}{*}{$\begin{array}{c}\text { Test } \\
\text { Time }\end{array}$} & \multicolumn{4}{|c|}{ Pressure-Normalized Flux (GPU) } & \multicolumn{4}{|c|}{ Selectivity } \\
\cline { 2 - 10 } & $\mathrm{O}_{2}$ & $\mathrm{~N}_{2}$ & $\mathrm{CH}_{4}$ & $\mathrm{CO}_{2}$ & $\mathrm{H}_{2}$ & $\mathrm{O}_{2} / \mathrm{N}_{2}$ & $\mathrm{~N}_{2} / \mathrm{CH}_{4}$ & $\mathrm{CO}_{2} / \mathrm{CH}_{4}$ & $\mathrm{H}_{2} / \mathrm{CH}_{4}$ \\
\hline Before & 48 & 11 & 4.6 & 134 & 250 & 4.3 & 2.4 & 29 & 55 \\
\hline After & 420 & 440 & 500 & 515 & 1,000 & 0.95 & 0.88 & 1 & 2 \\
\hline
\end{tabular}

\section{Tests at the Equistar Petrochemical Complex in Chocolate Bayou, TX}

As a result of the failure of the membrane modules tested at the Channelview plant, we developed new modules for additional tests. Because of a scheduled plant turnaround, we relocated the membrane system to the Equistar complex in Chocolate Bayou, TX. Installation of the membrane module system at this site is shown in Figure 29. The propylene plant at Chocolate Bayou is similar to the one at Channelview, and the membrane system was again installed upstream of the acetylene converter reactor. The gas composition at the two plants was also similar, but the gas at Chocolate Bayou was available at lower pressure. To achieve reasonable flow and pressure, the 4 -inch module was isolated; only the 3 -inch module was used. The feed flow rate was $1 \mathrm{scfm}$ at $100 \mathrm{psig}$ and $30^{\circ} \mathrm{C}$. This corresponds to an activity of about $60 \%$.
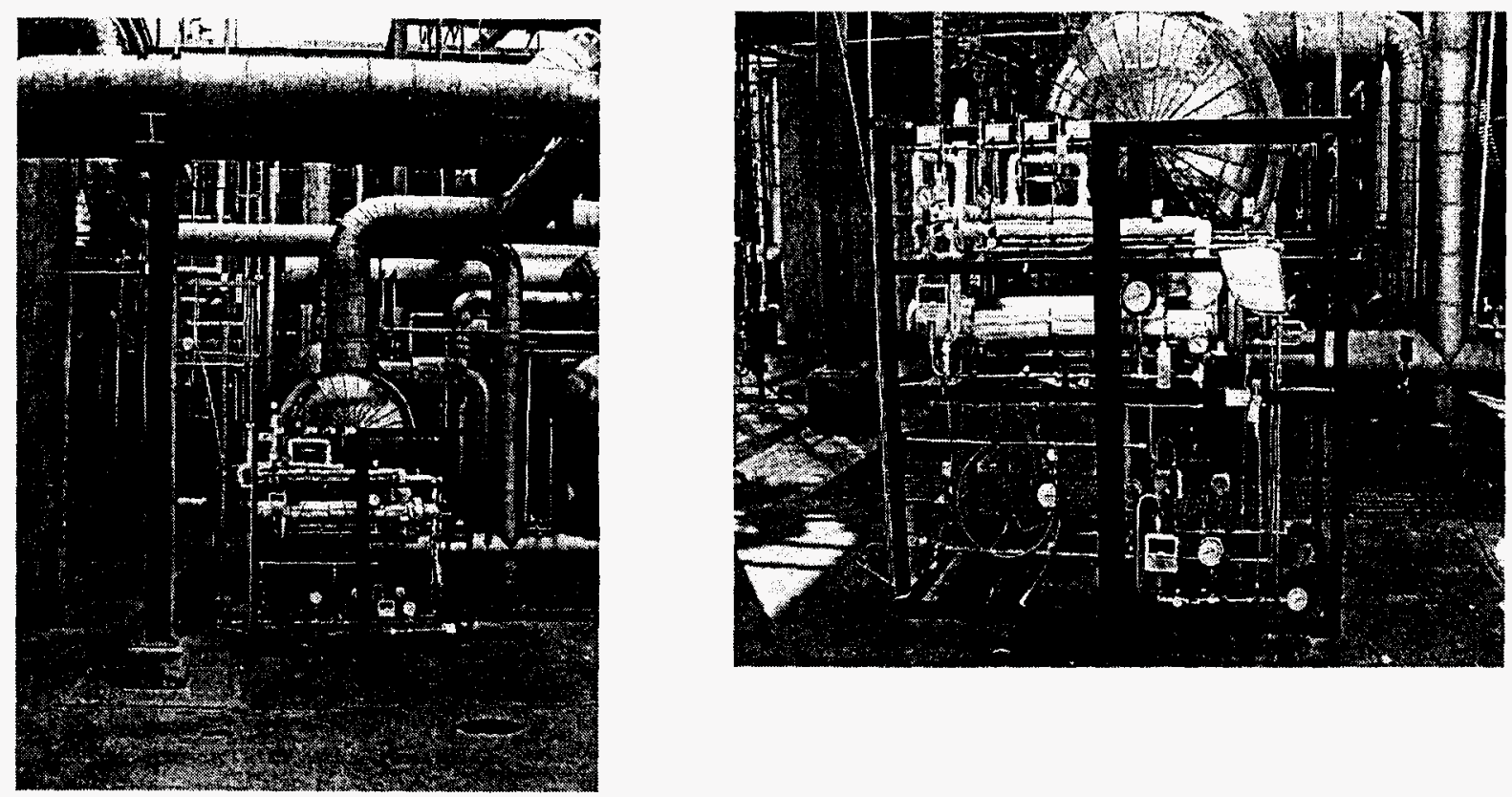

Figure 29. Membrane system installed at Equistar's Chocolate Bayou Petrochemical Complex. 
The system operated for 14 weeks. Because the laboratory gas chromatograph was not in service, performance was not measured during the first four weeks of operation. As shown in Figure 30, propylene/propane selectivity was initially 4 and slowly declined to about 3 after 50 days. The membrane flux dropped by a factor of two during this time. At around day 50, a step change in module performance occurred and flux increased to close to the original value and stayed at this value. Thereafter, the membrane selectivity continued to decline, reaching about 2 after 90 days. During the last two weeks of operation, selectivity was stable at about 2.
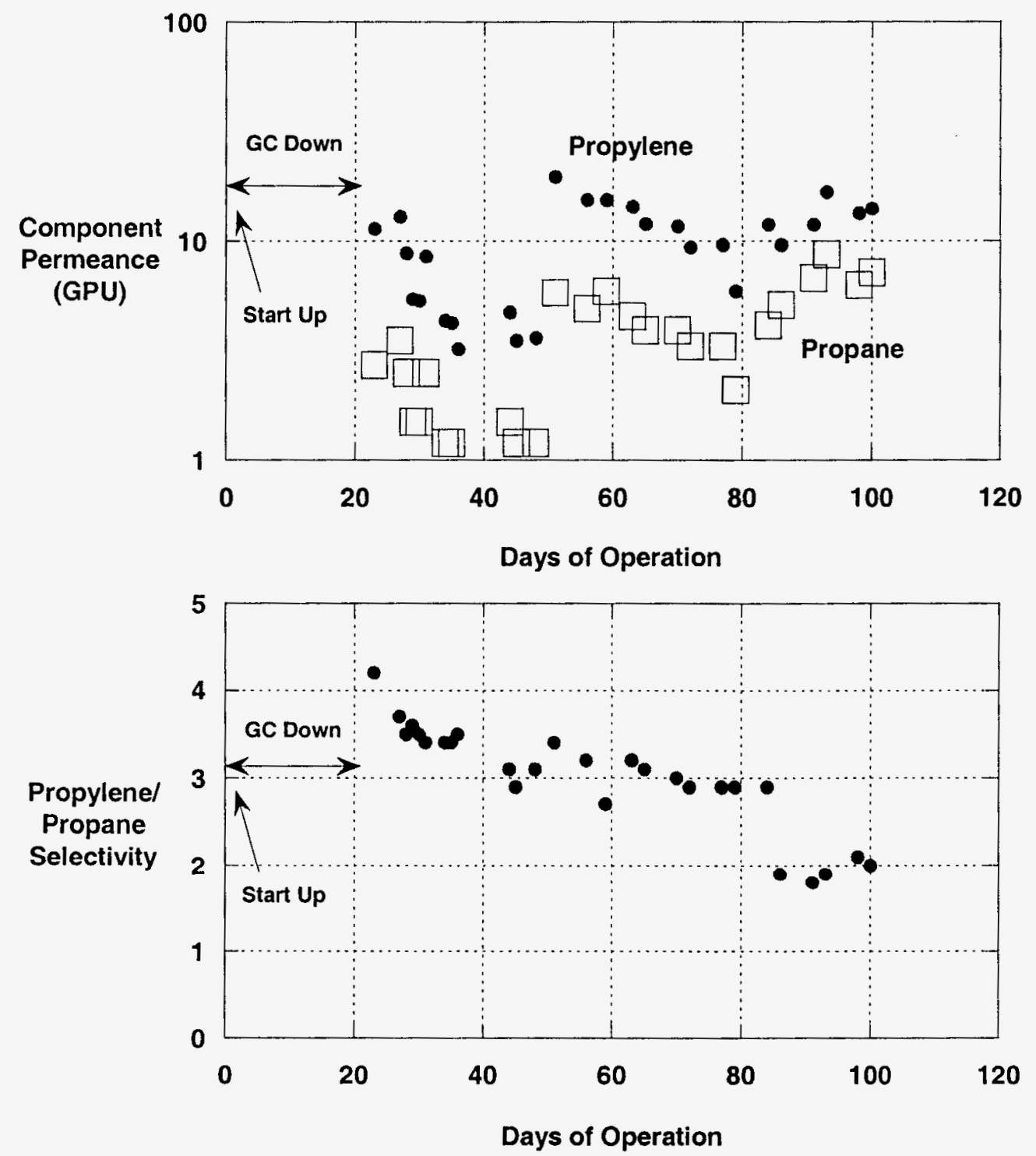

Figure 30. Results from field tests at Equistar's Chocolate Bayou plant. Propylene and propane permeances (top) and propylene/propane selectivity (bottom) for $1 \times 2 \%$ PDMS/1×0.25\% Cytop/PEI 3-inch Membrane Module 2413. 
Typical compositions of the feed, residue and permeate streams are shown in Table 17. Sample permeation performance data for all components are given in Table 18.

Table 17. Composition of Streams Tested with 3-inch Membrane Module 2413 at Equistar's Propylene Plant at Chocolate Bayou, TX

\begin{tabular}{||l|c|c|c||}
\hline \multirow{2}{*}{ Component } & \multicolumn{3}{|c|}{ Stream Composition (mole\%) } \\
\cline { 2 - 4 } & Feed & Residue & Permeate \\
\hline Propylene & 92.5 & 92.4 & 89.5 \\
Propane & 3.7 & 3.9 & 1.1 \\
Methyl Acetylene & 1.6 & 1.6 & 4.1 \\
Propadiene & 2.1 & 2.1 & 5.2 \\
Ethane & 0.007 & 0.00 & 0.004 \\
Cyclopropane & 0.06 & 0.003 & 0.04 \\
\hline
\end{tabular}

Table 18. Initial Permeation Properties of $1 \times 2 \% \mathrm{PDMS} / 1 \times 0.25 \%$ Cytop/PEI 3 -inch Membrane Module 2413 tested at Equistar's Propylene Plant at Chocolate Bayou, TX*

\begin{tabular}{||l|c|c|}
\hline \multicolumn{1}{|c|}{ Component } & Component Permeance (GPU) & $\begin{array}{c}\text { Propylene/Component } \\
\text { Selectivity }\end{array}$ \\
\hline Propylene & 11 & 1 \\
Propane & 3 & 3.7 \\
Methyl Acetylene & 56 & 0.2 \\
Propadiene & 50 & 0.2 \\
Ethane & 6.5 & 1.7 \\
Cyclopropane & 30 & 0.3 \\
\hline
\end{tabular}

*Pressure: 110 psig; temperature: $32{ }^{\circ} \mathrm{C}$.

This module had been tested with a propylene/propane gas mixture before the field tests. A comparison of module pure-gas data obtained before the pilot tests (but after laboratory mixed-gas tests) and stamp data obtained after the pilot tests is given in Table 19.

Table 19. Pure-Gas Permeation Properties Before and After Pilot Tests of $1 \times 2 \%$ PDMS/ $1 \times 0.25 \%$ Cytop/PEI Membrane Module 2413 at Equistar's Channelview Petrochemical Complex

\begin{tabular}{||c|c|c|c|c|c|c|c|c|c|}
\hline \multirow{2}{*}{$\begin{array}{c}\text { Test } \\
\text { Time }\end{array}$} & \multicolumn{3}{|c|}{ Pressure-Normalized Flux (GPU) } & \multicolumn{4}{c|}{ Selectivity } \\
\cline { 2 - 10 } & $\mathrm{O}_{2}$ & $\mathrm{~N}_{2}$ & $\mathrm{CH}_{4}$ & $\mathrm{CO}_{2}$ & $\mathrm{H}_{2}$ & $\mathrm{O}_{2} / \mathrm{N}_{2}$ & $\mathrm{~N}_{2} / \mathrm{CH}_{4}$ & $\mathrm{CO}_{2} / \mathrm{CH}_{4}$ & $\mathrm{H}_{2} / \mathrm{CH}_{4}$ \\
\hline Before (module 2413) & 75 & 19 & 9.5 & 220 & 390 & 4 & 2 & 23 & 41 \\
\hline After (stamp) & 41 & 31 & 41 & 69 & 212 & 1.3 & 0.8 & 1.7 & 5 \\
\hline
\end{tabular}


The module had good permeation properties after laboratory tests and performed well for 12 weeks. However, the final properties (shown in Table 19) indicate that the membrane was damaged. It is possible that the protective PDMS layer partially lifted off the membrane due to swelling in the hydrocarbons. This would have exposed any pinholes (defects) in the selective layer to the gas mixture, leading to an increase in the pressure-normalized fluxes, as shown in Figure 30.

The data obtained in the field tests indicate that we were successful in reproducing laboratory performance in an industrial environment in the presence of impurities ranging from trace components to dust, rust, etc. However, it is also clear that additional membrane development is required to achieve high performance for the expected life of the membranes (three years). In addition, impurities such as oligomers must be removed from the stream to maintain performance. Removal of oligomers from polymerization reactor purge streams is also beneficial to the overall petrochemical process. These oligomers tend to build up and foul vital items of equipment. The industry is aware of this and is working to find a solution that reduces these compounds to trace levels.

\section{TECHNICAL AND ECONOMIC ANALYSIS}

\subsection{Polypropylene Reactor Vents}

A block flow diagram of a typical polyolefin plant is shown in Figure 31. Olefin monomer, hydrogen, catalysts, and other raw materials are fed to a polymerization reactor that operates in either the gas or the liquid phase. The polymer product is transferred continuously to a low-pressure flash tank, where the residual monomer and other gases are released. These gases are compressed and recirculated to the reactor. As the reaction progresses, inert paraffins build up in the process loop. These inert gases enter the process in the feed gas, which typically has a composition of $99 \%$ olefin monomer and about $1 \%$ paraffin. Paraffin build-up is controlled by continuously removing a fraction of the monomer flash-tank recycle stream as a purge, which is then used as fuel or flared. The polymer powder still contains significant amounts of sorbed, unreacted hydrocarbons. To eliminate safety hazards, these hydrocarbons are removed by degassing with a nitrogen purge. The "clean" polymer powder is then conditioned with additives for specific properties, extruded , and pelletized before packaging and/or shipment to end-users., ${ }^{7,822.23}$

The reactor and nitrogen purge streams are both attractive target streams for application of membrane technology. A typical polypropylene plant loses approximately $500 \mathrm{lb} / \mathrm{hr}$ of monomer from the reactor purge stream. Unless a propylene/propane splitter is in use at the same site for another purpose, by-product streams such as this one must be used as fuel, wasting the significant chemical feedstock value of the gas. Similar vent streams are generated in the production of acrylonitrile, cumene, propylene oxide, and isopropyl alcohol. ${ }^{6}$ 


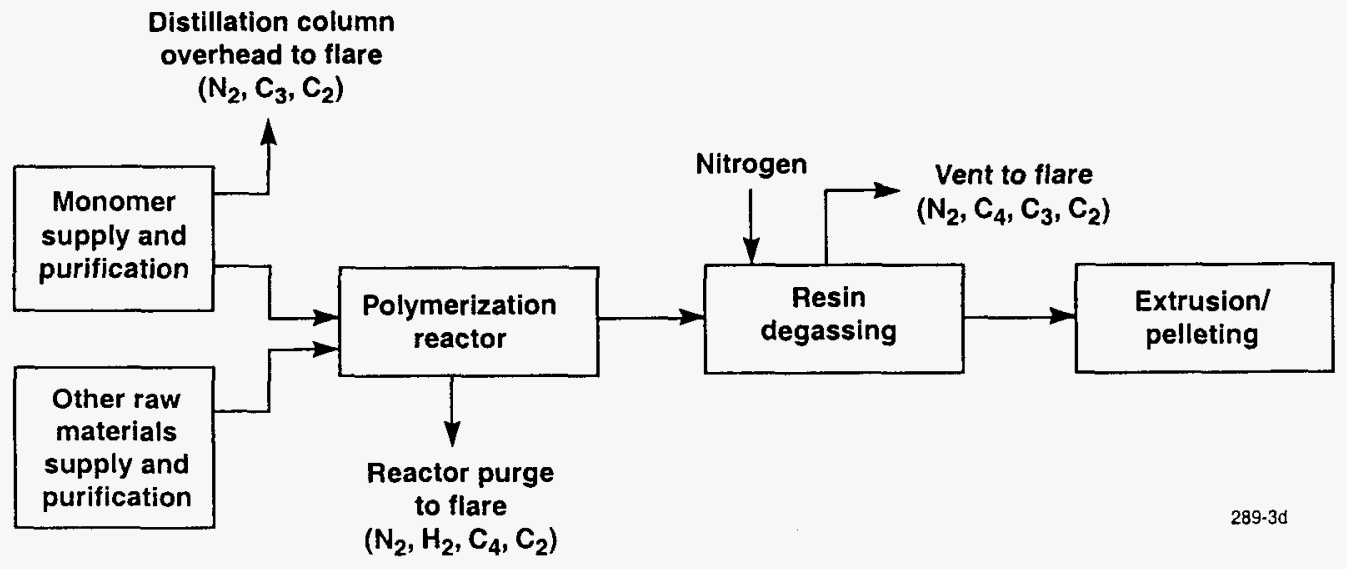

Figure 31. Block flow diagram of a typical polyolefin production process.

For the technical and economic analysis of the process, we used ChemCAD 5.0, a process simulation computer package integrated with an in-house developed membrane simulation program. Our analysis focused on the recovery of propylene from a 250,000 ton/year (550 million lb/year) polypropylene plant. To prevent build-up in the polymerization reactor loop, $159 \mathrm{lb} / \mathrm{h}$ of propane must be purged. In addition to propane, the reactor purge contains $608 \mathrm{lb} / \mathrm{h}$ of propylene (which is required for the polymerization reaction). This valuable monomer is used as fuel or flared.

A stream composition calculation for a system designed to achieve $80 \%$ propylene recovery with a membrane having a propylene/propane selectivity of 3 and propylene pressure-normalized flux of 50 GPU is shown in Figure 32. As described in Section 4, these permeation properties were achieved in our tests. This analysis included capital and operating costs of the membrane and compressor required to deliver recovered propylene to the polymerization reactor at pressure. Amortization of capital was not taken into account and simple payback periods were calculated.

The estimated capital and operating costs of this plant are given in Table 20 and are based on our experience in designing similar membrane systems. Clearly, installing the membrane system makes good economic sense. The system produces a net credit of $\$ 713,000 /$ year after operating costs. Put another way, with a capital cost of almost $\$ 400,000$, the system has a simple payback time of about six months. This plant also reduces waste gas emissions by 4.1 million $\mathrm{lb} /$ year (which corresponds to the amount of propylene recovered). 


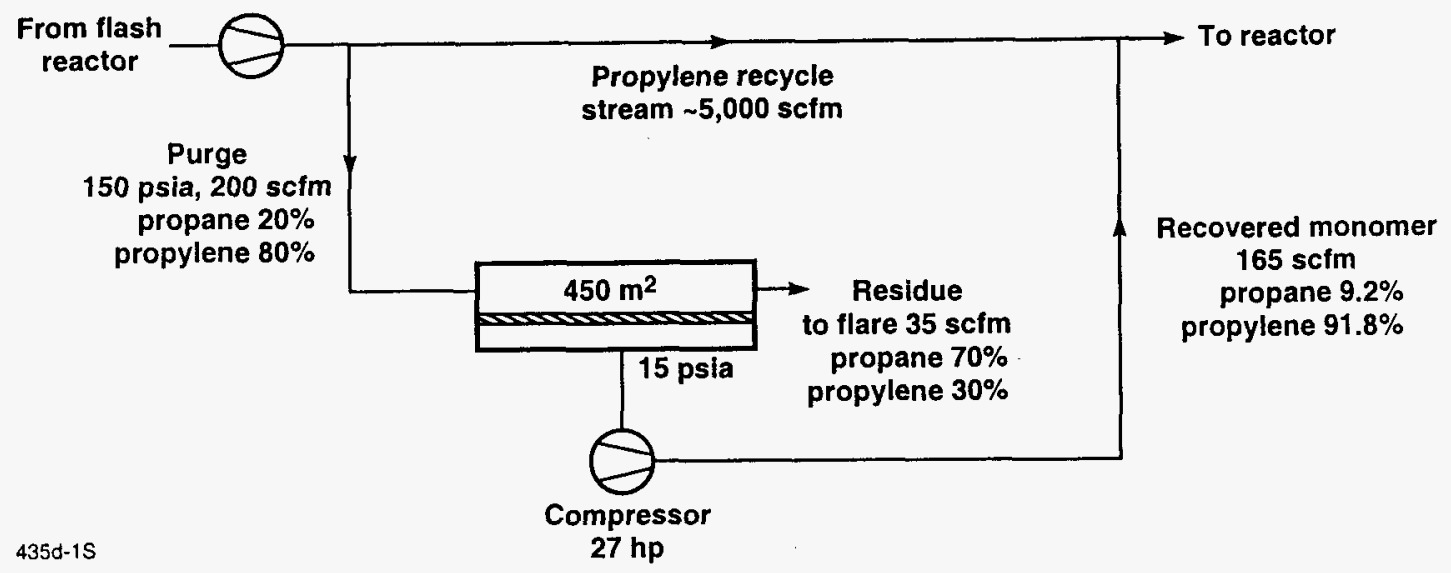

Figure 32. Stream composition in a membrane purge-gas treatment system designed to recover $80 \%$ monomer (propylene) and purge $35 \mathrm{scfm}$ of propane. Calculations are based on a membrane with a propylene/propane selectivity of 3 and propylene pressurenormalized flux of $50 \mathrm{GPU}$.

Table 20. Capital and Operating Cost of the Full-Scale Propylene/Hydrogen Recovery System Shown in Figure 32

\begin{tabular}{|c|c|c|}
\hline Capital Cost (\$) & & \\
\hline $400 \mathrm{~m}^{2}$ membrane at $\$ 175 / \mathrm{m}^{2}$ & & 71,000 \\
\hline Module housings ( $4 \times 8$-inch tubes) & & 24,000 \\
\hline $45 \mathrm{~kW}$ (actual) recompressor & & 45,000 \\
\hline Frame/controls/valves/fittings etc. & & 10,000 \\
\hline & & 150,000 \\
\hline Engineering/Installation/Margins at $150 \%$ of component cost & & 225,000 \\
\hline & Total Capital Cost & 375,000 \\
\hline Annual Operating Cost (\$) & & \\
\hline Maintenance at $5 \%$ of capital & & 19,000 \\
\hline Membrane replacement (3-year lifetime) & & 67,000 \\
\hline Power: $45 \mathrm{~kW}$ at $\$ 0.05 / \mathrm{kWh}$ & & $\frac{18,000}{104,000}$ \\
\hline Credit for recovered propylene: $487 \mathrm{lb} / \mathrm{hr}$ at $\$ 0.20 / \mathrm{lb}$ & & 818,000 \\
\hline Net Credit & $\$ 71$ & $3,000 /$ year \\
\hline Simple Payback Period & $6.4 \mathrm{Mo}$ & \\
\hline
\end{tabular}




\subsection{The Effect of Membrane Permeation Properties on Process Economics}

Our permeation tests showed that propylene/propane selectivity varied from 3 to 5 and pressure-normalized fluxes varied with process conditions. Under near-saturation conditions, pressure-normalized flux increases to $50 \mathrm{GPU}$ or higher; propylene/propane selectivity remains unchanged. To determine the minimum required membrane permeation properties for a viable process, we calculated economic performance for selectivities of 3 and 5 for pressure-normalized fluxes ranging from 10 to $50 \mathrm{GPU}$. The results of our economic analysis are shown in Figure 33. At $10 \mathrm{GPU}$, system payback time is less than 20 months at a propylene/propane selectivity of 5 and about 40 months at a selectivity of 3 . At 20 GPU, payback times decrease to 9 and 15 months, respectively. At $50 \mathrm{GPU}$, the payback times are similar, falling in the range of 4-6 months at both selectivities. Therefore, a selectivity of 3 and flux of $20 \mathrm{GPU}$ are the minimum required permeation properties. The perfluorinated membranes developed in this project meet these criteria. In the analysis that follows, we used 50 GPU because it is a more realistically achievable value.

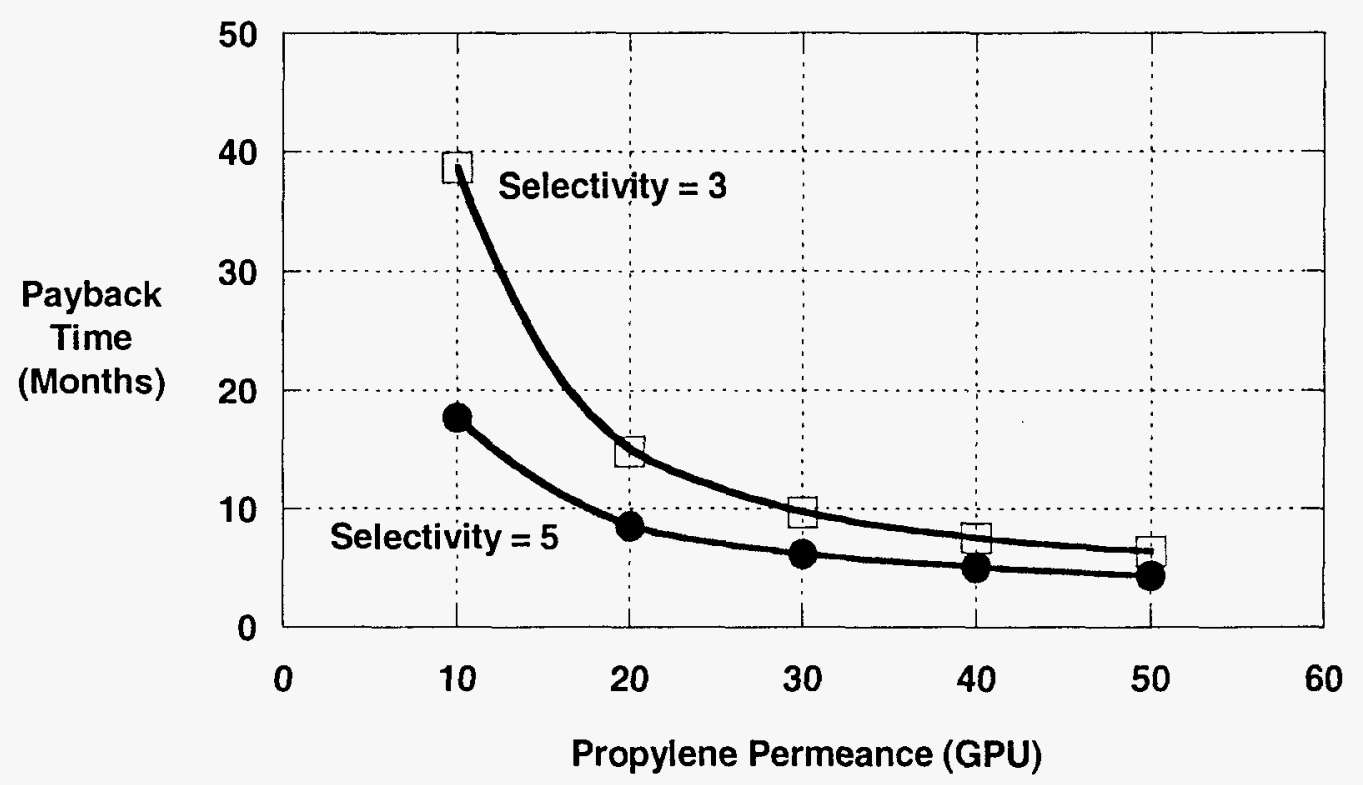

Figure 33. The effect of propylene flux on membrane system payback time at propylene/propane selectivities of 3 and 5. Propylene recovery: $80 \%$; propylene spot price: $\$ 0.20 / \mathrm{lb}$.

\subsection{The Effect of Market Price on Process Economics}

Olefin recovery economics depend strongly on the market price of olefins. This analysis assumes a propylene price of $\$ 0.20 / \mathrm{lb}$. However, olefin prices are cyclic, bottoming out at $\$ 0.10 / \mathrm{lb}$ in 1999 and then increasing to more than $\$ 0.30 / 1 b$ by mid-2000-the highest propylene price since 1996 (Figure 34). ${ }^{24}$ 
The effect of propylene spot price on membrane process economics at $80 \%$ propylene recovery is shown in Figure 35 . With propylene at $\$ 0.10 / \mathrm{lb}$, the payback times are 10 and 15 months at selectivities of 5 and 3 , respectively. The economic viability of the membrane process improves significantly as the propylene price increases. For example, at a propylene price of $\$ 0.20 / \mathrm{lb}$, the simple payback time for a membrane with propylene/propane selectivity of 3 and propylene pressure-normalized flux of $50 \mathrm{GPU}$ is just over six months. These economics are compelling. The technology developed in this project could be widely adopted, particularly by grass roots plants, once demonstrated on a commercial scale.

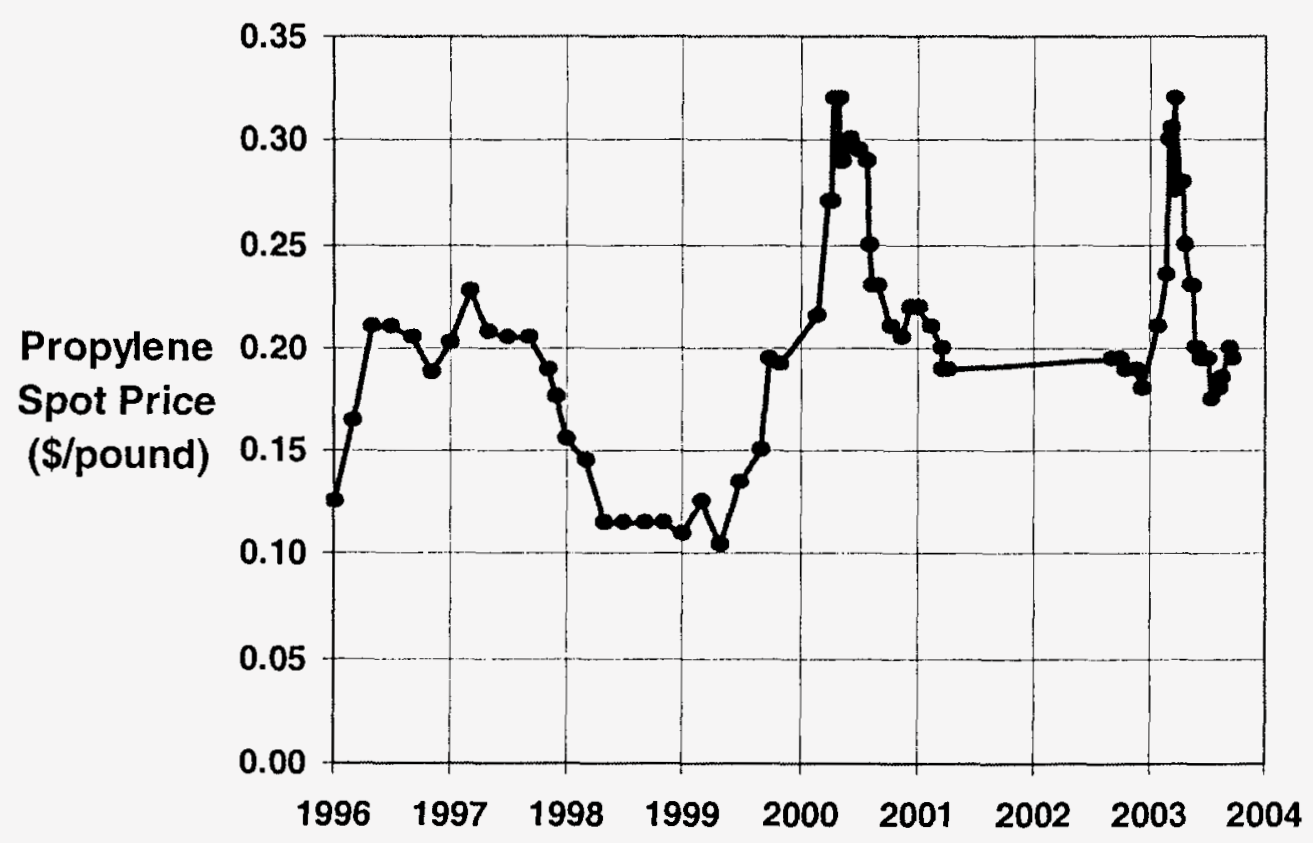

Figure 34. U.S. spot price of polymer-grade propylene, 1996-2003. 


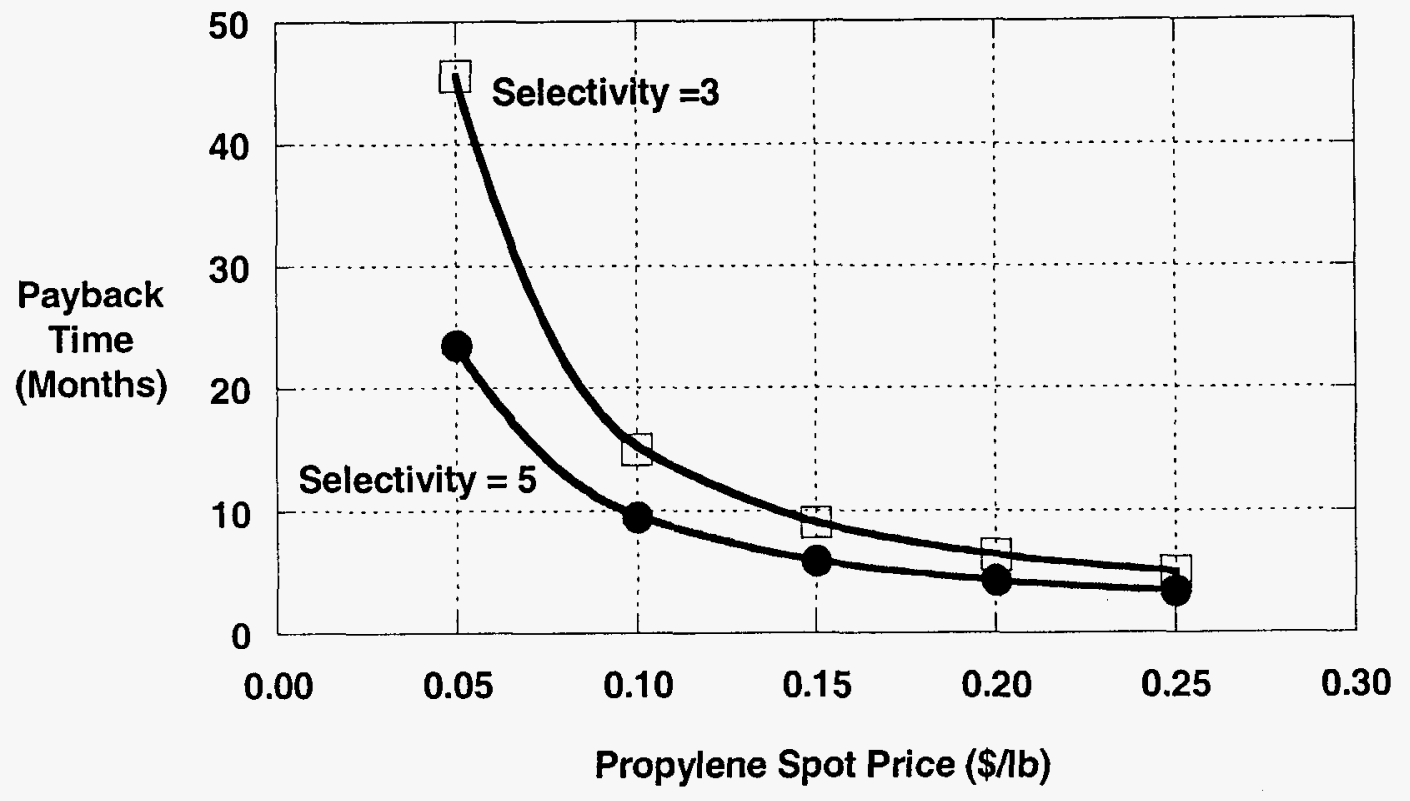

Figure 35. The effect of propylene spot price on membrane system payback time at propylene/propane selectivities of 3 and 5. Propylene recovery: 80\%; propylene pressure-normalized flux: $50 \mathrm{GPU}$.

\subsection{The Effect of Propylene Recovery on Process Economics}

The effect of propylene recovery is shown in Figure 36. As expected, the economics are better at propylene/propane selectivity of 5 . However, at constant permeation properties, economic performance varies little in the range of 50 to $80 \%$ propylene recovery. At recoveries of more than $80 \%$, payback time increases sharply due to increased membrane area and compressor power requirements. In addition, it is not possible to satisfy the process purging needs of inerts (other than propane) that permeate with the propylene and return to the polymerization reactor. For this reason, propylene recovery is limited to $80 \%$ in most of the analyses presented here. 


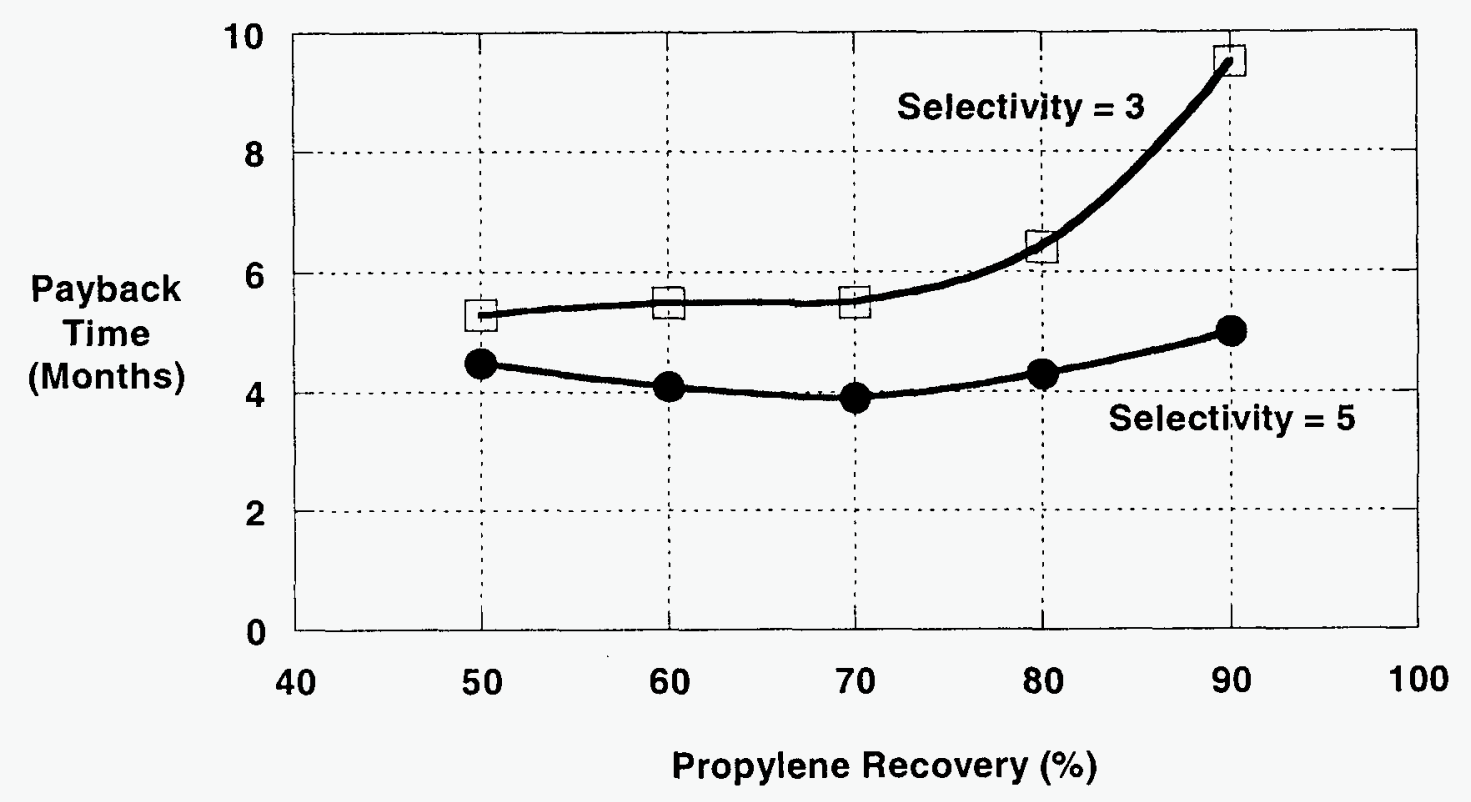

Figure 36. The effect of propylene recovery on membrane system payback time at propylene/propane selectivities of 3 and 5. Propylene pressure-normalized flux: 50 GPU; propylene spot price: $\$ 0.20 / \mathrm{lb}$.

\section{PROCESS BENEFITS AND COMMERCIALIZATION PLAN}

The first, most easily realized application is propylene recovery from the by-product and vent streams of petrochemical processes. These streams cannot be economically separated by current technology and are generally used as fuel or flared. We estimate that 420 million pounds of propylene currently lost per year as waste gas are potentially recoverable. This represents almost $1.5 \%$ of global propylene production (29 billion pounds).

A web-based DOE OIT chemical project evaluation tool was used to estimate the market size and energy benefits of the membrane process. According to DOE, the total U.S. waste propylene market will reach 780 million pounds in 2020 . The estimated energy used in the membrane process is about $300 \mathrm{Btu} / \mathrm{lb}$ of propylene recovered. Assuming an annual growth rate of $1 \%$ and initial sales in 2005, we can reach $60 \%$ saturation of the market available to us ( 780 million pounds) by 2020 . This will lead to a total energy savings of 800 billion Btu/year according to DOE production energy data and the DOE energy-assessment tool. Other benefits include reduction in the pollutants associated with combustion of fuels. The results of this analysis are shown in Table 21. 
Table 21. Membrane Process Impact and Benefits

\begin{tabular}{||l|c|c|}
\hline \multicolumn{1}{|c|}{ Parameter } & 2005 & 2020 \\
\hline U.S. Waste Propylene Market (million Ib/year) & 420 & 780 \\
\hline Market Penetration (\%) & 5 & 60 \\
\hline Market Penetration (million Ib/year) & 20 & 470 \\
\hline Energy Savings (billion Btu/year) & 34 & 800 \\
\hline Pollutant Reduction (Ib/year) & 18,000 & 400,000 \\
\hline
\end{tabular}

If membranes with better properties are developed, they may supplement (as part of a hybrid system) or replace distillation in the recovery of olefins from the steam cracking process. By 2020 , production of propylene will require an estimated 140 trillion Btu of energy; application of membrane separation technology to the process could reduce energy use significantly.

We have surveyed potential customers for the membrane process developed in this project to understand their needs and the specifics of their processes. MTR is familiar with this customer base because the company currently provides other types of hydrocarbon recovery technology to the chemical industry. This information will be used to initiate the commercialization of new membrane systems for propylene recovery. Our approach to commercialization is to protect our intellectual property; to manufacture membranes and modules in-house; and to perform systems engineering, procurement, sales and marketing in-house. Skids will be fabricated and assembled by external fabricators. MTR has a strong patent portfolio, including four patents directly related to the work carried out in this project ${ }^{25-28}$ and several related patents. ${ }^{29,30}$

Our benchmark is the success achieved in the development and commercialization of the VaporSep ${ }^{\circledR}$ process for the petrochemical industry. From 1995 to 2001, we sold and installed more than 60 plants worldwide. MTR's engineering and technical sales groups are responsible for these activities. Thus, the company has the infrastructure and tools needed to introduce the new technology to the petrochemicals industry.

\section{CONCLUSIONS}

We evaluated the permeation properties of several polymers and found that PPO and polyimide membranes, which are characterized by high propylene/propane selectivity at low feed and permeate pressures, fail under realistic industrial conditions. We discovered novel plasticization-resistant, robust perfluoropolymer membranes based on Hyflon and Cytop that perform adequately at high vapor activity, including saturated conditions. We successfully scaled up these membranes and developed high-performance, defect-free spiral-wound modules. Parametric studies allowed us to identify process conditions for best performance. 
The perfluoropolymer membranes developed in this project were characterized by a propylene/propane selectivity of 3 to 5 and propylene pressure-normalized fluxes of up to 50 GPU, or higher at saturation conditions. We tested membrane modules at a Chevron Phillips slurry reactor polypropylene plant in Pasadena, TX and at Equistar ethylene cracker plants in Channelview, TX and Chocolate Bayou, TX. The initial performance of the membrane system agreed with laboratory results, but performance declined after three months of operation due to the presence of highmolecular-weight impurities (oligomers) in the feed.

We completed a technical, economic, and benefit analysis that will be a valuable tool in the commercialization of this technology. To successfully commercialize this technology, however, it is imperative to demonstrate long-term (one to two years) performance of a semi-commercial plant. To meet the requirements of long-term operation, additional membrane optimization may be required. Our strong patent portfolio protects intellectual property arising from this project. The portfolio includes four patents that resulted from or are relevant to this work and several other related patents. $^{25-30}$

In this project, we have developed membrane technology that successfully addresses one of the most challenging separations in the petrochemical industry: propylene from propane. This work will be the basis of additional developments with potential for significant energy reduction.

\section{ACKNOWLEDGEMENTS}

We would like to acknowledge financial support from the U.S. Department of Energy, Office of Industrial Technology to develop this technology. We would like to thank Chevron Phillips and Equistar for hosting and supporting the pilot tests. We particularly thank the following individuals and their teams:

Carl Fenderson (Chevron Phillips)

Mark Garner (Chevron Phillips)

Steve Coleman (Equistar)

Raghu Narayan (Equistar)

Shawn Cullen (Equistar) 


\section{REFERENCES}

1. P. J. Chenier, Survey of Industrial Chemistry, 2nd ed.;VCH Publishers, New York, NY (1992).

2. "Industry Survey: Markets and Economics (June 28, 1995).

3. J.L. Humphrey, A.F. Seibert, and R.A. Koort, "Separation Technologies Advances and Priorities," U.S. Department of Energy Report, 12920-1 (1991).

4. T.S. Barron, J.A. Heist, K.M. Hunt, and P.J. Wrobel, "Industrial Application of Freeze Concentration Technology," Final Report to Electric Power Research Institute, EM-5232-1 (June 1987).

5. R.B. Eldridge, Ind. Eng. Chem. Res. 32, 3208 (1993).

6. D.E. Gottschlich and D.L. Roberts, "Energy Minimization of Separation Processes Using a Conventional /Membrane Hybrid System," Report to the DOE, DE910047-10 (September 1990).

7. J.A. Reid, "Refinery Propylene Recovery Operations for Polymer-Grade Propylene Production 1997," Dewitt Petrochemical Review, Houston, TX (March 1997).

8. G.M. Wells, Handbook of Petrochemicals and Processes, Gower Publishing Company (1991).

9. J.D. Wang and R.D. Nobel, Facilitated Transport in Membrane Handbook, W.S. Ho and S.S. Sirkar, Eds.; Van Nostrand, New York, NY (1992).

10 J.C. Davis, R.J. Valus, R. Eshranghi, and A.E. Velikoff, Sep. Sci. Tech. 28, 463 (1993).

11. R.D. Hughes, J.A. Mahoney, and E.F. Steigelmann, Recent Developments in Separation Science, N.N. Li and J.M. Calo, Eds.; CRC Press, Boca Raton, FL (1986).

12 Y. Mehra, Chem. Eng. 93, 53 (1986).

13. D.G. Tajbl, J.S. Kanofsky, and J.M. Braband, Energy Processes/Canada 82, 61 (1980).

14. "Recovering Olefins Using Adsorption," Chem. Eng., p. 124 (November 1997).

15. K.R. Lee and S.-T. Hwang, J. Memb. Sci. 73, 37 (1992).

16. O.M. Ilinitch, G.L. Semin, M.V. Chertova, and K.I. Zamaraev, J. Memb. Sci, 66, 1 (1992).

17. K. Tanaka, A. Taguchi, J. Hao, H. Kita, and K. Okamoto, J. Memb. Sci. 121, 197 (1996).

18. A. Shimazu, K. Ikeda, and H. Hachisuka, "Method of Selectively Separating Unsaturated Hydrocarbon," U.S. Patent 5,749,943 (May 12, 1998).

19. "Field Demonstration of a Membrane Process for Olefin/Paraffin Separation in the Chemical Industry," MTR Research Proposal, submitted in response to DOE Solicitation DE-PS0702ID14407 (November 20, 2002).

20. A. Shimazu, T. Miyakzaki, M. Maeda, and K. Ikeda, "Relationships Between the Chemical Structures and the Solubility, Diffusivity, and Permselectivity of Propylene and Propane in 6FDA-Based Polyimides," J. Polym. Sci., Polym. Phys. Ed. 38, 2525-2536 (2000).

21. C. Staudt-Bickel and W.J. Koros, "Olefin/Paraffin Gas Separatons With 6FDA-Based Polyimide Membranes," J. Memb. Sci. 170, 205-214 (2000).

22. U.S. Department of Energy, Office of Industrial Technologies, "2000 Energy and Environmental Profile of the U.S. Chemical Industry," Energetic, Inc., Columbia, Maryland.

23. A.R. Da Costa, J.S. Wijmans, and R.W. Baker, "Ethylene Recovery by Membrane Technology," AIChE National Meeting, Houston, TX (Spring 2001). 
24. Chemical Week (1996-2003).

25. R.W. Baker, A.R. Da Costa, R. Daniels, I. Pinnau, and Z. He, "Membrane-Augmented Polypropylene Manufacturing," U.S. Patent 6,271,319 (August 7, 2001).

26. R.W. Baker, A.R. Da Costa, and R. Daniels, "Membrane-Augmented Manufacture of Propylene Derivatives," U.S. Patent 6,414,202 (July 2, 2000).

27. R.W. Baker, A.R. Da Costa, and R. Daniels, "Membrane-Augmented Manufacture of Cumene," U.S. Patent 6,525,236 (February 5, 2003).

28. A.R. Da Costa, R. Daniels, and A.D. Jariwala, "Liquid-Phase Separation of Low-MolecularWeight Organic Compounds," Patent Application No. 10/384,477 (March 7, 2003).

29. I. Pinnau, Z. He, A.R. Da Costa, K. D. Amo, and R. Daniels, "Gas Separation Using Organic-Vapor-Resistant Membrane," U.S. Patent 6,361,583 (March 26, 2002).

30. I. Pinnau, Z. He, A.R. Da Costa, K. D. Amo, and R. Daniels, "Gas Separation Using $C_{3+}$ Hydrocarbon-Resistant Membranes," U.S. Patent 6,361,582 (March 26, 2002). 